UNIVERSIDADE DE SÃO PAULO

FACULDADE DE ECONOMIA, ADMINISTRAÇÃO E CONTABILIDADE DEPARTAMENTO DE ADMINISTRAÇÃO PROGRAMA DE PÓS-GRADUAÇÃO EM ADMINISTRAÇÃO

DISTRIBUIÇÃO DE VALOR PARA O STAKEHOLDER FUNCIONÁRIO E DESEMPENHO ORGANIZACIONAL

Greici Sarturi

Orientador: Prof. Dr. João Maurício Gama Boaventura 
Prof. Dr. Marco Antonio Zago

Reitor da Universidade de São Paulo

Prof. Dr. Adalberto Américo Fischmann

Diretor da Faculdade de Economia, Administração e Contabilidade

Prof. Dr. Roberto Sbragia

Chefe do Departamento de Administração

Prof. Dr. Moacir de Miranda Oliveira Júnior Coordenador do Programa de Pós-Graduação em Administração 


\title{
GREICI SARTURI
}

\section{DISTRIBUIÇÃO DE VALOR PARA O STAKEHOLDER FUNCIONÁRIO E DESEMPENHO ORGANIZACIONAL}

\author{
Tese apresentada ao Departamento de \\ Administração da Faculdade de Economia, \\ Administração e Contabilidade da \\ Universidade de São Paulo, como requisito \\ parcial para obtenção do título de Doutor em \\ Ciências.
}

Orientador: Prof. Dr. João Maurício Gama Boaventura

\author{
Versão Corrigida
}

(versão original disponível na Faculdade de Economia, Administração e Contabilidade)

\section{SÃO PAULO}


FICHA CATALOGRÁFICA

Elaborada pela Seção de Processamento Técnico do SBD/FEA/USP

Sarturi, Greici.

Distribuição de valor para o stakeholder funcionário e

desempenho organizacional / Greici Sarturi. - São Paulo, 2016.

$110 \mathrm{p}$.

Tese (Doutorado) - Universidade de São Paulo, 2016.

Orientador: João Maurício Gama Boaventura.

1. Stakeholder. 2. Desempenho organizacional. 3. Estratégia organizacional. I. Universidade de São Paulo. Faculdade de Economia, Administração e Contabilidade. II. Título.

CDD -658.401 
À minha família,

por todo amor, paciência e apoio. 

Agradeço aos meus pais, Eugênio e Paula, à minha irmã Sara e à minha tia Iraci por todo apoio, amor e incentivo em todos os momentos da minha vida.

Ao meu orientador, Professor João Maurício, pelo incentivo, dedicação e amizade. Agradeço pelos valiosos ensinamentos que contribuíram significativamente para meu desenvolvimento acadêmico e profissional.

Ao Professor Richard Priem pela orientação, paciência e apoio no doutorado sanduíche. Sinto-me privilegiada por este tempo de convivência e aprendizado sob sua orientação.

Ao Professor Abdul Rasheed que gentilmente me recebeu na University of Texas at Arlington durante o período de doutorado sanduíche.

Ao Centro de Estudos de Sustentabilidade da Fundação Getúlio Vargas - GV-CES, na pessoa de seu coordenador, Prof. Dr. Mario Monzoni, que disponibilizou acesso ao banco de dados do Índice de Sustentabilidade Empresarial - ISE, sem o qual esta pesquisa não seria possível.

Aos amigos, tão especiais, que compartilharam conhecimentos, experiências e as angústias do doutorado, em especial, Keysa Mascena, Cristina Espinheira, Simone Barakat, Joice Chiareto, Ivan Ferraz, Taiguara Langrafe e Augusto Nishimura.

Aos professores com quem tive a oportunidade de aprender nas disciplinas, especialmente, Professor Eduardo Kayo, Professor Adalberto Fischmann. Professor José Afonso Mazzon, Professor Martinho Isnard, Professora Maria Aparecida e Professor Décio Zylbersztajn.

Aos colaboradores da secretaria do PPGA e da pós-graduação pelo carinho e presteza.

Aos colegas do grupo de pesquisa Stakeholders \& Networks pela convivência e troca de experiências nas nossas reuniões.

Às Professoras Mônica e Luciana pelas importantes contribuições na banca de qualificação deste trabalho.

À Coordenação de Aperfeiçoamento de Pessoal de Nível Superior (CAPES) pelo apoio financeiro durante o período de doutorado e doutorado sanduíche. 



\section{RESUMO}

A teoria dos stakeholders tem apresentado significativos avanços conceituais quanto a criação e distribuição de valor para os stakeholders. No entanto, algumas questões ainda são pouco exploradas nessa literatura. Uma delas refere-se à relação entre a distribuição de valor para os stakeholders e o desempenho organizacional. Esta pesquisa contribui com esta questão ao analisar a relação entre distribuição de valor tangível e intangível para o stakeholder funcionário e o desempenho organizacional. Como objetivos específicos, definiu-se: a) analisar a relação entre distribuição de valor tangível para os funcionários e o desempenho de curto e longo prazo da empresa; b) analisar a relação entre distribuição de valor intangível para os funcionários e o desempenho de curto e longo prazo da empresa. Para operacionalização da pesquisa foi selecionado o stakeholder funcionário, uma vez que este é um dos stakeholders mais estreitamente ligado à criação de valor da empresa, tem acesso a informações chaves, possui competências críticas para a geração de renda, e, consequentemente, um custo de reposição muito alto. A Revisão de Literatura abordou três teorias. A primeira foi a Teoria dos Stakeholders, da qual emergiu o problema de pesquisa. A segunda teoria utilizada foi a Gestão Estratégica de Recursos Humanos que contribuiu para a discussão sobre atendimento do stakeholder funcionário e desempenho organizacional. Por fim, foram empregadas teorias de motivação para explicar como o valor distribuído ao funcionário afeta sua motivação e, consequentemente, o desempenho organizacional. O método utilizado compreende uma abordagem quantitativa, cuja análise dos dados foi realizada por meio da técnica de regressão. Foram analisadas 40 empresas ao longo de quatro anos. A amostra compreendeu o conjunto de empresas que responderam ao questionário do Índice de Sustentabilidade Empresarial (ISE), da BM\&FBovespa, nos anos de 2010 à 2013. Este conjunto incluiu tanto empresas de capital aberto, listadas na Bolsa de Valores, quanto suas controladas. Os resultados desta pesquisa indicam que o valor tangível está mais associado ao desempenho de curto prazo enquanto o valor intangível tem efeitos no desempenho de longo prazo. Esta pesquisa apresenta contribuições teóricas e gerenciais. Sob o ponto de vista teórico, apresenta os mecanismos pelos quais a distribuição de valor para o stakeholder funcionário afeta o desempenho organizacional e testa empiricamente essa relação. Em termos gerenciais, os resultados são úteis para os gestores na decisão de que tipo de valor distribuir para o atendimento do funcionário que resulte em um melhor desempenho organizacional. 



\begin{abstract}
The Stakeholder Theory has shown significant conceptual advances regarding the value creation and distribution for stakeholders. However, some issues remain little explored in this literature. One of these issues is relate to the relationship between value distribution for stakeholders and organizational performance. This research contributes to this issue since analyze the relationship between the distribution of tangible and intangible values for the employee stakeholder and organizational performance. The specific objectives are: a) analyze the relationship between distribution of tangible value for employees and short and long-term organizational performance; b) analyze the relationship between distribution of intangible value for employees and short and long-term organizational performance. In order to perform the research it was selected the employee stakeholder, since this is one of the most closely stakeholder associated with the firm's value creation, has access to key information, critical skills to generate rent, and high replacement cost. The Literature Review section covers three theories. The first one is the Stakeholders Theory, from which the research problem emerged. The second theory is the Strategic Human Resource Management (SHRM), which contributed to the discussion on the employee stakeholder and organizational performance. Finally, theories of motivation were used to explain how the value distributed for employees affects their motivation and therefore organizational performance. The method comprised a quantitative approach, which analysis was performed through the regression technique. It was analyzed 40 firms over four years. The sample is composed by firms that responded the Corporate Sustainability Index (ISE) questionnaire, from the BM\&FBovespa, in the years from 2010 to 2013. This set of firms included both publicly traded companies listed on the Stock Exchange, and their subsidiaries. The results indicate that the tangible value is more associated with shortterm performance while the intangible value has effects on long-term performance. This research presents theoretical and managerial contributions. From the theoretical point of view, this study presents the mechanisms through which the distribution of value for employees affects organizational performance and test empirically this relationship. In terms of management, the results are useful to managers decide what kind of value distribute to employees in order to achieve a better firm performance.
\end{abstract}





\section{LISTA DE ABREVIATURAS E SIGLAS}

$\Delta \mathrm{VT}$ - Variação do valor total criado

CHCOs - Conhecimentos, habilidades, competências, e outras características

CSP - Corporate social performance

CFP - Corporate financial performance

EGT - Equipes de gestão de topo

Endiv - Endividamento

FER - Fator de Equidade na Remuneração

FGV-EAESP - Escola de Administração de Empresas de São Paulo da Fundação Getúlio Vargas

GERH - Gestão Estratégica de Recursos Humanos

GVCes - Centro de Estudos em Sustentabilidade

ISE - Índice de Sustentabilidade Empresarial

MQO - Mínimos Quadrados Ordinários

RH - Recursos humanos

ROA - Retorno sobre ativos

ROE - Retorno sobre o patrimônio líquido

ROS - Retorno sobre as vendas

ROCE - Retorno sobre capital investido

SM_GRUPO - soma da remuneração paga aos membros do "GRUPO” no "período"

Tam - Tamanho

VCA - Valor criado e apropriado

VIF - Variance inflation fator

VTan - Valor Tangível

VIn - Valor Intangível 



\section{LISTA DE TABELAS}

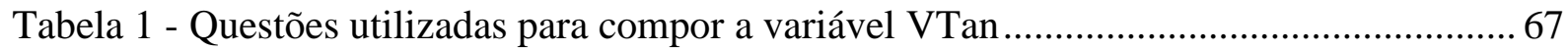

Tabela 2 - Questões utilizadas para compor a variável VIn.................................................. 68

Tabela 3 - Relação de empresas por setor de atuação ............................................................ 75

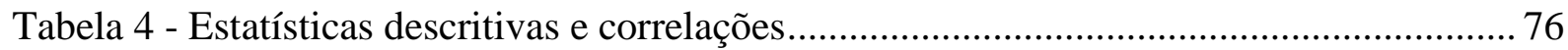

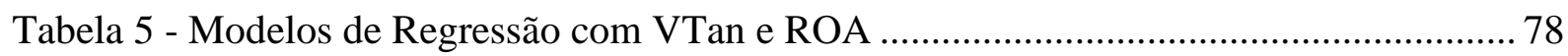

Tabela 6 - Modelos de Regressão com VIn e ROA .............................................................. 80

Tabela 7 - Modelos de Regressão com VTan, VIn e ROA …................................................. 81 



\section{LISTA DE ILUSTRAÇÕES}

Ilustração 1 - Dimensões da Teoria dos Stakeholder ............................................................. 23

Ilustração 2 - O que a teoria dos stakeholders não é .............................................................. 27

Ilustração 3 - Muito ou pouco valor alocado para os stakeholders .......................................... 36

Ilustração 4 - Framework multinível da estrutura e função do Recurso de Capital Humano .. 43

Ilustração 5 - Dimensões das características do capital humano ............................................ 44

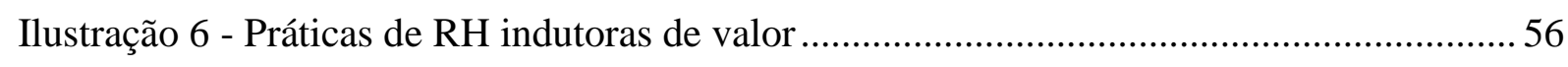

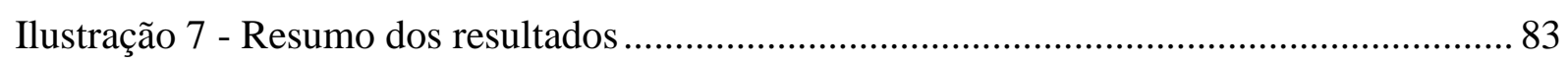





\section{SUMÁRIO}

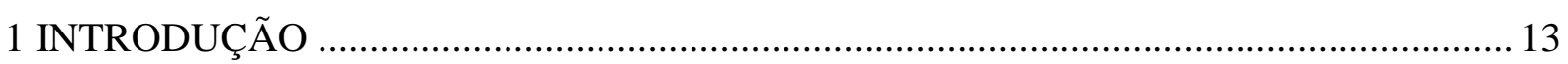

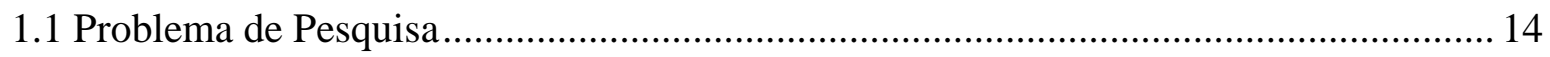

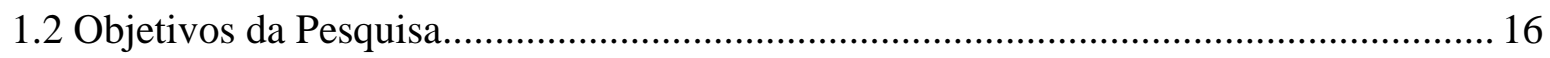

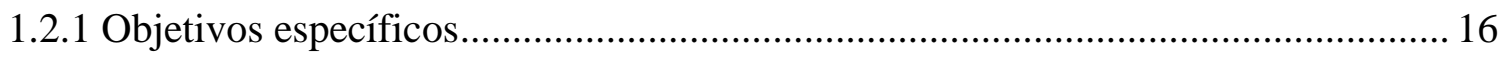

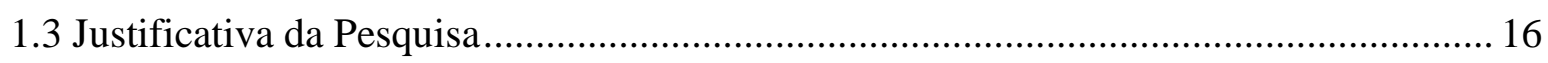

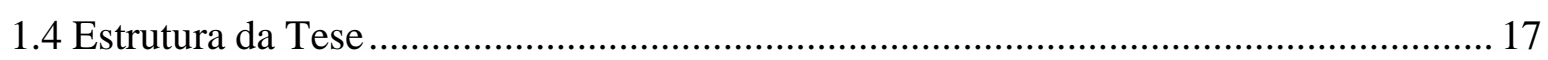

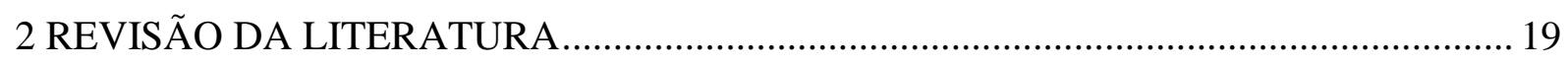

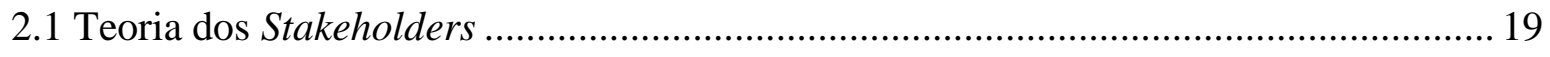

2.1.1 Conceito de Stakeholder .................................................................................... 21

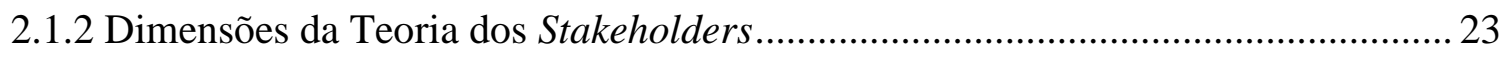

2.1.3 Críticas à Teoria dos Stakeholders …………………………………………..... 26

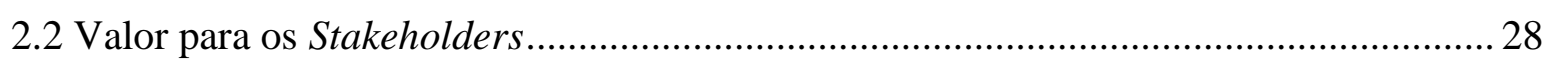

2.2.1 Gestão de stakeholders sob a perspectiva do valor ................................................ 29

2.2.2 Diferentes abordagens para a gestão de stakeholders ............................................... 33

2.2.3 Modelos para análise da distribuição de valor .............................................................. 34

2.2.4 Análise dos estudos encontrados na literatura........................................................ 40

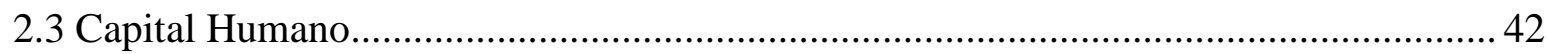

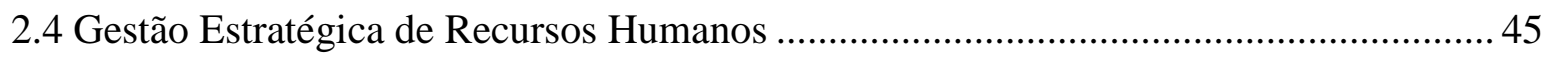

2.5 Práticas de RH e Desempenho Organizacional ............................................................... 46

2.5.1 Práticas de RH: Abordagem Universal e Estratégica ............................................... 47

2.5.2 Práticas de RH: Abordagem Comportamental e Baseada em Recursos .................. 52

2.5.3 Práticas de RH indutoras de valor para os funcionários........................................... 55

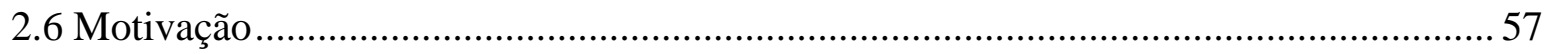

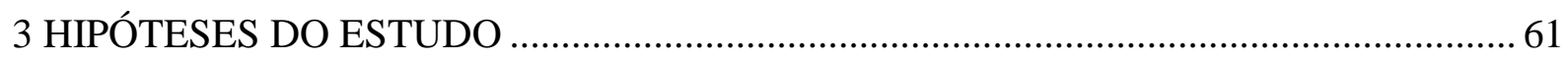

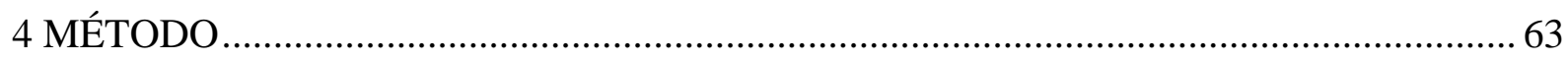

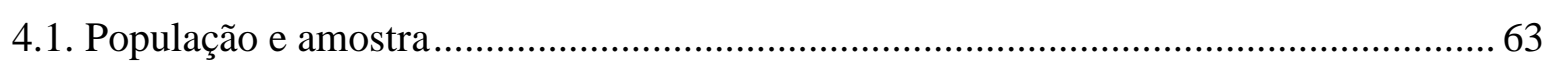

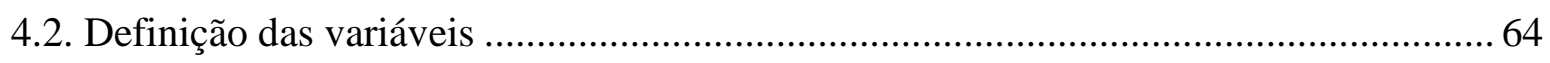

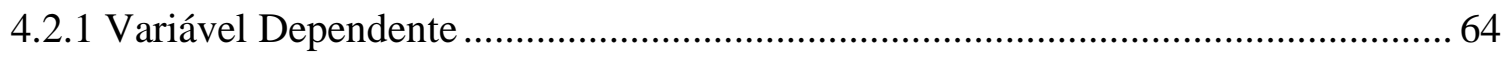

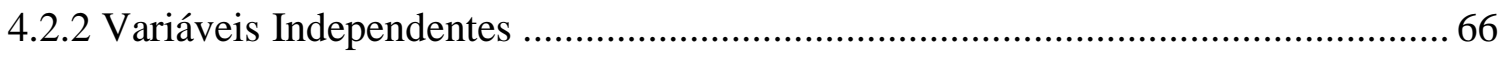

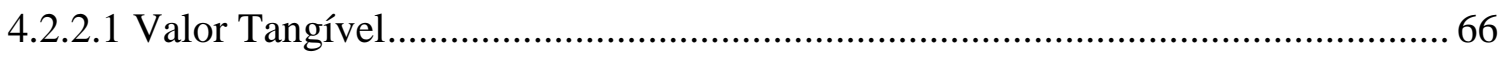




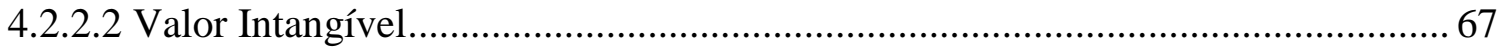

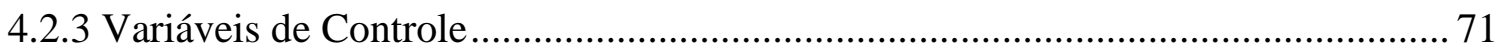

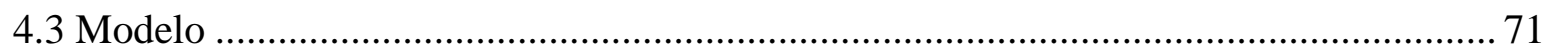

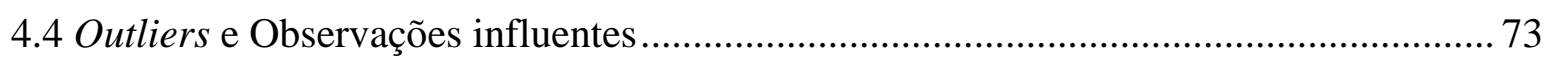

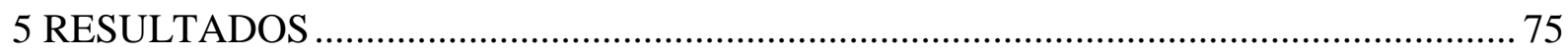

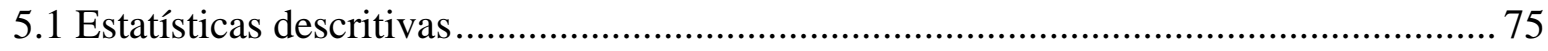

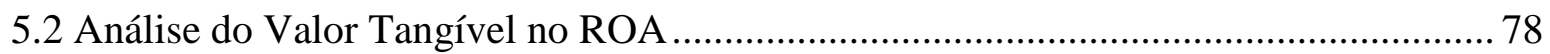

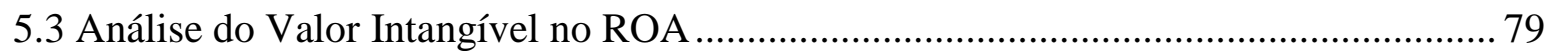

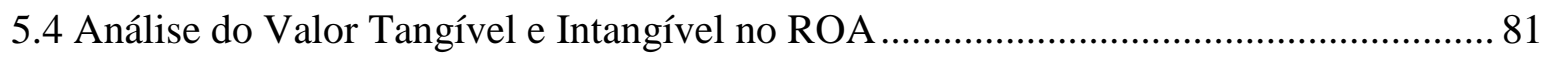

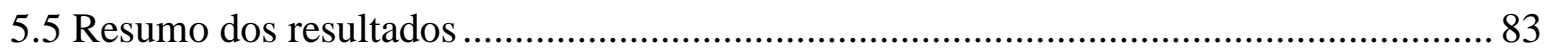

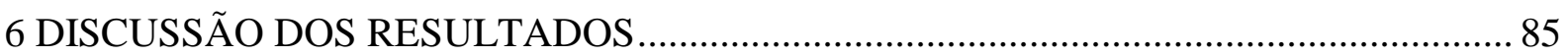

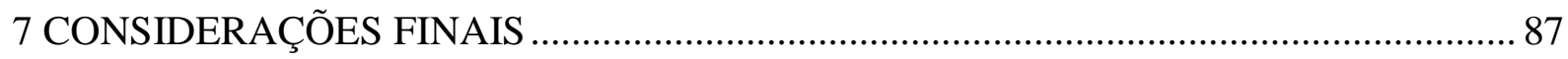

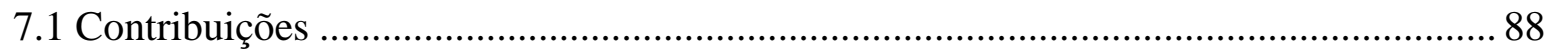

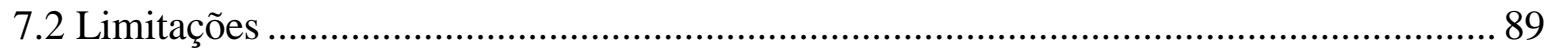

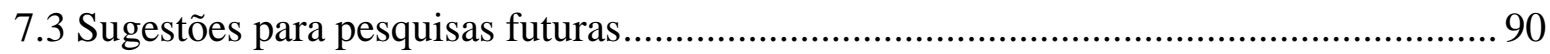

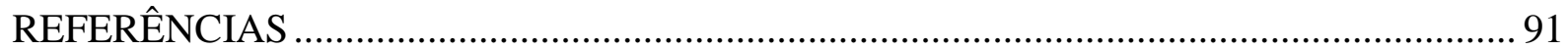

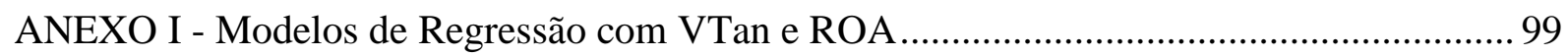

ANEXO II - Modelos de Regressão com VIn e ROA …….................................................. 103

ANEXO III - Modelos de Regressão com VTan, VIn e ROA ............................................. 107 


\section{INTRODUÇÃO}

A gestão estratégica diz respeito à direção que os gestores de uma organização decidem seguir, o que envolve uma grande variedade de decisões. Essas decisões incluem a seleção de metas, produtos e serviços a serem oferecidos, posição de competição no mercado, sistemas e políticas internas (Rumelt, Schendel \& Teece, 1991), assim como com quais stakeholders a empresa pretende se relacionar (Freeman, 1984).

Como campo de estudos, os pesquisadores de gestão estratégica buscam explicar e predizer o sucesso organizacional (Rumelt et al., 1991). Durante o desenvolvimento inicial do campo, o conceito de stakeholders teve um papel importante nessa discussão e, recentemente, a teoria dos stakeholders ressurgiu no debate envolvendo estratégia e vantagem competitiva (Harrison, Bosse \& Phillips, 2010).

A primeira vez que a palavra stakeholder apareceu na literatura foi em 1963, em um memorando interno da Stanford Research Institute (SRI International Inc.) (Freeman, 1984). Originalmente, o termo stakeholder foi definido como aqueles grupos que, sem seu apoio, uma organização deixaria de existir (Freeman, 1984). Segundo os pesquisadores da SRI, a menos que os executivos compreendessem as necessidades e preocupações desses grupos de stakeholders, eles não poderiam formular objetivos corporativos que recebessem o apoio necessário para a sobrevivência continuada da empresa (Freeman, 1984).

Contudo, é a obra de Freeman (1984), intitulada "Strategic Management: A Stakeholder Approach", que trouxe a teoria dos stakeholders para o mainstream da literatura de gestão (Frooman, 1999). Freeman (1984) definiu o termo stakeholder como grupos ou indivíduos que podem afetar ou serem afetados por uma organização na busca de seus objetivos.

Já em 1995, Donaldson e Preston (1995) destacavam que desde a publicação do livro de referência de Freeman (1984) cerca de uma dúzia de livros e mais de 100 artigos foram publicados com ênfase principal no conceito de stakeholders. Desde então, o interesse sobre o tema aumentou ainda mais e várias edições de periódicos importantes da área de gestão, como Business Ethics Quarterly, Academy of Management Review e Academy of Management 
Journal, têm se dedicado a elaborar e debater sobre o conceito de stakeholders (Friedman \& Miles, 2006, p.3).

\subsection{Problema de Pesquisa}

Os estudos sobre a teoria dos stakeholders vem se desenvolvendo sob diferentes aspectos. Até recentemente, os pesquisadores da área dedicaram esforços para identificar e classificar quem são os stakeholders da empresa (por exemplo, Clarkson, 1995 e Mitchell, Agle \&Wood, 1997), e para entender os consequentes de uma gestão voltada aos stakeholders, ou seja, a relação entre a gestão de stakeholders e diferentes resultados organizacionais (por exemplo, Barnett \& Salomon, 2012).

No entanto, nos últimos anos, os pesquisadores têm voltado sua atenção para questões relacionadas ao valor criado e distribuído aos stakeholders. Segundo Garcia-Castro e Aguilera (2015), esse interesse pode estar associado à introdução dos stakeholders como reivindicadores e capazes de capturar valor por meio de sua interação com a empresa. Além disso, o valor é apontado por Freeman, Harrison, Wicks, Parmar, e De Colle (2010) como uma questão central da teoria dos stakeholders, uma vez que, na visão desses autores, a teoria surgiu para entender e resolver três problemas interligados de negócios: (1) o problema de como o valor é criado e distribuído; (2) o problema de conexão entre a ética e o capitalismo; e (3) o problema do modelo mental gerencial que ajuda os gestores a pensar sobre os dois primeiros problemas (Freeman et al., 2010).

Embora a literatura apresente significativos avanços conceituais, ainda existem muitos desafios (Garcia-Castro \& Aguilera, 2015). Esses desafios podem ser evidenciados nos recentes comentários de pesquisadores do tema sobre questões-chave ainda não respondidas, as quais incluem (Tantalo \& Priem, 2016): o que significa "valor" para determinado grupo de stakeholders? Como as empresas criam diferentes tipos de "valor"? (Freeman et al., 2010).

De fato, os estudos sobre valor têm apresentado significativos avanços teóricos e pontos de consenso. A exemplo das proposições de Harrison et al. (2010) e Tantalo e Priem (2016), há 
um consenso quanto a ideia de que os grupos de stakeholders possuem diferentes funções utilidade, compostas por valores tangíveis e intangíveis. Além disso, os estudos sobre o tema consideram que o valor distribuído pela empresa para satisfazer a função utilidade dos seus stakeholders afeta o desempenho organizacional (Bosse, Phillips \& Harrison, 2009, Harrison \& Bosse, 2013, Harrison \& Wicks, 2013, Tantalo \& Priem, 2016),

No entanto, algumas questões ainda são pouco exploradas nessa literatura. Em primeiro lugar, uma vez que a função utilidade dos stakeholders inclui valores tangíveis e intangíveis, pouco se sabe sobre como esses dois tipos de resultado estão associados com o desempenho organizacional, ou seja, os dois tipos de valor afetam igualmente o desempenho organizacional? Em segundo lugar, embora os estudos considerem que diferentes grupos de stakeholders têm funções utilidade distintas, poucos estudos consideram que dentro do mesmo grupo também podem haver diferentes preferências para resultados tangíveis ou intangíveis (por exemplo, Bridoux \& Stoelhorst, 2014). Neste sentido, a teoria não recomenda se ambos os resultados são igualmente importantes ou podem variar dependendo de características específicas. Finalmente, como os estudos sobre valor são proposições teóricas, não se sabe como o atendimento da função utilidade dos stakeholders e o desempenho da empresa se comportam empiricamente.

Em função desses pontos que a teoria dos stakeholders pode ser desenvolvida, o problema desta pesquisa consiste em investigar qual a relação entre distribuição de valores tangíveis e intangíveis e o desempenho organizacional.

Para operacionalização da pesquisa foi selecionado o stakeholder funcionário, uma vez que este é um dos stakeholders mais estreitamente ligado a criação de valor da empresa (Harrison \& Bosse, 2013), tem acesso a informações chaves, competências críticas para a geração de renda, e, consequentemente, um custo de reposição muito elevado (Coff, 1999). 


\subsection{Objetivos da Pesquisa}

O objetivo desta pesquisa é analisar empiricamente a relação entre distribuição de valor tangível e intangível para o stakeholder funcionário e o desempenho organizacional.

\subsubsection{Objetivos específicos}

a) Analisar a relação entre distribuição de valor tangível para os funcionários e o desempenho de curto e longo prazo da empresa.

b) Analisar a relação entre distribuição de valor intangível para os funcionários e o desempenho de curto e longo prazo da empresa.

\subsection{Justificativa da Pesquisa}

Estudar a relação entre a distribuição de valor e o desempenho organizacional apresenta contribuições teóricas e gerenciais.

Sob o ponto de vista teórico, o estudo apresenta duas contribuições. A primeira contribuição refere-se à proposição de Phillips, Freeman e Wicks (2003) de que as discussões sobre a teoria têm se preocupado com a distribuição de valores tipicamente financeiros, enquanto questões importantes de equidade processual, distribuição de bens não-financeiros e informacionais são subestimados. Harrison et al. (2010) corroboram essa visão ao destacar que, sem dúvida, os resultados financeiros e materiais são importantes, porém eles não os únicos objetos de distribuição. Embora essa discussão venha sendo abordada na literatura em termos conceituais, 
esta pesquisa apresenta evidências empíricas da distribuição de valores não financeiros ao stakeholder funcionário e sua relação com o desempenho organizacional.

Em segundo lugar, ao estudar a distribuição de valor para os funcionários, este trabalho amplia a discussão sobre valor, alinhada ao argumento de Priem (2007) de que a atenção ao valor contribui para a compreensão dos fatores que levam ao alto desempenho sustentado, o que é fundamental para o sucesso da gestão estratégica.

Em termos gerenciais, os resultados são úteis para os gestores na decisão de que tipo de valor distribuir para o atendimento do stakeholder funcionário que resulte em um melhor desempenho organizacional. Essa questão é especialmente importante dado que os recursos da organização são limitados (Moura-Leite, Padgett \& Galan, 2014) e uma alocação eficiente destes recursos no atendimento dos stakeholders pode contribuir para a sobrevivência da empresa no longo prazo (Clarkson, 1995; Coff, 1999).

\subsection{Estrutura da Tese}

Esta tese está estruturada em 6 capítulos. O Capítulo 1 apresenta a introdução, problema, objetivos e a justificativa da pesquisa. O Capítulo 2 apresenta a fundamentação teórica, abordando a Teoria dos Stakeholders, com ênfase na distribuição de valor para os stakeholders, a Gestão Estratégica de Recursos Humanos e a relação entre as práticas de RH e o desempenho organizacional e, por fim o tema Motivação. O Capítulo 3 apresenta as hipóteses do estudo. No capítulo 4 está a seção de método, com as etapas metodológicas desenvolvidas na pesquisa. No capítulo 5 são apresentados os resultados do estudo. No capítulo 6 apresenta-se a discussão. Por fim, no Capítulo 7 estão as considerações finais. 


\section{REVISÃO DA LITERATURA}

Para o desenvolvimento desta tese foram utilizados três arcabouços teóricos. O primeiro referese a Teoria dos Stakeholders, do qual emergiu o problema de pesquisa. Neste sentido são abordados temas relacionados ao conceito de stakeholders, críticas à teoria e questões sobre distribuição de valor para stakeholders. A segunda teoria utilizada é a Gestão Estratégica de Recursos Humanos (GERH) que contribuiu para a discussão sobre atendimento do stakeholder funcionário e desempenho organizacional. A GERH foi importante para identificar as práticas de recursos humanos (RH) que podem ser utilizadas como fontes de utilidade, as quais, em última instância, refletem o valor distribuído pela empresa para o atendimento da função utilidade do stakeholder funcionário. Por fim, foram empregados conceitos de motivação para explicar como o valor distribuído ao funcionário afeta sua motivação e, consequentemente, o desempenho organizacional.

\subsection{Teoria dos Stakeholders}

A Teoria dos Stakeholders tem como marco teórico a obra "Strategic Management: A Stakeholder Approach" de Freeman (1984), que delineou e desenvolveu as características básicas do conceito de stakeholders (Jones, 1995). Segundo Freeman (1994), a teoria dos stakeholders é articulada em função de duas questões: 1) qual é o propósito da empresa e 2) qual a responsabilidade dos gestores para com seus stakeholders. Responder a essas questões ajuda os gestores a definir sobre o valor que eles desejam criar junto com seus principais stakeholders, assim como na definição de quais tipos de relações eles querem e precisam desenvolver para atender ao propósito da empresa (Freeman, Wicks \& Parmar, 2004).

Nesta perspectiva, os gerentes não são responsáveis apenas pela maximização do valor do acionista, como proposto pela teoria da firma, mas também pelo bem-estar de outras partes afetadas por decisões corporativas, as quais podem ajudar ou dificultar a realização dos objetivos da empresa (Cragg \& Greenbaum, 2002; Phillips et al., 2003). Certamente, os 
acionistas são um componente importante e os lucros são uma característica fundamental da atividade da empresa, porém a preocupação com os lucros é um resultado, e não o condutor no processo de criação de valor (Freeman et al., 2004). Segundo a teoria dos stakeholders, o verdadeiro objetivo da empresa, é, portanto, servir como um veículo para coordenar os interesses dos stakeholders (Evan \& Freeman, 1993 apud Clarkson, 1995), onde o desempenho de um grupo é otimizado em termos de valor global criado (Harrison \& Bosse, 2013).

Donaldson e Preston (1995) argumentam que a teoria dos stakeholders é gerencial no sentido amplo do termo, pois ela não se limita a descrever as situações existentes e prever as relações de causa-efeito, mas também, recomenda atitudes, estruturas e práticas, ou seja, ela reflete e orienta como os gestores operam (Donaldson \& Preston, 1995; Freeman, 1994). Neste sentido, a teoria permite que os gestores compreendam e gerenciem de forma estratégica os stakeholders da empresa (Frooman, 1999).

A teoria dos stakeholders tem interfaces com diversos outros temas da literatura de gestão, como a literatura de planejamento, responsabilidade social, teoria dos sistemas (Freeman, 1984) e governança corporativa (Freeman \& Reed, 1983). Contudo, uma ênfase excessiva na sociedade como stakeholder parece ter levado alguns estudiosos de gestão estratégica acreditar que a teoria dos stakeholders é sobre como gerenciar os interesses sociais de forma responsável (Harrison et al., 2010). A teoria dos stakeholders, no entanto, foi desenvolvida para o gerenciamento eficaz da empresa (Harrison et al., 2010; Harrison \& Wicks, 2013).

Esta pesquisa está alinhada a visão de Harrison et al. (2010), Harrison e Wicks (2013) e Freeman (1984), pois entende-se que bom gerenciamento dos stakeholders, por meio da distribuição de valor, resultará em melhor desempenho e a conquista de uma vantagem competitiva. 


\subsubsection{Conceito de Stakeholder}

Um dos conceitos mais utilizados para o termo stakeholder é a proposição de Freeman (1984) que define stakeholder como grupos ou indivíduos que podem afetar ou serem afetados pela organização na busca por seus objetivos. Além disso, o autor argumenta que stakeholder conota legitimidade. A legitimidade é entendida por Freeman (1984, p. 45) em um sentido gerencial, no qual os stakeholders são avaliados em função de sua capacidade de afetar a direção da empresa.

Embora uma grande parte dos pesquisadores utilizem uma variação do conceito de Freeman, a possibilidade de ampliar ou restringir a definição de stakeholder tem promovido debate na literatura (Rowley, 1997). Friedman e Miles (2006), por exemplo, identificaram mais de 50 definições para o termo stakeholder. Com base nessas definições os autores propõem um modelo de classificação das definições do termo stakeholder composto por quatro dimensões: ampla, restrita, normativa e estratégica.

As dimensões ampla e restrita estão relacionadas ao verbo da definição. O verbo utilizado geralmente indica a natureza da relação entre a organização e os stakeholders. Os verbos podem ter um sentido amplo (como afetar, impactar, influenciar, interagir) ou mais restrito (como apoiar, depender, dar significado, beneficiar ou prejudicar, investir ou arriscar algo de valor) (Friedman \& Miles, 2006).

As dimensões normativa e estratégica, por sua vez, referem-se ao predicado da definição, que pode ser um adjetivo ou outro aspecto relacionado. A definição proposta por Freeman (1984), por exemplo, utiliza como predicado a expressão "realização dos objetivos da organização", a qual é classificada como estratégica. Outras definições podem utilizar expressões como "reivindicações legítimas", que são classificadas como normativas (Friedman \& Miles, 2006, p.11).

Embora sejam encontradas inúmeras definições para o termo, a identidade dos stakeholders é considerada uma lacuna importante na teoria. Segundo Phillips e Reichart (2000), a teoria é, 
muitas vezes, incapaz de distinguir os indivíduos e grupos que são stakeholders daqueles que não são. Alguns autores propõem modelos e classificações para abordar esta questão.

Mitchell et al. (1997), por exemplo, propuseram o modelo de Saliência, o qual considera que um stakeholder deve ter, ao menos, um dos seguintes atributos: poder, legitimidade e urgência. De acordo com esse modelo, quanto mais atributos o stakeholder detém, maior é sua importância para o gestor.

Phillips et al. (2003), por sua vez, sugerem que os stakeholders podem ser utilmente separados em normativos e derivativos. Stakeholders normativos são aqueles a quem a organização tem a obrigação moral direta com o seu bem-estar. Eles fornecem a resposta para a questão "em benefício de quem a empresa deve ser gerenciada?". Esses stakeholders são os mais citados no debate sobre stakeholders e incluem os acionistas, funcionários, clientes, fornecedores e comunidades locais. Por outro lado, os stakeholders derivativos são aqueles grupos ou indivíduos que podem beneficiar ou causar dano à organização, mas aos quais a organização não tem nenhuma obrigação moral direta. Este grupo pode incluir concorrentes, ativistas, terroristas e meios de comunicação. Phillips et al. (2003) destacam, ainda, que a organização não é gerenciada para o benefício dos stakeholders derivativos, mas à medida em que eles podem influenciar a empresa ou os seus stakeholders normativos, os gestores devem considerálos em suas tomadas de decisão.

Clarkson (1995) também divide os stakeholders em dois grupos: primários e secundários. Os primários correspondem aos grupos de stakeholders que são cruciais para a sobrevivência e rentabilidade da empresa, como empregados, fornecedores, acionistas, clientes, governo e comunidade. Por outro lado, os stakeholders secundários, são aqueles que, embora afetem e sejam afetados, não são essenciais para a sobrevivência da empresa, como a mídia.

Segundo Harrison e Bosse (2013) os stakeholders primários são os stakeholders mais estreitamente associados às atividades de criação de valor da empresa, e incluem os funcionários, fornecedores, compradores, comunidade e acionistas da empresa. Sob essa perspectiva do valor, Garcia-Castro e Aguilera (2015, p. 138) conceituam stakeholder como "qualquer grupo ou indivíduo que cria e captura valor econômico em sua interação com a empresa". 
Com base nas definições de Garcia-Castro e Aguilera (2015) e Harrison e Bosse (2013), para esta pesquisa define-se stakeholder como "qualquer grupo ou indivíduo que contribui para a criação de valor da empresa e recebe como recompensa valor econômico e não econômico". Nesta pesquisa, será analisado o stakeholder funcionário uma vez que este grupo é um dos stakeholders mais estreitamente relacionado com a criação de valor da empresa (Harrison \& Bosse, 2013) e está em melhor posição para capturar valor da empresa (Coff, 1999). Além disso, ele tem melhores informações, habilidades críticas para gerar renda e, consequentemente, um custo muito elevado de substituição (Coff, 1999).

\subsubsection{Dimensões da Teoria dos Stakeholders}

O desenvolvimento da teoria dos stakeholders tem ocorrido em diferentes perspectivas. A classificação mais aceita para o desenvolvimento da teoria é a classificação proposta por Donaldson e Preston (1995). Segundo esses autores, a teoria dos stakeholders tem avançado e tem sido justificada na literatura de gestão sob três aspectos ou dimensões: descritiva/empírica, instrumental e normativa, conforme apresentado na Ilustração 1. Embora inter-relacionadas, essas dimensões são bastante distintas, envolvem diferentes tipos de provas e argumentos e têm diferentes implicações (Donaldson \& Preston, 1995).

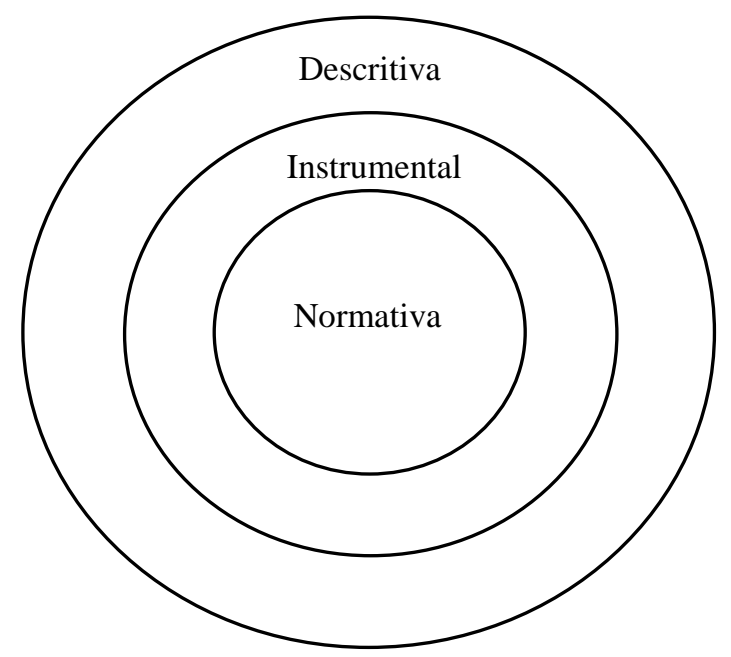

Ilustração 1 - Dimensões da Teoria dos Stakeholder Fonte: Donaldson e Preston (1995, p.74). 
Sob a perspectiva descritiva, a teoria descreve o que a empresa é. Nesta dimensão, a empresa é entendida como uma constelação de interesses cooperativos e competitivos que possuem valor intrínseco (Donaldson \& Preston, 1995).

Na dimensão instrumental, a teoria estabelece uma estrutura para examinar as conexões, caso existam, entre a prática da gestão de stakeholders e a realização de várias metas de desempenho corporativo. Nesta dimensão, a proposição é de que as empresas que gerenciam seus stakeholders serão relativamente bem sucedidas em termos de desempenho convencionais, como rentabilidade, estabilidade e crescimento (Donaldson \& Preston, 1995).

A última dimensão, a normativa, é considerada a base fundamental da teoria. Nesta dimensão a teoria é usada para interpretar a função da empresa, incluindo a identificação de diretrizes morais ou filosóficas para a operação e gestão de empresas. Esta dimensão envolve a aceitação das seguintes ideias: (a) os stakeholders são pessoas ou grupos com interesses legítimos na empresa e (b) os interesses de todos os stakeholders tem valor intrínseco (Donaldson \& Preston, 1995).

Após essa proposição de Donaldson e Preston (1995), Jones e Wicks (1999) publicaram o artigo "Convergent Stakeholder Theory", onde reconhecem a importância do trabalho de Donaldson e Preston (1995) por acrescentar coerência considerável para o conceito de stakeholder e por fornecer uma taxonomia dos tipos de teoria dos stakeholders. Contudo, Jones e Wicks (1999) sugerem a necessidade de uma convergência da teoria dos stakeholders.

O argumento central de Jones e Wicks (1999) é que nenhuma das dimensões da teoria dos stakeholders está completa sem a outra. Esses autores propõem a teoria convergente dos stakeholders, que combina elementos normativos e instrumentais. Jones e Wicks (1999) também argumentam que a teoria convergente dos stakeholders, ao contrário de outras teorias de organização, demonstra como os gestores podem criar formas morais e viáveis de fazer negócios. Assim, a questão central abordada pela teoria convergente dos stakeholders é: que tipos de relações com os stakeholders são tanto moralmente justificáveis e viáveis?

No mesmo ano de 1999, Freeman (1999) publica uma resposta a proposição de Jones e Wicks (1999) de uma teoria convergente de stakeholders. Embora Freeman (1999) reconheça que há muitos aspectos úteis na proposta de Jones e Wicks (1999), entre eles, a ênfase dada à dimensão 
instrumental como a candidata mais promissora para o desenvolvimento da teoria, o autor faz uma crítica à tentativa de teorização de Jones e Wicks (1999).

Freeman (1999) argumenta que não é preciso mais teoria convergente, mas sim, narrativas divergentes, capazes de mostrar diferentes maneiras de entender as organizações em termos de seus stakeholders. O autor explica que seu livro "Strategic Management: A Stakeholder Approach" foi construído sobre premissas instrumentais, o qual sugere que as organizações que buscam ser eficazes vão prestar atenção apenas para as relações que podem afetar ou ser afetadas pela realização dos objetivos organizacionais. Ou seja, o gerenciamento dos stakeholders é fundamentalmente um conceito pragmático. Independentemente do propósito de uma empresa, a empresa eficaz irá gerenciar as relações que são importantes (Freeman, 1999).

Mais recentemente, Heath e Norman (2004) expandem a classificação proposta por Donaldson e Preston (1995) e apresentam nove diferentes visões da teoria dos stakeholders. Segundo os autores, o pensamento sobre o papel dos stakeholders nas empresas envolve uma enorme gama de diferentes teorias, disciplinas e metodologias (tais como: economia, direito, ética, filosofia política, e todos as ciências sociais subjacentes às subdisciplinas gerenciais). As visões propostas por Heath e Norman (2004) são:

1) Stakeholder ontológico: uma teoria sobre a natureza e o propósito da empresa. Nesta visão, a empresa é essencialmente uma entidade organizacional, através do qual muitas pessoas e diferentes grupos tentam alcançar seus objetivos.

2) Stakeholder explicativo: uma teoria que se propõe a descrever e explicar como as empresas e seus gestores realmente se comportam.

3) Stakeholder estratégico: teoria sobre como a dedicação de recursos e atenção gerencial suficientes no relacionamento com stakeholders pode levar a resultados rentáveis para a empresa.

4) Stakeholder de marca e cultura corporativa: um subconjunto do stakeholder estratégico. Esta é uma teoria sobre como o compromisso de prestar atenção extraordinária aos interesses de stakeholders particulares, como clientes e/ou funcionários, pode ser um aspecto fundamental da identidade visual básica e da cultura de uma empresa. 
5) Stakeholder deôntico: uma teoria que determina os interesses e direitos legítimos dos diferentes agentes que, presumivelmente, vão além de seus direitos legais.

6) Stakeholder gerencial: incorpora teorias do comportamento organizacional, gestão de recursos humanos, liderança, operações, contabilidade, e assim por diante, que ajudam os gestores perceberem os benefícios estratégicos e satisfazerem as exigências deônticas dos stakeholders.

7) Stakeholder de governança: teoria sobre como grupos específicos de stakeholders devem exercer supervisão e controle sobre a gestão. Essa teoria discute questões como, quais grupos, além de acionistas, devem ser representados no conselho e como o conselho deve funcionar.

8) Stakeholder regulamentação: teoria de que os direitos e interesses de grupos específicos de stakeholders devem ser protegidos por regulamentação governamental.

9) Stakeholder de direito empresarial: uma teoria sobre como a tradicional lei corporativa deve ser alterada para refletir os princípios e práticas defendidos pelos stakeholders ontológicos, deônticos e de governança.

Esta pesquisa está inserida na dimensão instrumental, conforme proposta por Donaldson e Preston (1995), e na visão estratégica de Heath e Norman (2004), uma vez que o objetivo é investigar a relação entre a distribuição de valor e o desempenho organizacional.

\subsubsection{Críticas à Teoria dos Stakeholders}

O termo stakeholder tem evocado elogios e críticas de uma grande variedade de pesquisadores (Phillips et al., 2003). Para Phillips et al. (2003), a teoria dos stakeholders pode ser prejudicada em função de duas direções: distorções e más interpretações amigáveis. Motivados pela questão de o que a teoria dos stakeholders não é, Phillips et al. (2003) apresentam argumentos decorrentes dessas duas direções, que segundo os autores, são interpretações erradas da teoria. Esses argumentos e seus respectivos defensores são apresentados na Ilustração 2. 


\begin{tabular}{|c|c|}
\hline Distorções & Más interpretações \\
\hline $\begin{array}{c}\text { A teoria dos stakeholders é uma desculpa } \\
\text { para o oportunismo (Jensen, 2002; } \\
\text { Marcoux, 2000; Sternberg, 2000). }\end{array}$ & $\begin{array}{c}\text { A teoria dos stakeholders exige mudanças } \\
\text { na lei (Hendry, 2001; Van Buren, 2001). }\end{array}$ \\
\hline $\begin{array}{c}\text { A teoria dos stakeholders não é capaz de } \\
\text { oferecer uma função objetivo específica } \\
\text { para a organização (Jensen, 2002). }\end{array}$ & $\begin{array}{c}\text { A teoria dos stakeholders é um socialismo } \\
\text { velado e refere-se a toda economia (Barnett } \\
\text { 1997; Hutton 1995; Rustin 1997). }\end{array}$ \\
\hline $\begin{array}{c}\text { A teoria dos stakeholders está preocupada, } \\
\text { principalmente, com a distribuição de } \\
\text { resultados financeiros (Marcoux, 2000). }\end{array}$ & $\begin{array}{c}\text { A teoria dos stakeholders é uma abrangente } \\
\text { doutrina moral (Orts \& Strudler, 2002). }\end{array}$ \\
\hline $\begin{array}{c}\text { Todos os stakeholders devem ser tratados } \\
\text { igualmente (Gioia, 1999; Marcoux, 2000; } \\
\text { Sternberg, 2000). }\end{array}$ & $\begin{array}{c}\text { A teoria dos stakeholders aplica-se apenas } \\
\text { para as corporações (Donaldson \& Preston, } \\
\text { 1995). }\end{array}$ \\
\hline
\end{tabular}

Ilustração 2 - O que a teoria dos stakeholders não é Fonte: Phillips et al. (2003, p. 482)

Phillips et al. (2003) descrevem cada um desses pontos, assim como indicam alternativas a estas más interpretações. Estas questões também são entendidas como limites da teoria dos stakeholders (Phillips, 2003; Freeman et al, 2010). Freeman et al. (2010) apresentam esses limites no livro "Stakeholder theory: the state of the art", reforçando a ideia de que estes ainda são limites atuais da teoria dos stakeholders.

Um desses limites, que é de especial interesse para esta pesquisa, é a questão de que a teoria está preocupada, principalmente, com a distribuição de resultados financeiros. Sobre esse ponto, Phillips et al. (2003) argumentam que os debates sobre a teoria dos stakeholders frequentemente se concentram em quanto cada grupo de stakeholders recebe e porquê. Neste contexto, dois aspectos são pouco abordados pela teoria: o primeiro é de que o processo de distribuição é tão importante quanto a distribuição de resultados em si; o segundo é de que a distribuição é normalmente considerada em termos monetários, embora resultados financeiros e materiais não sejam os únicos objetos de distribuição (Phillips et al., 2003; Harrison et al., 2010). Segundo Harrison e Wicks (2013), considerar que o único valor relevante criado pela empresa é econômico pode alimentar uma disputa dos stakeholders por sua parte. Essa visão é considera contrária à filosofia da teoria dos stakeholders que enfatiza a cooperação para o benefício dos stakeholders ao longo do tempo (Harrison \& Wicks, 2013). 
Esta lacuna vem sendo estudada na literatura em termos de gestão de stakeholders e distribuição de valor para os stakeholders. Os estudos que tem contribuído para esta discussão são apresentados na seção a seguir.

\subsection{Valor para os Stakeholders}

O debate e as dificuldades sobre o conceito e teorias de "valor" não são novas, podendo ser encontradas nas obras de antigos filósofos como Platão, Aristóteles e Xenofonte (Pitelis, 2009). Em termos de gestão estratégica, o valor tipicamente foi visto do lado da oferta, como algo criado exclusivamente pelos produtores (Priem, 2007). Nesse sistema, cada empresa acrescenta fatores de produção para fazer a sua própria contribuição única de valor, e cada um se esforça para capturar uma parcela de pagamentos do usuário final, pelo menos proporcional à sua contribuição (Priem, 2007). Priem (2007) argumenta que a atenção dos pesquisadores quanto ao valor e sua relação com outros atores contribui para a compreensão dos fatores que levam ao alto desempenho sustentado, o que é fundamental para o sucesso da gestão estratégica. Priem (2007) e Ye, Priem e Alshwer (2012) avançam nesta direção ao incorporar uma perspectiva do consumidor sobre o valor.

Na teoria dos stakeholders, a discussão e definições sobre o valor é um tema emergente e os pesquisadores têm evoluído teoricamente a respeito desta questão. Harrison e Wicks (2013), por exemplo, definem valor como aquilo que um stakeholder recebe e que realmente tem mérito para ele. Esses autores utilizam o termo "utilidade" para refletir este valor. A utilidade expressa as preferências dos stakeholders para determinados tipos de valor, mais especificamente, a função utilidade de um stakeholder são suas preferências para diferentes combinações de resultados tangíveis e intangíveis decorrentes de ações tomadas pela empresa (Harrison et al., 2010). A determinação da função utilidade inclui duas dimensões: 1) fatores que impulsionam a utilidade para os stakeholders, que incluem as preferências por diferentes combinações de resultados tangíveis e intangíveis e 2) o peso atribuído a cada um desses resultados. 
O valor pode ser distribuído por meio de diversas formas tais como, salários mais altos ou melhores benefícios para os funcionários, melhores condições aos fornecedores, programas de serviços à comunidade, preços mais baixos, produtos mais seguros ou melhores serviços para os clientes (Harrison et al., 2010). As empresas também distribuem valor aos stakeholders de outras maneiras que não são tão facilmente medidas em termos monetários, tal como a equidade nos processos e participação na tomada de decisão (Phillips, 2003, Harrison \& Bosse, 2013).

Para esta pesquisa adota-se o conceito de valor para stakeholder proposto por Harrison et al. (2010) e Harrison e Wicks (2013), que consideram valor como a utilidade que o stakeholder recebe da empresa em suas interações. Valor para stakeholder é entendido como o valor distribuído pela empresa para atender aos interesses dos seus stakeholders. Tendo em vista que o interesse desta pesquisa é a distribuição de valor, os processos de criação e apropriação de valor não serão analisados.

Na seção seguinte são apresentados os estudos que avançam na discussão sobre a forma como a gestão de stakeholders está relacionado ao valor. A fim de apresentá-los de forma didática, os estudos foram separados em quatro seções: (1) gestão de stakeholders sob a perspectiva do valor, (2) diferentes abordagens para a gestão de stakeholders, (3) modelos para análise da distribuição de valor para os stakeholders, e (4) análise dos estudos encontrados na literatura.

\subsubsection{Gestão de stakeholders sob a perspectiva do valor}

Nesta seção serão apresentados os estudos que tratam da gestão de stakeholders sob a perspectiva do valor. Esses estudos empregam a suposição de que um bom (Tantalo \& Priem, 2016) e justo (Bosse et al., 2009, Harrison et al., 2010) tratamento dos stakeholders da empresa pode levar a um alto desempenho, um aumento na criação de valor da empresa, assim como a uma vantagem competitiva sustentável. Esta perspectiva é discutida por Bosse et al. (2009), Harrison et al. (2010) e Tantalo e Priem (2016).

Bosse et al. (2009) propõem uma gestão de stakeholders baseada na justiça organizacional. Segundo os autores, as suposições sobre o comportamento humano baseadas no auto-interesse 
e oportunismo são limitadas para explicar as relações entre as empresas e seus stakeholders. Segundo essas suposições os agentes econômicos são exclusivamente egoístas maximizadores de utilidade. Como alternativa, os autores explicam como a reciprocidade pode afetar a relação entre a firma e seus stakeholders, assim como seu desempenho agregado. Segundo essa perspectiva as pessoas procuram maximizar sua utilidade considerando normas de reciprocidade.

Bosse et al. (2009) desenvolvem seus argumentos com base em três tipos de justiça: distributiva, processual e interacional. A justiça distributiva está relacionada aos resultados materiais de um regime de distribuição, isto é, a quantidade real de recursos materiais alocados para os stakeholders; a justiça processual diz respeito à equidade das regras e procedimentos desse regime de distribuição; e a justiça interacional refere-se à maneira pela qual os atores tratam uns aos outros (Bosse et al., 2009). Para esses autores, a percepção dos stakeholders quanto a esses três tipos de justiça influenciará sua disposição para contribuir com a empresa. Assim, o comportamento justo é recompensado, gerando reciprocidade positiva, e o comportamento injusto é punido, resultando em reciprocidade negativa. Considerando esses argumentos, os autores propõem que, ceteris paribus, empresas percebidas como justas por seus stakeholders, em termos de distribuição, processo e interação, criarão mais renda. Da mesma forma, empresas percebidas como injustas criarão menos renda.

Harrison et al. (2010) argumentam que as empresas podem alcançar vantagem competitiva através de uma boa gestão de stakeholders. A respeito disso, os autores discutem o conceito de "gestão para os stakeholders", o qual considera uma atribuição de valor para os stakeholders que é maior do que o mínimo necessário para apenas manter sua participação intencional no processo de criação de valor da firma. O pressuposto dessa proposição é que as empresas que gerenciam para os stakeholders desenvolvem relações de confiança, que incentivam os stakeholders a compartilhar informações sobre sua função utilidade. Este conhecimento permite que a empresa aloque seus recursos para áreas que melhor satisfaçam as necessidades e demandas de seus stakeholders.

Ao revelar informações sobre sua função utilidade, o stakeholder espera que a empresa ofereça uma proposta de valor melhor ou inovadora, que melhore seu bem-estar (Harrison et al., 2010). Essa lógica também se aplica à empresa quando revela informações sobre sua função utilidade para seus stakeholders. No entanto, algumas empresas podem usar essas informações para 
explorar o stakeholder, oferecendo uma proposta de valor que maximize os benefícios da empresa. Os autores denominam esse tipo de gestão como abordagem "arms-length". Em função disso, a confiança é considerada um elemento importante para que as empresas tenham acesso as informações das funções utilidades, pois quando há confiança, há uma crença por parte dos stakeholders de que as informações não serão utilizadas de forma contrária aos seus interesses. No entanto, a confiança não é o único fator necessário para que um stakeholder revele informações sobre suas preferências. Em função disso, os autores também utilizam os conceitos de reciprocidade, saliência e justiça distributiva, processual e interacional para explicar como empresas podem ter acesso ao conhecimento da função utilidade.

Harrison et al. (2010) explicam que o gerenciamento para os stakeholders pode ser sustentável, uma vez que é difícil de imitar devido à dependência de recursos e ambiguidade causal. A proposta dos autores também inclui algumas limitações, como a possibilidade de super alocação de valor para os stakeholders, dificuldade de medir o valor criado através de medidas contábeis tradicionais, dificuldade de traduzir o conhecimento em oportunidades de criação de valor e o potencial de oportunismo.

Segundo Tantalo e Priem (2016), embora os teóricos dos stakeholders tenham feito progressos na descrição do processo de gestão para os stakeholders, relativamente pouco se sabe sobre como a teoria dos stakeholders pode ser usada para melhorar as estratégias de criação de valor da empresa, o que tem limitado a teoria como uma ferramenta para a gestão estratégica (Tantalo \& Priem, 2016). Contribuindo com este problema, Tantalo e Priem (2016) desenvolveram um quadro teórico detalhando maneiras em que o valor pode ser criado simultaneamente para vários grupos de stakeholders essenciais. Estes autores explicam dois tipos de gestão da função utilidade dos stakeholders, a rotação de atenção não ponderada e a rotação de atenção ponderada pela saliência, e, em seguida, propõem uma abordagem alternativa para a gestão dos stakeholders.

De acordo com a abordagem rotação de atenção não ponderada, as alocações dos gestores mudam ao longo do tempo. Por exemplo, as alocações iniciais entre os stakeholders essenciais poderia ser, a maioria dos recursos para o reforço da utilidade do acionista, relativamente menos recursos para atender as utilidades dos fornecedores e dos clientes, e recursos mínimos para as utilidades dos funcionários e da comunidade. Mais tarde, os gestores podem alocar novos 
recursos para fornecedores, ou realocar recursos de acionistas para funcionários (Tantalo \& Priem, 2016).

A abordagem rotação de atenção ponderada pela saliência, por sua vez, é baseada no modelo de Saliência, proposto por Mitchell et al. (1997), que é composto pelos atributos de poder, legitimidade e urgência. Quanto maior for o grau de saliência, maior é a atenção que um grupo específico de stakeholders receberá dos gestores. Assim, de acordo com esta abordagem recursos são alocados de acordo com a saliência percebida pelos gestores para cada grupo específico de stakeholders.

Tanto a percepção de saliência, quanto a rotação de atenção não ponderada, se alteram ao longo do tempo e, como resultado, a alocação de recursos muda a fim de restaurar um perfil de utilidade total mais apropriado entre os stakeholders (Tantalo \& Priem, 2016). No entanto, estas duas abordagens podem afetar negativamente os stakeholders que estão recebendo apenas recursos mínimos no curto prazo.

Como abordagem alternativa, Tantalo e Priem (2016) argumentam que é possível a criação de valor, simultaneamente e de forma sinérgica, para vários grupos de stakeholders essenciais por meio da abordagem chamada sinergia dos stakeholders. O objetivo dessa abordagem é aumentar o "tamanho do bolo" disponível para dois ou mais grupos de stakeholders através de uma única ação estratégica ou um conjunto integrado de ações (ou seja, a estratégia da empresa).

Segundo esses autores, os grupos de stakeholders essenciais podem ser caracterizados por diferentes funções de utilidade multi-atributo que orientam a tomada de decisão de cada grupo de stakeholders. Essas funções de utilidade dos stakeholders contém mais do que apenas utilitários econômicos, e diferentes grupos de stakeholders podem atribuir pesos diferentes até mesmo para os utilitários econômicos. Neste sentido, um aumento na utilidade econômica de um grupo de stakeholders não necessariamente resulta em uma redução sobre a utilidade geral de outro grupo de stakeholders. Por exemplo, funções de utilidade dos clientes podem ser compostas por uma combinação de fatores econômicos, como preço, e fatores não-econômicos, como as características do produto, serviço ao cliente, perfil verde de um produto. Quando uma empresa diferencia seus produtos adicionando utilidade, a utilidade total do consumidor pode aumentar, mesmo quando os preços aumentam. Por conseguinte, o aumento da disposição dos 
consumidores em pagar mais pelos produtos da empresa pode resultar em um benefício para os acionistas. Assim, a mesma ação gerencial pode beneficiar dois ou mais grupos de stakeholders essenciais, o que representa um caso de sinergia de stakeholders (Tantalo \& Priem, 2016).

Para alcançar a sinergia de stakeholders, existem três métodos fundamentais. 1) Criação única de valor para os stakeholders: criar valor é aumentar a utilidade recebida por um grupo de stakeholders sem afetar negativamente a proposição de valor recebida por qualquer outro grupo de stakeholders (Tantalo \& Priem, 2016). 2) Utilidades complementares: quando os gerentes encontram complementaridades em necessidades ao longo de dois ou mais grupos de stakeholders. Neste caso, uma única inovação gerencial pode aumentar um tipo de valor para um grupo de stakeholders, além de ampliar um tipo diferente de valor para outro grupo, sem afetar negativamente qualquer outro grupo de stakeholders essenciais (Tantalo \& Priem, 2016). 3) Seguir eficiências: quando um, dois, ou mais grupos de stakeholders essenciais recebem aumento de valor por uma única inovação estratégica (Tantalo \& Priem, 2016).

Tantalo e Priem (2016) elencam alguns condutores de valor que são entendidos pelos autores como fontes de utilidade. Esses condutores de valor são classificados em tangíveis e intangíveis. Os condutores de valor tangível para funcionários incluem salário, benefícios, responsabilidade social corporativa e políticas de qualidade da vida. Os condutores de valor intangível para funcionários incluem percepção de justiça do ambiente de trabalho, características do trabalho e variedade de habilidades.

\subsubsection{Diferentes abordagens para a gestão de stakeholders}

Uma premissa subjacente destes trabalhos e da teoria dos stakeholders é de que os stakeholders se preocupam com a justiça (Bridoux \& Stoelhorst, 2014). Bridoux e Stoelhorst (2014) questionam essa premissa e sugerem que tanto uma abordagem fairness quanto uma abordagem arms-length para o gerenciamento dos stakeholders podem levar à criação de valor sustentável.

Uma abordagem fairness é baseada na justiça e se manifesta de três maneiras: 1) a equidade conduz o processo de dividir o valor criado, 2) os contratos formais entre firmas e seus 
stakeholders tendem a ser menos detalhados porque as partes baseiam-se na confiança e autoreforço e 3) as relações com os stakeholders tendem a ser de longo prazo. Por outro lado, uma abordagem arms-length interage com seus stakeholders com base no poder de barganha. Esta abordagem difere da abordagem fairness em três aspectos: 1) o poder de negociação em relação aos stakeholders impulsiona o processo de dividir o valor criado; 2) os contratos são formais, com padrões detalhados de desempenho e requisitos e 3) as relações tendem a ser de curto prazo.

Os autores argumentam que diferentes abordagens para gerenciar os stakeholders estão relacionadas com diferentes tipos de indivíduos envolvidos no processo de criação de valor. Enquanto os indivíduos recíprocos preocupam-se com relações justas, os indivíduos autointeressados são mais motivados por benefícios individuais e monetários. Com base no mecanismo de motivação de cada um destes dois tipos de indivíduos, Bridoux e Stoelhorst (2014) propõem que uma abordagem fairness seria mais eficaz para atrair, reter e motivar os stakeholders recíprocos e uma abordagem arms-length estaria relacionada aos stakeholders auto-interessados com alto poder de barganha (Bridoux \& Stoelhorst, 2014). Além disso, os autores ressaltam que é importante que a empresa tenha consistência na sua gestão e não mude de uma abordagem para outra ao longo do tempo.

2.2.3 Modelos para análise da distribuição de valor

Nesta seção, serão apresentados três estudos que discutem como analisar o impacto da distribuição de valor tanto para as empresas quanto para os stakeholders. Harrison e Bosse (2013) apresentam um modelo para analisar o potencial de sub ou super alocação de valor para os stakeholders, Harrison e Wicks (2013) apresentam um modelo para identificar fontes de utilidade e Garcia-Castro e Aguilera (2015) demonstram como o valor apropriado por um dos stakeholders afeta outros stakeholders.

Harrison e Bosse (2013) argumentam que há benefícios no tratamento generoso dos stakeholders, mas também há custos substanciais associados a esse comportamento. Segundo 
esses autores, embora a teoria dos stakeholders promova o melhor tratamento de um amplo grupo de stakeholders, ela não estabelece limites no que diz respeito a esse comportamento. Devido ao seu aparente fracasso em estabelecer limites para o tratamento favorável dos stakeholders, a teoria parece promover a posição da empresa de "dar a loja", em que as empresas gastam tantos recursos para satisfazer as demandas dos stakeholders que sacrificam a rentabilidade. Um sinal dessa situação é quando não há valor material suficiente para outros stakeholders manter sua participação na empresa (Harrison \& Bosse, 2013).

A fim de analisar quanto valor atribuir para os stakeholders, os autores sugerem considerar o seu custo de oportunidade. Em outras palavras, o tipo de relacionamento entre o stakeholder e a empresa e, portanto, o comportamento do stakeholder, depende da proposta de valor que a empresa apresenta em relação a outras oportunidades disponíveis para eles. Esta proposta de valor inclui fatores tangíveis e intangíveis. Quando os stakeholders recebem valor acima de seu custo de oportunidade, eles tendem a retribuir com comportamentos que ajudam a empresa a criar mais valor dentro de seu sistema total de criação de valor. Esse valor adicional pode ser distribuído entre os stakeholders, continuando, assim, um ciclo positivo. Por exemplo, se o funcionário acredita receber um valor total que é maior do que seu custo de oportunidade, então a reciprocidade positiva pode influenciar o seu comportamento. Isto é, além de fidelidade, o funcionário tem mais probabilidade de gastar energia adicional, compartilhar informações importantes e trabalhar para melhorar o bem-estar do empregador (Harrison \& Bosse, 2013).

Considerando esse contexto, Harrison e Bosse (2013) propõem que, para analisar o potencial de sub ou super alocação de valor para um stakeholder particular, os gerentes podem usar duas dimensões: poder e importância estratégica. A primeira dimensão é o poder que um stakeholder tem e se refere à capacidade ou propensão deste stakeholder prejudicar a empresa. A segunda dimensão, importância estratégica, refere-se a capacidade de contribuição de um stakeholder para tornar a empresa mais competitiva. A combinação dessas duas dimensões, pode ajudar os gestores a identificar quais stakeholders podem ser sub ou super-recompensados tendo em vista a eficiência da empresa. A Ilustração 3 apresenta o modelo proposto pelos autores em função dessas duas dimensões. 
Importância do stakeholder para a competitividade da empresa

(Importância Estratégica)

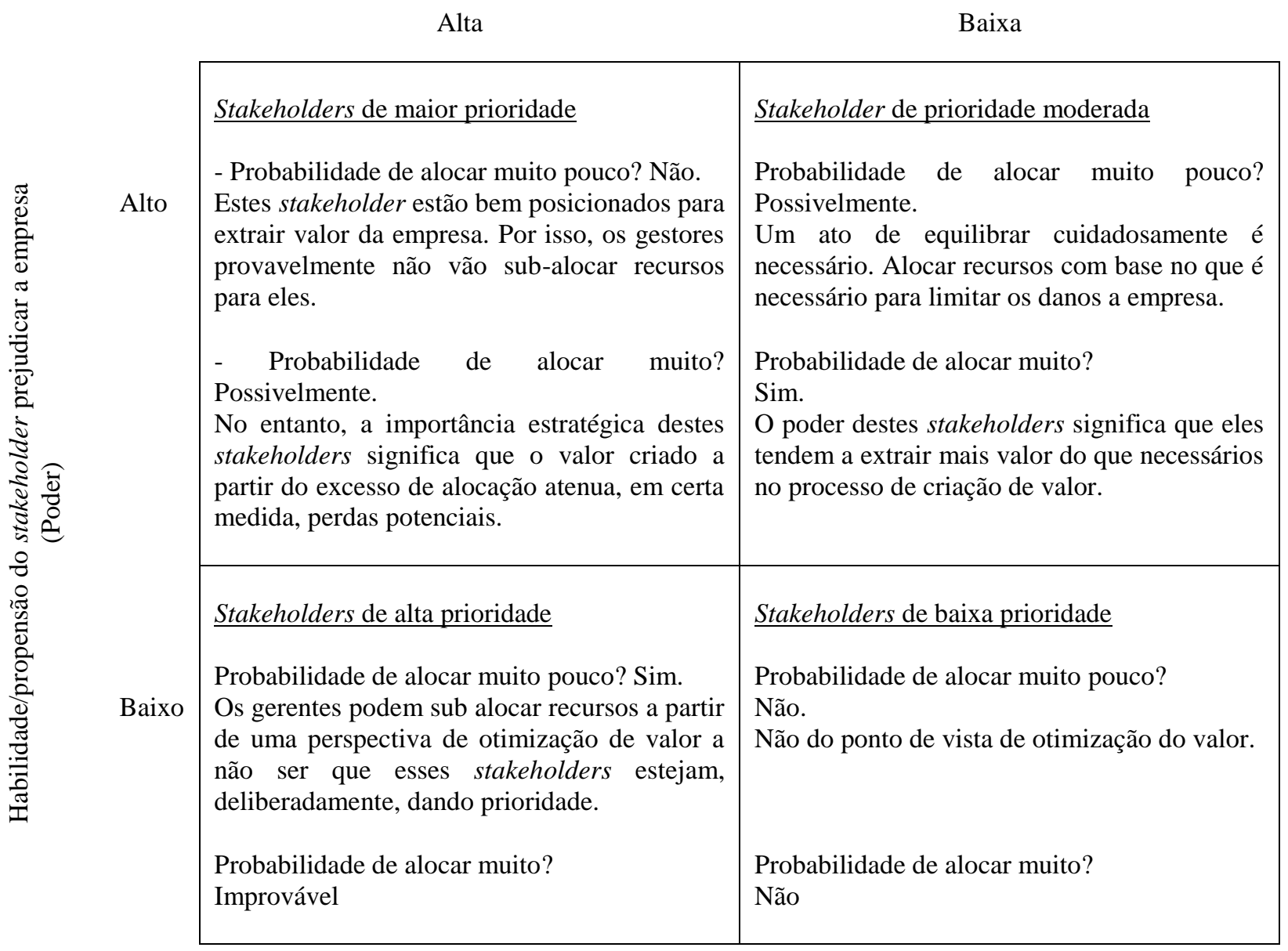

Ilustração 3 - Muito ou pouco valor alocado para os stakeholders

Fonte: Harrison e Bosse (2013, p. 319)

No primeiro quadrante do modelo estão os stakeholders de maior prioridade para a empresa, os quais possuem alto poder e alta importância estratégica. Estes stakeholders estão propensos a já estar recebendo um atrativo conjunto de valor da empresa. O poder destes stakeholders poderia resultar em mais alocação de valor, no entanto, uma super alocação não prejudicaria a empresa devido à importância estratégica destes stakeholders para a geração de valor (Harrison \& Bosse, 2013).

No outro extremo do modelo, estão os stakeholders com baixa prioridade, os quais possuem baixo poder e baixa importância estratégica. A falta de poder significa que eles não podem extrair muito valor adicional da empresa e sua falta de importância estratégica significa que eles pouco contribuem para a criação de valor (Harrison \& Bosse, 2013). 
Esta situação contrasta com os stakeholders que são poderosos, mas não são estrategicamente importantes. Para estes stakeholders é necessário um cuidadoso equilíbrio. Como eles não são importantes para a competitividade, a empresa não receberá tanto retorno em troca de um valor adicional atribuído. Porém, devido a sua capacidade de ferir a empresa, eles não devem ser negligenciados (Harrison \& Bosse, 2013).

Por fim, estão os stakeholders com baixo poder e alta importância estratégica. Embora importantes para a competitividade da empresa e criação de valor, estes stakeholders estão propensos a ter valor sub alocado, pois eles não são tão salientes para os gestores devido à sua falta de poder (Harrison \& Bosse, 2013).

Segundo Harrison e Wicks (2013), a quantidade de utilidade que os stakeholders recebem influencia sua decisão de se relacionar com a empresa, assim como seu comportamento em relação a ela. Em função disso, os autores propõem um modelo composto por quatro fatores, que são definidos em termos da utilidade que os stakeholders percebem receber da empresa. Essa perspectiva é amparada na proposição de Barney (2011) de que a utilidade é influenciada pela percepção. Os quatro fatores incluem tanto aspectos tangíveis quanto intangíveis da distribuição de valor e estão intimamente associados com a motivação dos stakeholders para cooperar com a criação de valor das atividades da empresa. Os fatores são:

(1) Utilidade dos stakeholders associada a produtos e serviços reais: esta é considerada a fonte de utilidade mais óbvia e refere-se os bens físicos e serviços prestados pela empresa. Os bens físicos também incluem remuneração financeira em uma variedade de formas (Harrison \& Wicks, 2013).

(2) Utilidade dos stakeholders associada a justiça organizacional: a justiça distributiva, mais associado a fatores econômicos, é complementada por percepções de justiça processual e interacional. Por exemplo, com base na justiça distributiva uma empresa pode oferecer um salário e benefícios que satisfaçam, mas não excedam as expectativas dos funcionários. No entanto, os funcionários ainda podem receber utilidade da empresa em termos de como eles são tratados do ponto de vista de justiça processual e interacional. Lógica semelhante aplica-se a todos os stakeholders de uma empresa (Harrison \& Wicks, 2013). 
(3) Utilidade dos stakeholders associada a filiação: os stakeholders também recebem utilidade ao filiar-se a organizações que apresentam comportamentos consistentes com coisas que eles valorizam. Utilidade através da filiação pode também fornecer estima e satisfação. Por estima os autores referem-se ao sentimento de apoio prestado a uma organização cujo comportamento é visto como virtuoso ou desejável. Satisfação é conceituada como os sentimentos reais de felicidade. Neste caso, o sentimento de se relacionar com uma organização vai além do que eles podem sentir ao se relacionar com alguma outra empresa (Harrison \& Wicks, 2013).

(4) Utilidade dos stakeholders associadas a custos de oportunidade percebidos: como mencionado anteriormente, a utilidade é baseada na percepção (Barney, 2011), e a percepção é influenciada, em grande parte, pelo fato dos stakeholders acreditarem que estão fazendo um bom negócio com a organização em comparação ao que eles poderiam receber através de interações com outras empresas que servem a propósitos semelhantes (Harrison \& Wicks, 2013).

Segundo os autores, o modelo proposto e a noção mais ampla de utilidade de stakeholders, podem ser operacionalizados de diferentes maneiras. Contudo, é importante considerar cinco questões essenciais: 1) o reconhecimento de que o propósito de uma empresa e, assim, o seu desempenho, baseia-se na quantidade de valor que a empresa fornece aos seus stakeholders, 2) inclusão de ambos os fatores econômicos e não-econômicos que fornecem utilidade para os stakeholders, 3) inclusão de medidas para todos os stakeholders primários, 4) o reconhecimento de que diferentes atores tendem a valorizar coisas diferentes (ou seja, suas funções de utilidade são diferentes) e 5) as medidas devem ter a capacidade de reconhecer um nível de utilidade dos stakeholders que excede a mera satisfação com a empresa (Harrison \& Wicks, 2013).

Enquanto Harrison e Bosse (2013) avançaram na análise de quanto valor alocar aos stakeholders e Harrison e Wicks (2013) contribuíram com a identificação de fontes de utilidade para os stakeholders, Garcia-Castro e Aguilera (2015) propuseram uma taxonomia para análise do valor criado e apropriado (VCA) nas empresas que permite avaliar se a apropriação de valor por um stakeholder tem impacto positivo, negativo ou neutro sobre outros stakeholders. Os autores argumentam que a forma tradicional de análise de valor baseada na (1) disposição para pagar e (2) custos de oportunidade é difícil de ser estimada e como alternativa sugerem a análise do valor incremental. O pressuposto subjacente desse critério é de que o aumento do valor global criado entre dois períodos de tempo deve ser igual à soma dos aumentos no valor 
apropriado pelos vários stakeholders no mesmo período. Neste caso, a disposição a pagar e custos de oportunidade são assumidos como estáveis e as mudanças no valor criado e apropriado são decorrentes de variações de preços e custos. Conforme o sinal do valor total criado, pode-se encontrar três possibilidades: jogo de soma positiva, jogo de soma negativa e jogo de soma zero.

No jogo de soma positiva, há um aumento do valor total criado $(\Delta \mathrm{VT}>0)$ e todos os stakeholders podem aumentar simultaneamente a sua fração de valor capturado no período. Contudo, mesmo quando o valor total for positivo, não há garantias de que todos os stakeholders irão receber ganhos econômicos, uma vez que um stakeholder pode apropriar mais valor que outros. Em função disso, os autores introduziram o conceito de elasticidade do valor apropriado do stakeholder, que corresponde a relação entre o valor apropriado de um stakeholder e o valor total criado em um período de tempo. Em função da elasticidade do stakeholder pode-se encontrar três possibilidades: (os autores exemplificam suas ideias utilizando como exemplo os stakeholders funcionário - L e provedores de capital - K)

$\Delta \mathrm{VT} / \Delta \mathrm{VL}>1$ - indica que o VCA do stakeholder é elástica, ou seja, qualquer ganho adicional de L (funcionários) resulta em um aumento do valor apropriado por K (provedores de capital).

$\Delta \mathrm{VT} / \Delta \mathrm{VL}=1$ - indica que o stakeholder é neutro, e que qualquer ganho adicional de L tem um efeito neutro em $\mathrm{K}$.

$\Delta \mathrm{VT} / \Delta \mathrm{VL}<1$ - indica que o stakeholder é inelástico, onde qualquer ganho adicional de L resulta em uma redução do valor apropriado por K.

As variações na elasticidade dos stakeholders resultam em três possíveis cenários:

1) situação de ganha-ganha em que o aumento do valor total criado é distribuído entre L e K.

2) situação de efeito neutro em que um dos stakeholders é capaz de apropriar todo valor criado deixando outro stakeholder sem ganhar ou perder.

3) situação de ganha-perde em que um dos stakeholders apropria valor em excesso em detrimento de outro stakeholder. 
Nos jogos de soma negativa há redução de valor total criado $(\Delta \mathrm{VT}<0)$ e pelo menos um dos stakeholders perde algum valor. Assim como para os jogos de soma positiva, os autores vislumbram três cenários para esse jogo:

4) L e K perdem valor;

5) um dos stakeholders absorve as perdas de valor e outro não sofre efeitos positivos ou negativos

6) semelhante ao cenário 3, porém há uma propensão maior por disputas entre os stakeholders para apropriar valor.

Por fim, no jogo de soma zero $(\Delta \mathrm{VT}=0)$ qualquer ganho marginal de um stakeholder implica necessariamente na perda de valor de outro.

2.2.4 Análise dos estudos encontrados na literatura

Os estudos descritos nas seções anteriores apresentam algumas questões importantes com relação a distribuição de valor para os stakeholders. Primeiro, eles assumem que cada grupo de stakeholders tem uma função utilidade específica, composta por resultados tangíveis e intangíveis. Em segundo lugar, o valor distribuído pelas empresas para satisfazer a função utilidade dos seus stakeholders afeta o desempenho geral da empresa. Mesmo que esses estudos assumam que a distribuição de valor e o desempenho estão relacionados (Bosse et al., 2009, Harrison \& Bosse, 2013, Harrison \& Wicks, 2013, Tantalo \& Priem, 2016), esta distribuição de valor pode levar a diferentes resultados. Por um lado, a distribuição de valor pode apresentar uma relação positiva com o desempenho da empresa. Sob este ponto de vista, os autores argumentam que quando a empresa distribuiu valor para os seus stakeholders ela aumenta a disposição desses stakeholders de contribuir para os objetivos da empresa. Por outro lado, os autores também advertem que uma distribuição inadequada de valor, tais como uma super alocação, assim como uma distribuição injusta de valor pode sacrificar a rentabilidade da empresa e destruir valor (Bosse et al., 2009, Harrison \& Bosse, 2013, Tantalo \& Priem, 2016). 
Considerando estes aspectos, algumas questões ainda são pouco exploradas nessa literatura. Em primeiro lugar, uma vez que a função utilidade dos stakeholders inclui os resultados tangíveis e intangíveis, pouco se sabe sobre como esses dois tipos de resultados estão associados com o desempenho geral da empresa, ou seja, existe uma combinação ótima de resultados tangíveis e intangíveis que afetam o desempenho? Em segundo lugar, embora esses estudos considerem que diferentes grupos de stakeholders têm diferentes funções utilidade, eles não consideram que dentro do mesmo grupo também pode haver diferentes preferências para resultados tangíveis ou intangíveis. A exceção é Bridoux e Stoelhorst (2014) que discutem sobre diferentes abordagens para a gestão de stakeholders. Neste sentido, a teoria não recomenda se ambos os resultados, tangíveis e intangíveis, são igualmente importantes ou podem variar dependendo de características específicas, tais como o tipo de stakeholder envolvido no processo de criação de valor. Finalmente, uma vez que estes estudos são proposições teóricas, não se sabe como o atendimento da função utilidade dos stakeholders e o desempenho da empresa se comportam empiricamente.

Com base na proposição de Bridoux e Stoelhorst (2014), considera-se que o tipo de stakeholder, se auto-interessado ou recíproco, irá definir quão importante cada fator da função utilidade (tangível e intangível) é. Portanto, uma abordagem fairness com stakeholders recíprocos estaria mais associada com a distribuição de resultados intangíveis, enquanto a abordagem arms-length com stakeholders auto-interessados estaria mais associada a resultados tangíveis.

Uma vez que esta pesquisa tem como foco o stakeholders funcionário, na próxima seção serão apresentas questões relacionadas ao capital humano e a GERH, assim como as práticas utilizadas para motivar os funcionários e melhorar o desempenho da empresa. A teoria da GERH foi escolhida para tratar de questões relacionadas aos funcionários, pois relaciona as práticas de RH com o desempenho da empresa e não ao desempenho individual dos funcionários. Nesta pesquisa, as práticas de RH são entendidas como fontes de utilidade, as quais correspondem a condutores de valor para os funcionários. 


\subsection{Capital Humano}

O pensamento acadêmico sobre a importância do capital humano tem uma longa tradição, cuja origem pode ser associada a assertiva de Adam Smith (1963/1776) de que as habilidades adquiras e úteis dos indivíduos podem ser uma fonte de receitas e lucros (Ployhart \& Moliterno, 2011). Em 1964, Becker (1964) propõe o conceito de capital humano, o qual tem desempenhado um importante papel em modelos de desempenho individual e organizacional (Pil \& Leana, 2009). Capital humano pode ser conceituado como o conjunto de conhecimentos, habilidades, competências, e outras características (CHCOs) dos indivíduos que são capazes de gerar resultados econômicos (Coff, 1997, Lepak \& Snell, 2002, Ployhart, Nyberg, Reilly \& Maltarich, 2014).

Ployhart et al. (2014) argumenta que há diferenças entre o conceito de capital humano e recursos de capital humano, os quais normalmente são tratados como sinônimos pela literatura. Segundo os autores o capital humano é um subconjunto de CHCOs do indivíduo que são importantes para atingir resultados financeiros. O recurso de capital humano, por sua vez, é um subconjunto de CHCOs que são acessíveis para atingir os objetivos da unidade. Em outras palavras, para que a habilidade de uma pessoa seja ou não considerada um recurso, a unidade deve ser capaz de usar esta capacidade individual para o desenvolvimento de seus resultados (Ployhart et al., 2014).

Segundo Ployhart et al. (2014), os recursos de capital humano podem ser analisados em função de três elementos: a sua estrutura, sua função, e o nível em que eles existem. A estrutura referese ao que o capital humano é, e inclui as capacidades individuais do indivíduo que são decorrentes de suas CHCOs. Quanto à estrutura, os recursos de capital humano podem ser classificados em recursos de capital humano, os quais são capacidades baseadas em CHCOs acessíveis para o desempenho da unidade, ou recursos estratégicos de capital humano, os quais são capacidades baseadas em CHCOs acessíveis para a vantagem competitiva. A função referese ao que o recurso de capital humano faz para a empresa, ou seja, suas consequências. Quanto a função, o recurso de capital humano pode gerar uma paridade competitiva, ou, quando o recurso de capital humano for estratégico, ele proporcionaria uma vantagem competitiva à 
empresa. Por fim, o recurso de capital humano pode existir em nível individual ou de unidade. O modelo proposto pelos autores é apresentado na Ilustração 4.

\begin{tabular}{|c|c|c|}
\hline \multirow[b]{2}{*}{ Nível } & \multicolumn{2}{|c|}{ Função (Relevância para unidade) } \\
\hline & $\begin{array}{c}\text { Paridade Competitiva } \\
\text { "Busca de Melhores Práticas" }\end{array}$ & $\begin{array}{l}\text { Vantagem Competitiva } \\
\text { "Busca de Diferenciação" }\end{array}$ \\
\hline Unidade & $\begin{array}{l}\text { Recursos de Capital Humano } \\
\text { Capacidades de unidade com base nas } \\
\text { CHCOs da pessoa que são acessiveis para o } \\
\text { desempenho da unidade. } \\
\text { [Gestão Estratégica de Recursos, Grupos e } \\
\text { equipes, e.g., Crook, Todd, Combs, Woehr, } \\
\text { \& Ketchen, 2011; Ployhart, Van Iddekinge, } \\
\text { \& MacKenzie, 2011] }\end{array}$ & $\begin{array}{l}\text { Recursos de Capital Humano Estratégico } \\
\text { Capacidades de unidade com base nas } \\
\text { CHCOs da pessoa que são acessíveis para a } \\
\text { vantagem competitiva da unidade. } \\
\text { [Human Capital na Strategia/RBV, Equipes } \\
\text { de gestão do topo, e.g., Kor \& Leblebici, } \\
\text { 2005; Carpenter, Geletkanycz, \& Sanders, } \\
\text { 2004] }\end{array}$ \\
\hline Individual & $\begin{array}{l}\text { Recursos de Capital Humano } \\
\text { Capacidades individuais com base nas } \\
\text { CHCOs da pessoa que são acessíveis para o } \\
\text { desempenho da unidade. } \\
\text { [Seleção do pessoal, Treinamento, CEO, } \\
\text { e.g., Nyberg, Fulmer, Gerhart, \& Carpenter, } \\
\text { 2010] }\end{array}$ & $\begin{array}{l}\text { Recursos de Capital Humano Estratégico } \\
\text { Capacidades individuais com base nas } \\
\text { CHCOs da pessoa que são acessíveis para a } \\
\text { vantagem competitiva da unidade. } \\
\text { [Estrelas/ Parceiros de Serviços Profissionais, } \\
\text { e.g., Hitt, Biermant, Shimizu, \& Kochhar, } \\
\text { 2001] }\end{array}$ \\
\hline
\end{tabular}

Nota: Cada célula apresenta o rótulo (em negrito), definição (em itálico), e exemplos pesquisas de recursos de capital humanos (em parênteses). O elemento "nível" de cada definição é identificada pelos termos unidade ou individual. Elemento estrutural de cada definição é definido por "capacidades com base nas CHCOs individuais que são acessíveis". O elemento função é definido por qualquer "vantagem competitiva relevante em termos de unidade" ou "desempenho relevante em termos de unidade." CHCOs = conhecimentos, habilidades, competências e outras características.

Ilustração 4 - Framework multinível da estrutura e função do Recurso de Capital Humano Fonte: Ployhart et al. (2014, p. 381)

Wright, Coff e Moliterno (2014) também propõem dimensões para a conceitualização e categorização do capital humano. Para tanto, os autores utilizam duas dimensões: o nível de análise e a estabilidade/maleabilidade das características dos indivíduos, conforme apresentado na Ilustração 5. A primeira dimensão inclui três níveis de análise em que o capital humano pode ser considerado. O nível intra-individual corresponde às características inerentes aos indivíduos. O nível individual refere-se à como essas características podem ser um capital para a empresa. Por fim, no nível de unidade o capital humano refere-se à agregação dos indivíduos com a empresa. A segunda dimensão do modelo, estabilidade/maleabilidade, inclui características que têm sido estudadas sob a ótica do capital humano estratégico. $\mathrm{Na}$ extremidade superior esquerda estão as características humanas que são mais estáveis e difíceis de mudar, tais como inteligência, personalidade e atributos físicos. No centro estão as 
características que são mutáveis, mas relativamente estáveis após adquiridas, como habilidades e conhecimentos. Por fim, na extremidade direita, encontram-se as características mais maleáveis e mais fáceis de serem mudadas, como a emoção ou o comportamento.

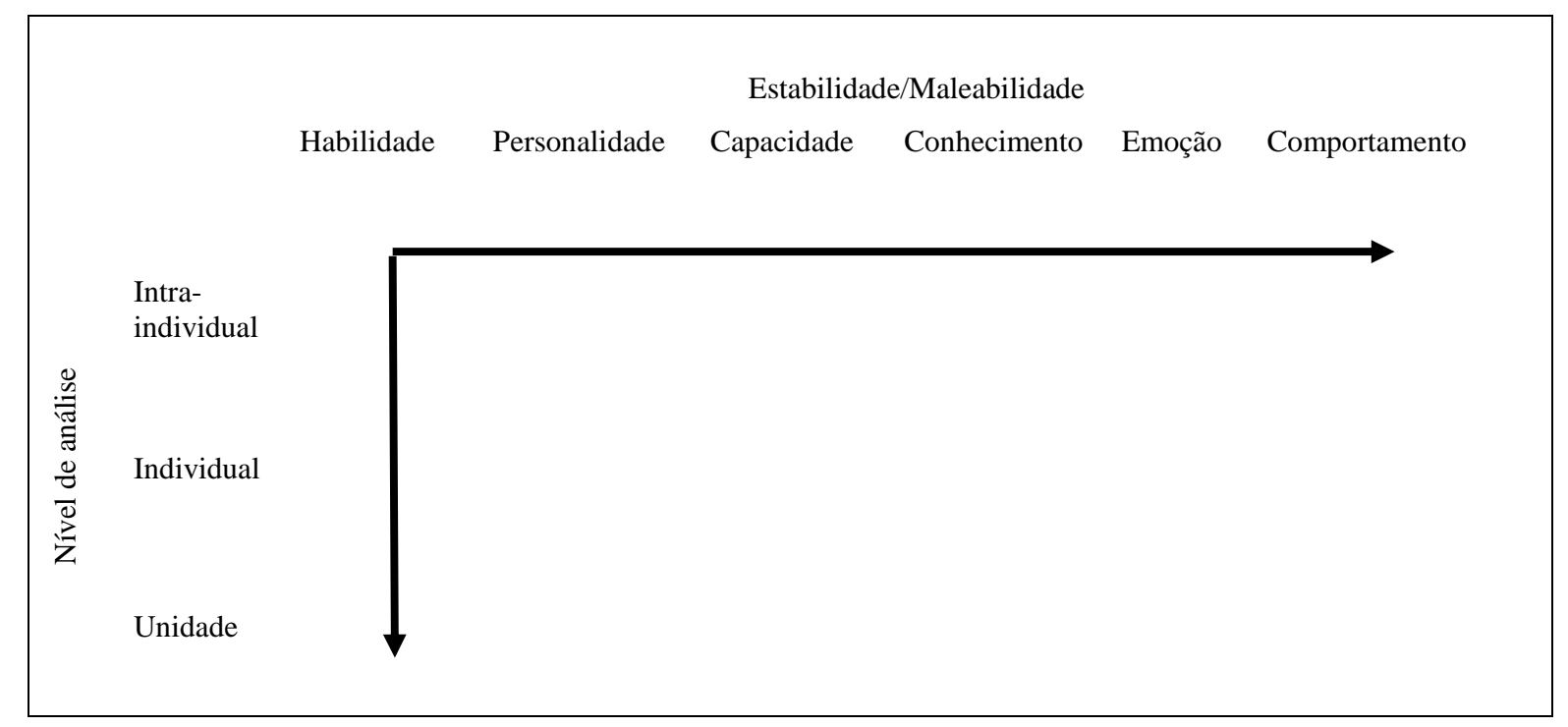

Ilustração 5 - Dimensões das características do capital humano Wright et al. (2014, p. 358)

Algumas características do indivíduo como conhecimento, educação, experiência e habilidades, são normalmente consideradas componentes fundamentais do capital humano. No entanto, Wright et al. (2014) fazem uma ressalva de que existem outras características individuais, como traços motivacionais, que despertam dúvidas se podem ou não ser consideradas capital humano.

Da mesma forma, Ployhart et al. (2014) argumentam que os seres humanos possuem diferentes capacidades individuais que incluem aspectos cognitivos, não cognitivos, características de personalidade, genéticas e físicas. Essas capacidades podem ser mais estáveis, como a capacidade e a personalidade, e mais maleáveis, como motivações e atitudes. No entanto, os autores são mais enfáticos ao argumentar nem todas as características podem ser consideradas CHCOs. Atitude, satisfação, motivação, emoção e características relacionadas, por exemplo, não são consideradas CHCOs por Ployhart et al., (2014), pois são induzidas situacionalmente e por isso são altamente variáveis.

Se, por um lado, na literatura da área não há um consenso sobre essas características, nas empresas essas características parecem já serem consideradas como parte do capital humano. 
Por exemplo, a IBM considera o envolvimento dos funcionários como parte de sua "prática de capital humano" (Wright et al., 2014).

Para esta pesquisa, assume-se que a motivação é uma característica de recursos de capital humano, uma vez que pesquisas na área da psicologia têm considerado que as motivações dos indivíduos para cooperar são características estáveis da personalidade e contribuem para a criação de valor das empresas (Bridoux, Coeurderoy \& Durand, 2011).

\subsection{Gestão Estratégica de Recursos Humanos}

Cada vez mais, estudiosos da estratégia tem empregado esforços para entender o papel do capital humano na criação de vantagem competitiva sustentável para as empresas (Bidwell, e Barbulescu \& Mollick, 2015; Coff, 1997). As pesquisas na área GERH têm buscado explicar como e porque o conjunto de práticas de RH contribui para o alcance dos objetivos da empresa (Jiang, Lepak, Hu \& Baer, 2012; Delery \& Doty, 1996; Huselid, Jackson \& Schuler, 1997). Ao contrário das pesquisas tradicionais em gestão de recursos humanos, baseadas no uso de práticas de RH de forma independente ou isolada, a perspectiva estratégica adota uma abordagem mais ampla, pois considera feixes de práticas de RH que são implementadas em combinação (Lepak \& Snell, 2002; Jiang et al., 2012).

Neste sentido, a GERH difere dos estudos de gestão de RH tradicional de duas maneiras importantes (Becker \& Huselid, 2006). Em primeiro lugar, essa abordagem tem como foco o desempenho organizacional ao invés do desempenho individual. Em segundo lugar, a GERH enfatiza o papel dos sistemas de gestão de RH ao invés de práticas de gestão de RH individuais como soluções para problemas empresariais (Becker \& Huselid, 2006). Além disso, a GERH está voltada para o gerenciamento da força de trabalho como um todo e não em cargos individuais e nos funcionários que os ocupam (Lepak \& Snell, 2002).

Os sistemas de práticas de RH podem receber diferentes nomenclaturas, tais como "sistema de trabalho de alta desempenho", "práticas de gestão de alta performance", "sistemas de trabalho de alto compromisso", "sistemas de trabalho de alto envolvimento" e "gestão de recursos 
humanos de alto desempenho" (Evans \& Davis, 2005, Gittell, Seidner \& Wimbush, 2010, Jiang et al., 2012). Apesar destas diferentes nomenclaturas, os estudos que utilizam esses conceitos têm como traço comum a premissa de que as organizações podem alcançar um alto desempenho adotando práticas que reconhecem e alavancam a capacidade dos trabalhadores para criar valor (Gittell et al., 2010).

Wright et al. (2001) argumentam que é por meio desses sistemas que a empresa gera vantagem no longo prazo, pois influencia seu capital humano e provoca o comportamento do empregado desejado (Wright et al., 2001, p. 705). Becker e Huselid (2006) reforçam a importância desses sistemas ao considerá-los como o recurso estratégico mais importante. Segundo esses autores os sistemas de RH são fonte de criação de valor e têm o potencial para uma maior inimitabilidade com base em como eles estão alinhados com a estratégia da empresa.

\subsection{Práticas de RH e Desempenho Organizacional}

As pesquisas no campo de GERH que buscam entender a relação entre a gestão de RH e o desempenho organizacional tem se desenvolvido sob diferentes perspectivas. Juntas, essas perspectivas ajudam na compreensão de como as práticas de gestão de RH influenciam os atributos dos funcionários e, consequentemente, podem levar a resultados desejados pela empresa, tais como a produtividade, desempenho financeiro e vantagem competitiva (Bowen \& Ostroff, 2004).

Essas pesquisas podem ser agrupadas em quatro abordagens, sendo elas: 1) abordagem universal/ melhores práticas, 2) abordagem estratégica (Youndt, Snell, Dean \& Lepak, 1996, Bowen \& Ostroff, 2004, Becker \& Huselid, 2006; Huselid, 1995; Huselid \& Becker, 2011), 3) abordagem comportamental e 4) abordagem baseada em recursos (Gittell et al., 2010, Jiang et al., 2012). Ressalta-se que essas abordagens são complementares e não excludentes, pois, por exemplo, um estudo pode analisar as práticas que influenciam o comportamento dos funcionários sob uma perspectiva universal e comportamental ao mesmo tempo. Nas próximas 
seções são apresentados estudos que explicam e testam empiricamente a relação entre diferentes práticas de RH com o desempenho organizacional.

\subsubsection{Práticas de RH: Abordagem Universal e Estratégica}

Os pesquisadores que adotam a abordagem universal defendem a existência de práticas de gestão de pessoas que são melhores que outras para criar valor para as empresas que as adotarem (Becker \& Huselid, 2006; Huselid, 1995). Ou seja, determinadas práticas de RH são melhores para todas as condições (Delery \& Doty, 1996). Pfeffer (1995), por exemplo, argumenta que uma maior utilização de 16 práticas de gestão resulta em maior produtividade e lucro para as empresas. Segundo o autor essas práticas incluem a participação e empoderamento, pagamento de incentivos, segurança no emprego, promoção interna, formação e desenvolvimento de competências (Pfeffer, 1995).

A perspectiva estratégica defende a ideia de que as práticas de gestão de pessoas devem estar alinhadas à estratégia das empresas (Delery \& Doty, 1996, Bowen \& Ostroff, 2004). Sob essa perspectiva, a eficácia de determinado conjunto de práticas deve ser avaliada considerando o contexto estratégico e ambiental específico de uma empresa (Huselid, 1995). Neste caso, as práticas de RH servem para desenvolver competências, conhecimento e motivação dos trabalhadores para que estes se comportem de maneira apropriada para a implementação de uma estratégia particular (Bowen \& Ostroff, 2004).

Os estudos da perspectiva estratégica podem, ainda, adotar uma abordagem contingencial ou configuracional. Na primeira abordagem, a premissa é de que as práticas de $\mathrm{RH}$ variam de acordo com a estratégia adotada pela empresa (Becker \& Huselid, 2006) e dependem de características contextuais como indústria, tamanho da empresa etc. (Bowen \& Ostroff, 2004). No segundo caso, assume-se que existem tipos de arquitetura de RH mais apropriados (Becker \& Huselid, 2006). Os estudos que adotam essa linha tentam identificar as configurações de práticas de RH que predizem um desempenho superior quando são utilizadas em associação umas com as outras, com a estratégia correta, ou ambas (Delery \& Doty, 1996). Essa abordagem 
adota a suposição de equifinalidade, em que múltiplos sistemas de RH são igualmente efetivos para o mesmo conjunto de condições (Delery \& Doty, 1996). Alguns estudos buscaram testar empiricamente essas abordagens tais como Arthur (1994), Youndt et al., (1996), Delery e Doty (1996) e Huselid et al. (1997).

Arthur (1994) analisou a relação entre dois tipos de sistemas de RH (sistema de controle e compromisso) e medidas de desempenho organizacional (desempenho de produção e rotatividade). Os sistemas de controle estão mais relacionados com estratégias de baixo custo, baseiam-se em regras específicas e recompensam os funcionários com base em algum critério de desempenho mensurável. Por outro lado, os sistemas de compromisso relacionam-se com estratégias de diferenciação e influenciam o comportamento e atitudes dos funcionários por meio de conexões psicológicas entre os objetivos organizacionais e os objetivos do funcionário. Segundo Arthur (1994), empresas com sistemas de RH baseado em compromisso apresentariam maior desempenho e menor rotatividade do que empresas com sistemas de $\mathrm{RH}$ focado no controle. Os sistemas de RH foram analisados em função de dez dimensões: descentralização, participação, treinamento geral, supervisor, competências, social, processo, salários, benefícios e bônus. Os resultados do estudo suportaram as hipóteses do autor demonstrando que sistemas de compromisso estavam associados com menores níveis de rotatividade e maiores níveis de produtividade.

Huselid (1995) investigou a relação entre sistemas de RH e o desempenho organizacional, assim como a premissa de que o juste, tanto interno (entre as práticas de $\mathrm{RH}$ ) quanto externo (entre as práticas de RH e a estratégia) levariam a um maior desempenho. Os autores utilizaram 13 práticas de RH para testar suas hipóteses. Por meio de análise fatorial, essas práticas foram classificadas em dois fatores, o primeiro denominado "competências dos funcionários e estrutura organizacional" e o segundo de "motivação dos funcionários". No primeiro fator ficaram concentradas as práticas destinadas a melhorar as CHCOs dos funcionários, que incluem: compartilhamento de informações, design de trabalho, procedimentos de reclamações, avaliação de atitude, programas com a participação dos funcionários, plano de incentivos, número médio de horas de treinamento por funcionário por ano, testes para seleção de pessoal. No segundo fator estão as práticas cujo objetivo é reconhecer e reforçar os comportamentos desejados pela empresa, entre elas estão: avaliação de desempenho formal, remuneração baseada em avaliação de desempenho, critérios de promoção (tempo de trabalho x mérito), intensidade de esforços de recrutamento. O desempenho organizacional foi mensurado pela 
rotatividade dos funcionários, produtividade e desempenho financeiro. Por fim, para a análise do ajuste externo as estratégias competitivas foram classificadas em estratégia de diferenciação e foco. Os resultados da pesquisa ofereceram suporte para a relação entre práticas de $\mathrm{RH}$ e as três medidas de desempenho, ou seja, as práticas de RH tiveram relação significativa com menor rotatividade de funcionários, maior produtividade e maior desempenho financeiro das empresas. No entanto, foram encontradas poucas evidências para a relação entre ajuste interno e externo e desempenho. Os autores argumentam que esse resultado pode indicar que apenas a adoção desses tipos de práticas de RH pode levar por si a um bom desempenho financeiro.

Youndt et al. (1996) investigaram empiricamente a relação entre as perspectivas de RH universal e estratégica e sua relação com o desempenho. Os autores analisaram em que medida os sistemas de RH melhoravam diretamente o desempenho, os efeitos moderadores da estratégia de produção na relação entre RH e desempenho operacional, e avaliaram em que medida as estratégias de produção e sistemas de RH são realmente utilizados em conjunto uns com os outros. Para análise da perspectiva estratégica os autores consideraram três estratégias de produção: custo, qualidade e flexibilidade. Quanto a gestão de recursos humanos os autores utilizaram quatro áreas: seleção, treinamento, avaliação de desempenho e remuneração. As práticas de seleção incluíram: (1) seletividade na contratação, (2) seleção de habilidades manuais e físicas, (3) seleção de habilidades técnicas, e (4) seleção para capacidade de resolver problemas. Práticas de treinamento incluíram: (1) abrangência, (2) políticas e formação processual, (3) treinamento para habilidades técnicas, e (4) formação de habilidades para resolver problemas. Para as práticas de avaliação de desempenho foram utilizadas três diferentes escalas: (1) foco no desenvolvimento, (2) avaliação baseada no desempenho, e (3) avaliação baseada em comportamento. Por fim, para sistemas de remuneração, os autores utilizaram: (1) pagamento por hora, (2) salário, (3) pagamento baseado em competências, (4) incentivos individuais, (5) incentivos de grupo, (6) título de capital individual, e (7) equidade externa. Os resultados do estudo forneceram mais apoio para a perspectiva estratégica ao mostrar que os principais efeitos do sistema de HR no desempenho foram decorrentes da combinação entre os sistemas de RH e estratégias de produção de qualidade.

Delery e Doty (1996) testaram três abordagens de práticas de RH (universal, contingencial e configuracional) e a sua relação com o desempenho da empresa, medido por ROA e ROE. Para testar as hipóteses do estudo quanto às três perspectivas, os autores utilizaram sete práticas consideradas na literatura como práticas estratégicas de RH. As práticas foram utilizadas de 
forma individual e combinada, e incluíram: (1) oportunidades internas de carreira, (2) treinamento, (3) avaliação orientada para resultados, (4) participação nos lucros, (5) segurança no emprego, (6) mecanismos de participação e (7) descrição de tarefas. Para a dimensão universalista, Delery e Doty (1996) analisaram a relação entre cada uma das práticas de RH com o desempenho. Para a análise da abordagem contingencial os autores utilizaram a inovação como variável de contingência. Por fim, para a análise da perspectiva configuracional, foram utilizadas as estratégias de defesa e de prospecção combinadas a dois sistemas de gestão de RH, o sistema interno e o sistema de mercado. Os resultados do estudo ofereceram um forte suporte à perspectiva universal e algum suporte para as perspectivas de contingência e configuracional. As práticas individuais de participação nos lucros, avaliações orientadas para os resultados, e segurança do emprego, apresentaram fortes relações universalistas com as medidas contábeis de desempenho (ROA e ROE). Relações de contingência entre a estratégia e três práticas de HR (participação do empregado, avaliação orientada para resultados e oportunidades internas de carreira) explicou uma parcela significativa da variação nas mesmas medidas de desempenho. Por fim, semelhanças com o sistema de RH de mercado também apresentou relação positiva com o desempenho da empresa (Delery \& Doty, 1996).

Huselid et al. (1997) também analisaram a influência de práticas de RH no desempenho da empresa. Os autores analisaram o impacto de dois conjuntos distintos de práticas: as práticas de RH técnicas e as estratégicas. As práticas técnicas correspondem a um conjunto de práticas normalmente empregadas por todas das empresas e tem como objetivo atender a normas de conformidade, muitas vezes reguladas pelo governo. Entre essas práticas estão: benefícios e serviços, remuneração, recrutamento e treinamento, segurança e saúde, educação e treinamento de funcionários, estratégias de aposentadoria, relações laborais, programas de responsabilidade social, programas para as mulheres, minorias, etc., gestão de custos do trabalho, testes de seleção, avaliação de desempenho, sistemas de informação de RH e avaliação das atitudes dos funcionários. Por outro lado, as práticas estratégicas incluem inovações no sistema de gestão de RH, com poucas diretrizes regulamentadas e são utilizadas por um número menor de empresas. Essas práticas normalmente estão associadas aos objetivos da empresa e incluem: trabalho em equipe, participação dos trabalhadores e empoderamento, planejamento da força de trabalho (flexibilidade e implantação), produtividade da força de trabalho e qualidade dos resultados, gestão e desenvolvimento de executivos, planejamento de sucessão e desenvolvimento para os gestores, estudos estratégicos, comunicação entre trabalhadores e gestores, e programas de trabalho/família. As medidas de desempenho utilizadas foram a 
produtividade dos funcionários, taxa bruta de retorno sobre ativos e Q de Tobin. Os resultados do estudo mostraram uma relação positiva e significante entre as práticas estratégicas e o desempenho da empresa. No entanto, as práticas técnicas não se apresentaram significativamente associada ao desempenho.

Collins e Clark (2003) examinaram as relações entre as práticas de RH e desempenho da empresa, considerando as redes internas e externas de equipes de gestão de topo (EGT) como um mediador dessa relação. Os autores utilizaram dois conjuntos de práticas para testas suas hipóteses: pagamentos de incentivos e práticas de $\mathrm{RH}$ para construção de redes. O primeiro conjunto considerou o pagamento de bônus, opções de ações e o nível em que as recompensas estavam diretamente associadas ao desempenho da empresa. $\mathrm{O}$ segundo conjunto incluiu aspectos relacionados a treinamento, avaliação de desempenho e recompensas que incentivassem os gestores de topo a construir relacionamentos com atores internos e externos. O desempenho da empresa foi mensurado em termos de vendas e desempenho de ações. Os resultados ofereceram suporte a ideia de que as práticas de RH têm impacto no desempenho da empresa por meio das redes de EGT. No entanto, as práticas de RH voltadas a construção de redes apresentaram um efeito maior tanto na construção de relacionamentos quanto no desempenho da empresa (em ambas as medidas) do que as práticas de pagamentos de incentivos. Esse resultado sugere que empresas podem usar conjuntos específicos de práticas de RH para desenvolver um recurso específico baseado no funcionário ou competência.

Em relação a esses estudos é possível se fazer três considerações. Primeiro, observa-se que os resultados dessas pesquisas são inconclusivos quanto à relação entre os tipos de práticas e o desempenho. Ou seja, não há um consenso se existe um conjunto de práticas que são melhores que as outras para todas as empresas ou se um conjunto apresenta melhores resultados quando alinhado com a estratégia da empresa. Em segundo lugar, os estudos que empregaram uma abordagem estratégica, normalmente tem analisado o alinhamento das práticas com estratégias operacionais ou competitivas. Em função disso, pouco se sabe sobre a relação entre o uso de práticas de RH alinhadas a estratégias globais da empresa, como estratégias de stakeholders. 
2.5.2 Práticas de RH: Abordagem Comportamental e Baseada em Recursos

Os estudos que utilizam a perspectiva comportamental, a qual normalmente baseia-se na motivação e comprometimento, argumentam que o desempenho será melhor à medida que as empresas influenciam seus funcionários à agirem de maneira consistente com os objetivos organizacionais (Gittell et al., 2010; Jiang et al., 2012). A perspectiva baseada em recursos argumenta que as empresas podem alcançar um desempenho superior por meio das CHCOs de seus funcionários (Jiang et al., 2012). Nesta pesquisa será enfatizada a perspectiva comportamental, pois entende-se que o valor distribuído pela empresa para o atendimento da função utilidade dos funcionários tem um impacto maior na motivação e comportamento do funcionário do que no desenvolvimento de suas CHCOs.

Bowen e Ostroff (2004) propõem um framework para entender como os sistemas de práticas de RH influenciam o desempenho. Os autores consideram as práticas de RH um importante mecanismo para motivar os funcionários a adotar atitudes e comportamentos apropriados, e o clima organizacional serve como um moderador da relação entre as práticas e o desempenho. Os autores baseiam sua explicação no conceito de situações fortes, conforme proposto por Mischel \& Peake (1982), em que as situações fortes apresentam um alto grau de conformidade ou baixa ambiguidade. Neste sentido, para que as práticas de RH sejam efetivas, elas devem gerar um clima organizacional forte capaz de promover interpretações comuns do que é um comportamento apropriado e esperado. Um clima forte é construído a partir de práticas de RH caracterizadas pelo caráter distintivo, consistência e consenso. Essas práticas comunicam claramente quais são as metas estratégicas mais importantes e quais comportamentos são esperados, apoiados e recompensados em relação a essas metas. Bowen e Ostroff (2004) discutem o sistema de gestão de RH tanto em termos de conteúdo (por exemplo, o conjunto específico de práticas de RH necessário para alcançar um objetivo organizacional), quanto em termos de processo (as características do sistema na gestão de recursos humanos que enviam sinais para os empregados que lhes permitam compreender o comportamento desejado e respostas adequadas a fim de formar um senso coletivo do que se espera).

Amparados pela proposição de Bowen e Ostroff (2004) de que sistemas de práticas de RH podem gerar uma situação forte, que comunica claramente qual é o comportamento desejado, 
DeVaro (2006) analisou o uso de competição por promoção como um mecanismo de incentivo capaz de gerar uma situação forte que motiva os funcionários a adotar comportamentos apropriados e alinhados com a estratégia da empresa. Segundo o autor, as competições por promoção podem contribuir para criar situações fortes uma vez que são mais visíveis do que apenas o aumento da compensação e, por isso, seus efeitos perdurariam por mais tempo. Além disso, a perspectiva de receber uma promoção motivaria os funcionários a aumentar seu desempenho em seus cargos atuais. Contudo, os resultados do estudo oferecem um fraco suporte ao modelo de competição. Neste caso, a amplitude da remuneração estava mais associada ao desempenho do funcionário do que os níveis da remuneração.

Gittell et al. (2010) consideram os relacionamentos entre empregados como um mecanismo para explicar a relação entre sistemas de RH e o desempenho organizacional. Os autores testam empiricamente a hipótese de que a coordenação relacional entre os funcionários é um mediador na relação entre os sistemas de RH e desempenho. Para a análise, os autores consideraram 6 práticas de RH: seleção, resolução de conflitos, avaliação de desempenho, recompensas multifuncionais, reuniões de equipe e boundary spanners. Para a dimensão coordenação relacional os autores empregaram sete perguntas relacionadas a: grau em que as relações são caracterizadas por objetivos comuns, conhecimentos partilhados e respeito mútuo, frequência, pontualidade e precisão da comunicação, e a natureza da comunicação de resolução de problemas. Os resultados do estudo corroboraram a proposição dos autores de que a perspectiva de coordenação relacional contribui para comportamentos sinérgicos, os quais contribuem para atingir os objetivos da empresa.

Por meio de uma meta análise, Jiang et al. (2012) investigaram os efeitos de três dimensões dos sistemas de RH em dois tipos de resultados organizacionais. As dimensões competênciasmotivação-oportunidade foram analisadas por meio de 14 práticas frequentemente utilizadas em pesquisas da área. A dimensão de reforço de competências considera as práticas de recrutamento, seleção e treinamento. A dimensão motivação inclui as práticas de avaliação de desempenho, remuneração, incentivos, benefícios, promoção e desenvolvimento de carreira, e segurança no trabalho. Por fim, a dimensão oportunidade inclui projeto de trabalho, equipes de trabalho, o envolvimento dos trabalhadores, os processos formais de reclamação, e compartilhamento de informações. Os resultados organizacionais foram classificados em resultados organizacionais proximais, tais como capital humano e motivação, e resultados distais que incluem turnover voluntário, resultados operacionais e financeiros da empresa. Além 
da análise da relação direta entre as dimensões de práticas de RH e resultados organizacionais, os autores também investigaram os mecanismos de mediação presentes nessa relação. Como resultado os autores evidenciam que: 1) gestão de $\mathrm{RH}$ relaciona-se primeiro com os resultados proximais, e depois com os resultados distais; 2) as relações entre gestão de RH e os resultados distais pode ser mediada através de múltiplos caminhos, como por meio do capital humano e da motivação dos funcionários; 3) as três dimensões de RH podem apresentar relações exclusivas com resultados organizacionais específicos. Por exemplo, para a melhoria do capital humano as práticas de RH de reforço de competências foram mais eficazes. Por outro lado, as práticas de RH que aumentam a motivação e práticas de RH de aumento de oportunidade foram mais propensas a melhorar a motivação dos funcionários. Além disso, os resultados apresentaram uma relação direta entre as dimensões competências e motivação e os resultados financeiros.

DeGeest, Follmer, Walter e O’Boyle (2015) analisaram o impacto das práticas de RH na sobrevivência da empresa no contexto de novos empreendimentos. Os autores destacam que existem práticas que são indispensáveis e outras que são opcionais. As práticas opcionais normalmente têm como objetivo motivar ou atrair funcionários. Os autores analisaram a relação entre um conjunto de quatro práticas para aumentar a motivação dos funcionários (programas de bônus, opções de ações, plano de saúde e horário flexível) e a relação com a sobrevivência de novas empresas. Os resultados do estudo indicaram uma associação positiva e significante entre o conjunto de práticas de motivação e a sobrevivência da empresa. Além disso, os autores encontraram suporte para a hipótese de que o ciclo de vida da empresa modera essa relação, em que, para as empresas em fase de viabilidade as práticas de RH apresentaram relação negativa com a sobrevivência e para as empresas em fase de crescimento a associação foi positiva.

Gambardella, Panico e Valentini (2015) analisaram empiricamente a combinação de atribuição de direitos de decisão e de compensação monetária, com os quais a empresa pode gerenciar e motivar os trabalhadores do conhecimento. Os autores argumentam que as empresas podem conseguir melhores resultados para atrair, reter e incentivar os esforços dos trabalhadores do conhecimento ao usar dois instrumentos (salários e autonomia) ao invés de apenas um (salário). Gambardella et al. (2015) identificaram que em projetos diretamente relacionados com o core business da empresa, os funcionários sentem-se felizes e os benefícios pessoais são suficientes para compensar o trabalhador. Neste caso a empresa não precisa liberar total autonomia para eles, nem oferecer-lhes um salário alto. Por outro lado, quando os projetos estão mais distantes 
do core business da empresa eles oferecem menos valor para o funcionário, em função disso as empresas podem motivá-los delegando maior autonomia. Os autores destacam, ainda, que delegar autonomia para os funcionários pode fazer o papel de um substituto para a compensação monetária e como resultado reduzir os custos da empresa (Gambardella et al., 2015).

Observa-se que há uma convergência entre as práticas analisadas pela maioria desses estudos. É possível agrupar as práticas de RH em três dimensões: competências, motivação e oportunidade, conforme proposto por Jiang et al. (2012). A dimensão competências normalmente inclui as práticas de recrutamento e seleção. Na dimensão motivação estão as práticas relacionadas à avaliação de desempenho e programas de recompensas. A dimensão oportunidade inclui as práticas relacionadas a participação de funcionários e compartilhamento de informações.

2.5.3 Práticas de RH indutoras de valor para os funcionários

Tendo em vista que o objetivo desta pesquisa visa analisar a relação entre a distribuição de valor para o funcionário e o desempenho organizacional, as práticas de RH são entendidas como fontes de utilidade e foram agrupadas em duas dimensões: práticas indutoras de valor tangível e práticas indutoras de valor intangível, conforme apresentado na Ilustração 6. Essa classificação está alinhada as proposições de Tantalo e Priem (2016) que exemplificam como condutores de valor tangível salário, benefícios, responsabilidade social corporativa e políticas de qualidade da vida e como condutores de valor intangível percepção de justiça do ambiente de trabalho, características do trabalho e variedade de habilidades. 


\section{Práticas indutoras de valor tangível}

Benefícios

Participação nos lucros

Plano de saúde

Programas de bônus

Programas de responsabilidade social

Promoção

Remuneração baseada em avaliação de desempenho

Remuneração

\section{Autores}

Arthur (1992), Huselid et al. (1997), Jiang et al. (2012)

Delery e Doty (1996)

DeGeest et al. (2015)

Arthur (1992), DeGeest et al. (2015)

Huselid et al. (1997)

Jiang et al. (2012)

Huselid (1995), Gittell et al. (2010)

Arthur (1992), Youndt et al., (1996), Huselid et al. (1997), Jiang et al. (2012), Gambardella et al. (2015)

\section{Práticas indutoras de valor intangível}

Atribuição de direitos de decisão

Compartilhamento de informações

Design de trabalho

Horário flexível

Processos formais de reclamação e de queixa

Programas para minorias

Programas para mulheres

Programas para resolução de conflitos

Programas de participação

\section{Autores}

Gambardella et al. (2015)

Huselid (1995), Jiang et al. (2012)

Huselid (1995)

DeGeest et al. (2015)

Huselid (1995), Jiang et al. (2012)

Huselid et al. (1997)

Huselid et al. (1997)

Gittell et al. (2010)

Arthur (1992), Huselid (1995), Delery e Doty (1996), Huselid et al. (1997)

Destaca-se que, em geral, os estudos que testaram empiricamente estas práticas de $\mathrm{RH}$ encontraram relações positivas e significantes com o desempenho organizacional. Esses resultados se aplicam tanto às práticas classificadas nesta pesquisa como indutoras de valor tangível quanto às práticas de valor intangível. No entanto, embora os estudos abordem algumas questões que podem ser classificadas como indutoras de valor intangível, questões de justiça organizacional e equidade são pouco analisadas por essas pesquisas. A exceção foi o trabalho de Huselid et al. (1997) que considerou práticas voltadas ao tratamento de mulheres e minorias. 
Esta pesquisa está alinhada à perspectiva comportamental, pois se entende que as práticas de RH adotadas pela empresa são capazes de motivar os funcionários a adotar comportamentos consistentes com os objetivos organizacionais (Gittell et al., 2010; Jiang et al., 2012) e influenciará na sua disposição para contribuir com a criação de valor da empresa. Tendo em vista que os funcionários podem variar quanto a sua motivação para cooperar, na próxima seção serão apresentadas diferentes visões sobre motivação.

\subsection{Motivação}

Mesmo indivíduos altamente qualificados podem apresentar baixa eficácia quando não devidamente motivados (Huselid, 1995). Para motivar os funcionários, as empresas utilizam diferentes práticas de $\mathrm{RH}$, as quais também servem para alinhar os interesses dos funcionários com os interesses de outros stakeholders da empresa, como o acionista (Huselid, 1995). A motivação dos funcionários é um desafio devido a um conjunto de características que são heterogêneas entre os indivíduos (Chadwick \& Dabu, 2009). Essas características influenciam a forma como os indivíduos interpretam as práticas de $\mathrm{RH}$, uma vez que, mesmo quando submetidos a práticas de RH equivalentes, eles podem apresentar diferentes comportamentos (Chadwick \& Dabu, 2009).

Fehr e Fischbacher (2002) e Camerer e Fehr (2006) defendem a importância de se considerar as preferências sociais dos indivíduos. Segundo esses autores, a maioria das análises econômicas são construídas sob duas suposições simplificadas da natureza humana: as pessoas tomam decisões racionais e suas preferências são baseadas apenas no auto-interesse. Contudo, um grande número de evidências tem questionado essas suposições e mostrado que as pessoas apresentam crenças não racionais e seu comportamento é motivado por vários detalhes contextuais que são objetivamente irrelevantes (Camerer \& Fehr, 2006). As pessoas nem sempre escolhem o que parece ser racionalmente melhor para seu interesse próprio e preferem ser tratados de forma justa (Camerer $\&$ Fehr, 2006). 
Estudos na área da psicologia social e economia comportamental têm contribuído para a discussão sobre a heterogeneidade de motivos dos indivíduos para cooperar (Bridoux et al., 2011). Segundo essas teorias, os indivíduos são fundamentalmente diferentes quanto à sua orientação social de valor, podendo ser classificados em dois grupos: auto-interessados e recíprocos (Bridoux et al., 2011; Fehr \& Fischbacher, 2002).

As suposições subjacentes ao conceito de indivíduos auto-interessados baseiam-se nos pressupostos do homo economicus, que define os indivíduos como maximizadores de utilidade, com comportamentos egoístas e socialmente distantes (Sauer \& Valet, 2013). Indivíduos autointeressados caracterizam-se pela busca de interesses individuais ou pessoais (Folger \& Salvador, 2008) e, desde que seu bem-estar econômico não seja afetado, não se importam com os resultados e comportamentos de outros indivíduos (Camerer \& Fehr, 2006). Os indivíduos auto-interessados são motivados por recompensas monetárias pessoais, onde seu comportamento cooperativo é decorrente de sua percepção do equilíbrio entre seus custos e benefícios pessoais de cooperar (Bridoux et al., 2011).

Por outro lado, as suposições subjacentes ao conceito de indivíduos recíprocos são aderentes aos pressupostos do homo socio-economicus, que considera os indivíduos não apenas maximizadores de utilidade de forma egoísta, mas que também são afetados por outras pessoas e seus comportamentos (Sauer \& Valet, 2013). Indivíduos recíprocos caracterizam-se por apresentar preferências sociais (Fehr \& Fischbacher, 2002) e agir de acordo com normas de reciprocidade (Halali, Bereby-Meyer \& Meiran, 2014). Esses indivíduos preocupam-se com os recursos materiais alocados a outros agentes (Fehr \& Fischbacher, 2002) e não são motivados apenas por benefícios pessoais, mas também pela equidade da distribuição de resultados entre os indivíduos (Bridoux et al., 2011). Para esses tipos de indivíduos, os incentivos explícitos podem ser interpretados de uma maneira negativa e reduzir qualquer esforço adicional (Fehr \& Fischbacher, 2002).

Segundo Bridoux et al. (2011) é por meio do sistema motivacional que as empresas alinham os motivos individuais de cooperação e a criação de valor coletiva. Esses sistemas têm como objetivo influenciar os funcionários a adotarem comportamentos que ajudem no alcance dos objetivos da empresa (Chadwick \& Dabu, 2009). Assim, quanto maior o alinhamento entre as motivações individuais e o sistema motivacional, maior é a criação de valor coletiva, o que resulta em um melhor desempenho organizacional (Bridoux et al., 2011). Bridoux et al. (2011) 
argumentam que em função de seu tipo de motivação, os indivíduos irão responder de forma diferente aos incentivos motivacionais da empresa. Os autores propõem um modelo baseado em três tipos de sistemas motivacionais e seus efeitos na criação de valor coletiva: 1) cooperação benevolente, 2) incentivos monetários individuais, e 3) cooperação disciplinada.

O primeiro sistema motivacional caracteriza-se pela ausência de mecanismos de sanções e a criação de valor é maior na presença de indivíduos recíprocos e diminui à medida que a quantidade de auto-interessados cresce. $\mathrm{O}$ segundo sistema motivacional caracteriza-se pelo uso de incentivos monetários como mecanismo de sanção e, ao contrário do primeiro sistema, a criação de valor é alta na presença de indivíduos auto-interessados e diminui à medida que a quantidade de recíprocos cresce. Por fim, no terceiro sistema motivacional as sanções são administradas pelos pares (ex. colegas de trabalho) e a criação de valor é maior quando o número de recíprocos é apenas suficiente para disciplinar os indivíduos auto-interessados, diminuindo à medida que a proporção de recíprocos cresce ou diminui. Ressalta-se que por sanções os autores entendem tanto recompensas quanto punições.

Esses dois tipos de indivíduos e sua relação com as práticas de RH serão utilizados no desenvolvimento das hipóteses deste estudo que são apresentadas na seção a seguir. 


\section{HIPÓTESES DO ESTUDO}

Nesta seção eu argumento que o desempenho organizacional é influenciado pelo valor que as empresas distribuem para seus funcionários. Esse argumento é desenvolvido com base em três mecanismos: 1) empresas motivam seus funcionários por meio dos tipos de valores distribuídos à eles para o atendimento de sua função utilidade; 2) diferentes tipos de valores associam-se diferentemente com diferentes tipos de funcionários; 3) funcionários motivados apresentam melhor desempenho individual o que resulta em um maior desempenho organizacional. Nesta pesquisa os funcionários são classificados em dois diferentes tipos, auto-interessados e recíprocos, e o valor é analisado em termos de valor tangível e intangível.

Pesquisas no campo da psicologia social e economia comportamental têm demonstrado que os motivos para cooperar são heterogêneos entre os indivíduos e que estes motivos afetam o comportamento em empreendimentos coletivos, tal como a criação de valor (Bridoux et al., 2011). Dada essa heterogeneidade, as práticas empregadas pelas empresas para motivar seus funcionários podem ser interpretadas de diferentes formas e, portanto, motivar os funcionários diferentemente (Chadwick \& Dabu, 2009).

A literatura de GERH tem apresentado inúmeras evidências de que as práticas adotadas pelas empresas para o gerenciamento de seus funcionários afetam o desempenho geral da empresa (Huselid, 1995; Delery \& Doty 1996; Huselid et al., 1997; Jiang et al., 2012). Um dos mecanismos pelo qual essas práticas afetam o desempenho é a motivação (Bowen e Ostroff, 2004; DeVaro, 2006). Segundo essa perspectiva, as práticas de RH motivam os funcionários a adotar comportamentos que contribuem para o alcance dos objetivos da empresa (Gittell et al., 2010; Jiang et al., 2012).

Práticas comumente utilizadas para motivar os funcionários incluem salário, benefícios, políticas de qualidade de vida, programa de bônus entre outras (Jiang et al., 2012, DeGeest et al. 2015). Essas práticas podem ser consideradas condutores de valor tangível com as quais as empresas atendem à função utilidade de seus funcionários (Tantalo \& Priem, 2016). Indivíduos do tipo auto-interessados são motivados por recompensas pessoais (Folger \& Salvador, 2008) e, desde que seu bem-estar econômico não seja afetado, não se importam com os resultados e 
comportamentos de outros indivíduos (Camerer \& Fehr, 2006). Portanto, funcionários do tipo auto-interessados são mais motivados pela distribuição de valor tangível. Além disso, o relacionamento com indivíduos auto-interessados tende ser de curto prazo (Bridoux \& Stoelhorst, 2014).

Em suma, os valores tangíveis afetam a motivação dos indivíduos do tipo auto-interessados, cujo desempenho é mais de curto prazo. O desempenho dos funcionários, por fim, afeta o desempenho organizacional. Assim, propõe-se a seguinte hipótese.

H1- A distribuição de valor tangível está positivamente associada com o desempenho organizacional de curto prazo.

As percepções de justiça, tanto em termos de justiça processual, interacional ou distributiva são consideradas condutores de valor intangível (Tantalo \& Priem, 2016, Harrison et al., 2010) e também podem ser utilizadas para a motivação dos funcionários. Se por um lado indivíduos auto-interessados são motivados por recompensas individuais, indivíduos do tipo recíprocos apresentam preferencias sociais (Fehr \& Fischbacher, 2002). Para criar mais valor, indivíduos recíprocos são mais motivados por um tratamento justo, mesmo que a sua contribuição não seja totalmente recompensada na forma de um benefício econômico pessoal (Bridoux \& Stoelhorst, 2014). Os recíprocos parecem interpretar o uso de recompensas financeiras ou sanções como um sinal de desconfiança, o que pode prejudicar sua vontade de contribuir para a criação de criação de valor (Fehr \& Falk, 2002; Fehr \& Rockenbach, 2003). Portanto, funcionários do tipo recíprocos são mais motivados pela distribuição de valor intangível. Ao contrário dos indivíduos auto-interessados, as relações com indivíduos recíprocos tendem ser de longo prazo (Bridoux \& Stoelhorst, 2014).

Se por um lado, a distribuição de valores tangíveis seria mais capaz de atrair, reter e motivar funcionários do tipo auto-interessados, os quais apresentariam um alto desempenho no curto prazo, por outro lado, a distribuição de valores intangíveis seria mais capaz de atrair, reter e motivar funcionários do tipo recíprocos, os quais apresentariam um alto desempenho no longo prazo. Assim, propõe-se a seguinte hipótese:

H2- A distribuição de valor intangível está positivamente associada com o desempenho organizacional de longo prazo. 


\section{MÉTODO}

Este capítulo apresenta os procedimentos metodológicos adotados para atender aos objetivos propostos. Esta pesquisa é de abordagem quantitativa e, conforme apresentado no Capítulo 1, tem como objetivo analisar a relação entre o valor distribuído para o stakeholder funcionário e o desempenho da empresa. Os objetivos específicos são: (i) analisar a relação entre distribuição de valor tangível para os funcionários e o desempenho de curto e longo prazo da empresa e (ii) analisar a relação entre distribuição de valor intangível para os funcionários e o desempenho de curto e longo prazo da empresa.

\subsection{População e amostra}

A população objeto de estudo desta pesquisa corresponde às 528 empresas de capital aberto listadas na bolsa de valores BM\&FBovespa, e suas controladas. A amostra analisada compreende o conjunto de empresas que responderam ao questionário do Índice de Sustentabilidade Empresarial (ISE), da BM\&FBovespa, nos anos de 2010 à 2013. Este conjunto inclui tanto empresas de capital aberto listadas na Bolsa de Valores, quanto suas controladas.

O ISE é uma ferramenta que objetiva comparar o desempenho das empresas listadas na Bolsa de Valores quanto à sustentabilidade corporativa. Para a composição da carteira, as empresas que detém as 200 ações mais líquidas da Bolsa de Valores são convidadas para responder ao questionário (ISE, 2015).

O questionário utilizado pelo ISE é desenvolvido pelo Centro de Estudos em Sustentabilidade (GVCes) da Escola de Administração de Empresas de São Paulo da Fundação Getúlio Vargas (FGV-EAESP). Este questionário inclui questões relacionadas à eficiência econômica, equilíbrio ambiental, justiça social, governança corporativa, nível de compromisso com o desenvolvimento sustentável, equidade, transparência e prestação de contas, natureza do 
produto, além do desempenho empresarial nas dimensões econômico-financeira, social, ambiental e de mudanças climáticas.

A escolha do questionário ISE como base de dados para esta pesquisa se justifica em função de dois aspectos importantes. O primeiro aspecto está relacionado à confiabilidade dos dados referentes a distribuição de valor para os stakeholders, pois as informações fornecidas pelas empresas ao ISE devem ser comprovadas mediante apresentação de documentos. O segundo aspecto é decorrente da amplitude temporal da base ISE que apresenta informações de diversos anos, o que permitiu a análise longitudinal necessária para testar as hipóteses deste estudo. Embora os dados do ISE sejam adequados aos objetivos da pesquisa, é importante explicitar a limitação decorrente da amostra que compõe a base, pois as empresas que respondem ao questionário são, na sua maioria, grandes empresas e não permitem generalizações.

Tendo em vista que os objetivos específicos visam analisar os efeitos do valor tangível (VTan) e do valor intangível (VIn) ao longo do tempo, foram consideradas apenas as empresas que participaram de 4 anos na carteira ISE. O cruzamento das informações do ISE com as informações financeiras resultou num total de 40 empresas analisadas ao longo de quatro anos.

\subsection{Definição das variáveis}

\subsubsection{Variável Dependente}

A variável dependente desta pesquisa refere-se ao desempenho organizacional. O desempenho organizacional pode ser mensurado de diferentes formas entre elas, o Desempenho Social Corporativo (do inglês corporate social performance - CSP) e Desempenho Financeiro Corporativo (do inglês corporate financial performance - CFP).

Conceitualmente, a CSP é uma variável agregada de observação indireta, pela qual busca-se avaliar o desempenho da organização no atendimento das demandas de seus diversos 
stakeholders (Boaventura, Silva \& Bandeira De Mello, 2012). A CSP é um constructo multidimensional, com comportamentos que variam em função de uma grande variedade de entradas (por ex. investimentos em equipamentos de controle de poluição ou outras estratégias ambientais), comportamentos internos ou processos (por ex. o tratamento de mulheres e minorias, a natureza dos produtos produzidos e relacionamentos com os clientes) e saídas (relações com a comunidade e programas filantrópicos) (Waddock \& Graves, 1997).

Um problema que tem atormentado os pesquisadores é o de medição da CSP (Waddock \& Graves, 1997). Essa problemática é também apontada por Boaventura et al. (2012) ao indicar duas questões como limitações dos estudos empíricos de CSP: a primeira questão refere-se a "quais" stakeholders avaliar e a segunda é "como" avaliar o atendimento de suas demandas.

Por outro lado, diferentemente da CSP, as variáveis usadas para mensuração da CFP são facilmente encontradas na literatura e, normalmente, incluem retorno sobre ativos (ROA), retorno sobre o patrimônio líquido (ROE), crescimento de vendas, retorno sobre as vendas (ROS), margem de contribuição, Q de Tobin, participação de mercado, risco da firma, retorno sobre capital investido (ROCE), lucro operacional, fluxo de caixa e ganho por ação (Boaventura et al., 2012).

Nesta pesquisa o desempenho organizacional será analisado em termos de desempenho financeiro, uma vez que as variáveis financeiras apresentam maior consenso dos pesquisadores quando à sua mensuração. Para testar os efeitos da distribuição de valor tangível e intangível no desempenho das empresas, foi utilizada como variável dependente o retorno sobre ativo (ROA). ROA é definido como lucro líquido dividido pelo total de ativos. Esta variável foi coletada para o ano de 2014 na base de dados Economática ${ }^{\circledR}$ e, especialmente no caso das controladas, em demonstrações financeiras disponíveis no site das empresas.

A variável ROA é apontada por Boaventura et al. (2012) como a medida mais utilizada nos estudos sobre stakeholders. Além disso, não foi possível utilizar nenhuma medida de mercado, pois a amostra também incluiu as empresas controladas, as quais não possuem essas informações. 
Para capturar o efeito do tempo, curto e longo prazo, foram utilizadas defasagens de 1, 2, 3 e 4 anos para as variáveis independentes Valor Tangível (VTan), Valor Intangível (VIn) e endividamento, as quais serão apresentadas nas próximas seções.

\subsubsection{Variáveis Independentes}

As variáveis independentes correspondem ao valor tangível e ao valor intangível distribuído pelas empresas para o atendimento da função utilidade de seus funcionários. Essas informações foram coletadas da base de dados do ISE. Ambas as variáveis são proxies que são explicadas nas seções a seguir.

\subsubsection{Valor Tangível}

O valor tangível é conceituado como o valor distribuído pela empresa que pode ser mensurado por meio de valores monetários. Os condutores de valor tangível para os funcionários incluem salário, benefícios, responsabilidade social corporativa e políticas de qualidade da vida (Tantalo \& Priem, 2016).

A variável VTan é composta por duas dimensões: benefícios e pagamentos. O escore final desta variável corresponde à soma das respostas das empresas para as cinco questões apresentadas na Tabela 1, sendo três delas referentes a benefícios e duas a pagamentos. 
Tabela 1 - Questões utilizadas para compor a variável VTan

\begin{tabular}{|c|c|c|}
\hline Dimensão & Questão & Resposta \\
\hline Benefícios & As Notas Explicativas abordam: Benefícios para os empregados & $\begin{array}{l}\text { Sim }=1 \\
\text { Não }=0\end{array}$ \\
\hline Benefícios & $\begin{array}{l}\text { As Notas Explicativas abordam: Dentro dos benefícios para os } \\
\text { empregados, especificamente Fundo de Pensão }\end{array}$ & $\begin{array}{l}\text { Sim }=1 \\
\text { Não }=0\end{array}$ \\
\hline Benefícios & $\begin{array}{l}\text { Oferece benefícios como opção de alimentos saudáveis, academia, } \\
\text { ginástica laboral, e outras atividades que promovam o bem estar e uma } \\
\text { vida mais saudável (física e psíquica) }\end{array}$ & $\begin{array}{l}\mathrm{Sim}=1 \\
\mathrm{Não}=0\end{array}$ \\
\hline Pagamentos & $\begin{array}{l}\text { A companhia calcula o lucro econômico ou outras medidas de geração de } \\
\text { valor econômico? Se SIM: Usa os valores obtidos como base para a } \\
\text { remuneração variável de seus executivos }\end{array}$ & $\begin{array}{l}\text { Sim }=1 \\
\text { Não }=0\end{array}$ \\
\hline Pagamentos & $\begin{array}{l}\text { A companhia calcula o lucro econômico ou outras medidas de geração de } \\
\text { valor econômico? Se SIM: Usa os valores obtidos como base para a } \\
\text { remuneração variável dos demais colaboradores }\end{array}$ & $\begin{array}{l}\mathrm{Sim}=1 \\
\mathrm{Não}=0\end{array}$ \\
\hline \multicolumn{2}{|c|}{ Máximo de pontos para a variável Valor Tangível } & 5 \\
\hline
\end{tabular}

Fonte: Questionários ISE 2010, 2011, 2012 e 2013.

Alguns exemplos de benefícios referentes a primeira questão são: seguro de vida, participação nos lucros, assistência médica e odontológica, auxílio alimentação e refeição e auxílio-creche.

\subsubsection{Valor Intangível}

O valor intangível é conceituado como o valor distribuído pela empresa que não pode ser facilmente mensurado em termos monetários. Os condutores de valor intangível para os funcionários incluem a justiça organizacional, divulgação de informações (Harrison, Bosse \& Phillips, 2010), participação no processo decisório (Phillips, 2003) e características do trabalho e variedade de habilidades (Tantalo \& Priem, 2016).

Para esta pesquisa, o valor intangível foi analisado em termos de justiça organizacional. Segundo Bosse et al. (2009) a justiça organizacional pode ser dividida em justiça distributiva, relacionada a quantidade real de recursos materiais alocados para os stakeholders; a justiça 
processual que diz respeito à equidade das regras e procedimentos desse regime de distribuição; e a justiça interacional que refere-se à maneira pela qual os atores tratam uns aos outros (Bosse et al., 2009).

A variável VIn foi mensurada por meio de duas dimensões: (1) Justiça distributiva, que inclui questões relacionadas a equidade na remuneração de minorias e (2) Justiça interacional que inclui ações em prol da diversidade.

A atribuição dos pesos para as questões de equidade na remuneração está alinhada a ideia de quanto maior o fator de equidade, maior é a justiça organizacional. O escore da variável VIn é resultado da soma das respostas das empresas para as questões apresentadas na Tabela 2.

Tabela 2 - Questões utilizadas para compor a variável VIn

\begin{tabular}{|c|c|}
\hline \multicolumn{2}{|c|}{ Dimensão 1: Justiça Distributiva } \\
\hline \multicolumn{2}{|c|}{ Questões relacionadas à equidade na remuneração de minorias } \\
\hline Questões e alternativas & $\begin{array}{l}\text { Pesos atribuídos às } \\
\text { alternativas }\end{array}$ \\
\hline \multicolumn{2}{|c|}{$\begin{array}{l}\text { Indique na tabela abaixo o Fator de Equidade na Remuneração (FER) que relaciona a remuneração } \\
\text { dos integrantes de cada um dos grupos indicados e a remuneração do conjunto de todos os ocupantes } \\
\text { de cargos de diretoria e cargos de gerência: }\end{array}$} \\
\hline \multicolumn{2}{|l|}{ 1. Mulheres em cargos de diretoria } \\
\hline a) 0 & a) 0 \\
\hline b) $<0,9$ & b) 1 \\
\hline c) 0,9 a 1,1 & c) 2 \\
\hline d) $>1,1$ & d) 3 \\
\hline
\end{tabular}

2. Mulheres em cargos de gerência
a) 0
a) 0
b) $<0,9$
b) 1
c) 0,9 a 1,1
c) 2
d) $>1,1$
d) 3

3. Negros (as) em cargos de diretoria
a) 0
b) $<0,9$
a) 0
c) 0,9 a 1,1
b) 1
d) $>1,1$
c) 2
e) N/D
d) 3
e) Dado perdido 
4. Negros (as) em cargos de gerência
a) 0
a) 0
b) $<0,9$
b) 1
c) 0,9 a 1,1
c) 2
d) $>1,1$
d) 3
e) $N / D$
e) Dado perdido

Dimensão 2: Justiça Interacional

Questões relacionadas a ações em prol da diversidade

Indique as medidas adotadas pela companhia visando promover a empregabilidade de pessoas com deficiência?

a) Investimento em meios de acessibilidade

a) 1

b) Investimento em tecnologias adequadas para a realização do trabalho

b) 1

c) Capacitação profissional

c) 1

d) Sensibilização e conscientização de seus funcionários para a recepção e boa

d) 1 convivência profissional

Total $=4$

Indique as medidas adotadas pela companhia visando respeitar a diversidade em termos de orientação sexual?
a) Possibilita a indicação de pessoas do mesmo sexo como cônjuges
a) 1
b) Inclui o tema em suas atividades de sensibilização e valorização da
b) 1 diversidade
Total $=2$

Máximo de pontos para a variável Intangível

18

Fonte: Questionários ISE 2010, 2011, 2012 e 2013

Para responder as questões de equidade na remuneração, os respondentes receberam as seguintes instruções no questionário ISE:

FER = SM_GRUPO “M”/ SM_GRUPO “G”

Onde:

FER = Fator de Equidade na Remuneração (número indicado no cabeçalho de cada coluna)

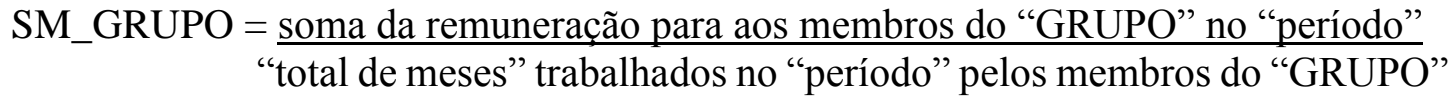

Membros do GRUPO "M": integrantes da "minoria" em questão, que trabalharam na companhia durante o "período", ocupando cargos no nível hierárquico a que se refere a questão. 
Membros do GRUPO “G”: todos que trabalharam na companhia durante o "período", ocupando cargos no nível hierárquico a que se refere a questão.

Remuneração: significa o pagamento efetivamente realizado ao diretor(a) ou gerente, excluindo todas as formas de remuneração variável associadas ao desempenho do profissional ou da companhia.

"Período" é o intervalo de tempo em que se baseia a avaliação.

Total de meses: significa a somatória do número de meses trabalhados no período pelos membros do grupo. Por exemplo, caso a minoria seja composta por dois indivíduos, sendo que o primeiro trabalhou 12 meses no "período" e o segundo trabalhou quatro meses no "período", o “total de meses” será 16.

O critério para definição das condições relativas à "cor ou raça" segue a metodologia do IBGE: deve ser o da autodeclaração do empregado quanto à pergunta sobre sua "cor ou raça". "Negro (a)" corresponde à soma das opções de "cor ou raça" "preta" e "parda". A alternativa "Não Disponível” (N/D) aplica-se apenas a companhias que por deliberação formal interna não controlem a variável "cor ou raça" em seus registros. Companhia que não tem representante da "minoria", indicar a alternativa "zero".

A fim de comparar os efeitos na variável dependente, tanto as variáveis VTan quanto VIn foram padronizadas pelo Z-score, calculado por meio da seguinte fórmula:

$$
\frac{X-\text { média }}{\text { desvio-padrão }}
$$

Após a padronização, as variáveis ficaram com média 0 e desvio-padrão 1 (Hair, Anderson, Tatham \& Black, 2005). Segundo Hair et al. (2005, p. 135) a padronização dos dados "permite ao pesquisador comparar o efeito relativo de cada variável independente sobre a variável dependente". 


\subsubsection{Variáveis de Controle}

Uma vez que a variável independente representa o desempenho financeiro da empresa, foram utilizadas como variáveis de controle fatores que poderiam afetar sistematicamente o desempenho financeiro (Barnett \& Salomon, 2012). Boaventura et al. (2012) destacam que na análise do desempenho organizacional os estudos empíricos utilizam uma ampla gama de variáveis de controle sendo indústria e tamanho as mais empregadas. Assim, controlou-se o efeito do tamanho da empresa e setor. Como proxy para tamanho foi utilizado o logaritmo natural do total de ativos. Para setor, foram criadas 4 variáveis dummies, uma vez que as empresas foram agrupadas em indústria, serviço, utilidades e bancos.

Segundo Barnett e Salomon (2012), o endividamento pode afetar negativamente o lucro, assim como restringir o comportamento dos gestores. Uma vez que o endividamento pode afetar o resultado financeiro, assim como a distribuição de valor para os funcionários à medida que restringe o comportamento dos gestores, a variável endividamento também foi incluída como controle no modelo. O endividamento é definido como o passivo total dividido pelo total de ativos.

\subsection{Modelo}

A técnica estatística utilizada para a análise dos dados foi a regressão linear múltipla pelo método dos Mínimos Quadrados Ordinários (MQO). Para evitar viés nos estimadores, os modelos analisados foram testados quanto à normalidade e variância constante dos termos de erros. Para testar a normalidade foi empregado o teste Shapiro Wilk e para analisar a homocedasticidade dos resíduos aplicou-se o teste de Breusch-Pagan. Nos casos em que a variância não é constante tem-se o problema de heterocedasticidade. Uma forma de corrigir esse problema é o uso de estimadores com erros robustos (Wooldridge, 2006). Nesta pesquisa, a maioria dos modelos apresentou distribuição normal dos resíduos, porém apresentou 
problemas de heterocedasticidade. Para a correção desse problema os modelos foram estimados com erros robustos para heterocedasticidade.

A técnica de regressão também é sensível a multicolinearidade e a presença de outliers. A presença de multicolinearidade foi analisada pelo fator de inflação de variação (variance inflation fator - VIF). Valores elevados de VIF indicam a presença de multicolinearidade (Hair et al., 2005). Segundo Hair et al. (2005, p.167) um ponto de referência é de que os valores de VIF não ultrapassem 10. O tratamento dos outliers será apresentado na seção 4.5.

Os modelos utilizados para testar as hipóteses deste estudo são apresentados nas Equações 1, 2 e 3. Para capturar o efeito do tempo, foram testadas quatro equações para cada modelo com defasagens de 1, 2, 3 e 4 anos nas variáveis independentes.

$$
\begin{aligned}
& \text { ROA }=\beta_{0}+\beta_{1} \text { VTan }_{t-n}+\beta_{2} \text { Tam }_{t}+\beta_{3} \text { Setor }_{t}+\beta_{4} \text { Endiv }_{t-n}+\varepsilon \\
& \text { ROA }=\beta_{0}+\beta_{1} \text { VIn }_{t-n}+\beta_{2} \text { Tam }_{t}+\beta_{3} \text { Setor }_{t}+\beta_{4} \text { Endiv }_{t-n}+\varepsilon \\
& \text { ROA }=\beta_{0}+\beta_{1} \text { VTan }_{t-n}+\beta_{2} \text { VIn }_{t-n}+\beta_{3} \text { Tam }_{t}+\beta_{4} \text { Setor }_{t}+\beta_{5} \text { Endiv }_{t-n}+\varepsilon
\end{aligned}
$$

em que:

ROA $=$ Retorno sobre ativo

VTan $=$ Valor tangível nos anos $\mathrm{t}-1, \mathrm{t}-2, \mathrm{t}-3$ e $\mathrm{t}-4$

VIn $=$ Valor intangível nos anos $\mathrm{t}-1, \mathrm{t}-2, \mathrm{t}-3$ e t-4

Tam $=$ Tamanho

Setor $=$ Setor

Endiv $=$ Endividamento nos anos $\mathrm{t}-1, \mathrm{t}-2, \mathrm{t}-3$ e $\mathrm{t}-4$ 


\subsection{Outliers e Observações influentes}

Segundo Aguinis, Gottfredson e Joo (2013) podem haver 3 tipos de outliers: outliers de erro, outliers interessantes e outliers influentes. O primeiro tipo inclui observações atípicas causadas por erros de amostragem, erros de observação, erros de gravação, erros na preparação dos dados, erro de cálculo, erros de codificação, ou erros na manipulação dos dados (Aguinis et al., 2013). Em suma, outliers de erro são observações não legítimas e normalmente são retirados da amostra. Os outliers interessantes, por sua vez, são dados que foram identificados como observações discrepantes, mas ainda não foram confirmados como valores outliers de erro real (Aguinis et al., 2013). Além disso, esses casos podem conter conhecimento potencialmente valioso ou inesperado (Cohen, Cohen, West \& Aiken, 2003, Mohrman \& Lawler, 2012). Esses dois tipos de outliers podem ser identificados por meio de técnicas univariadas ou multivariadas. As técnicas univariadas, ou de constructo simples, examinam valores extremos dentro de cada constructo individual. As técnicas multivariadas, ou de múltiplos constructos, avaliam a distância que uma observação está de um centroide de dados calculado a partir de dois ou mais constructos (Aguinis et al., 2013).

Por fim, existem dois tipos de outliers influentes: (a) outliers de ajuste do modelo, os quais alteram o ajuste de um modelo (por exemplo, o $\mathrm{R}^{2}$ ) e (b) outliers de previsão, cuja presença altera as estimativas dos parâmetros. Para análise de observações influentes existem três técnicas projetadas para avaliar a presença de outliers de previsão no contexto de regressão: DFITS, Cook D, e DFBETAS (diferença em BETA, Padronizado). DFFITS e Cook D são indicadores globais que avaliam a influência que o outlier tem nos coeficientes de regressão como um todo. Por outro lado, DFBETAS é mais específico e quantifica a influência do outlier em um coeficiente de regressão especial (Aguinis et al., 2013).

Nesta pesquisa foram utilizadas três técnicas para detectar outliers. Para outliers de erro e outliers interessantes foi empregada a técnica de múltiplos constructos resíduos estudentizados (Cohen et al., 2003), em que valores acima de 3 são considerados outliers. Para detectar outliers influentes foram utilizadas as técnicas de DFITS e Cook D, uma vez que essas técnicas analisam os outliers considerando a regressão como um todo. Como critério para identificar esses tipos de outliers foi utilizado o ponto de corte de valores Cook maiores que 1 (Hair et al., 2005, p. 
188) e DFITS maiores que DFITS $=2 / \sqrt{p / n}$, em que $p=$ número de variáveis independentes + 1 e $n$ é o tamanho da amostra (Hair et al., 2005, p. 188). Para a amostra estudada o valor de DFITS foi igual a 4,47 nos modelos com VTan e VIn analisados isoladamente e 4,21 nos modelos que VTan e VIn estavam em conjunto.

Para a exclusão ou permanência dos outliers na amostra estudada procedeu-se da seguinte forma. Primeiramente, foram identificados os outliers com resíduos estudentizados maiores que 3. Em seguida os outliers foram analisados em termos de influência nos estimadores da regressão por meio das técnicas DFITS e Cook D. O resultado desta análise indicou que nenhum dos outliers apresentou DFITS ou Cook acima dos valores estabelecidos. Em função disso, procedeu-se a uma análise qualitativa, tendo em vista detectar se os outlier poderiam ser provenientes de erro de coleta ou ser do tipo interessantes. Uma vez que não foi detectado evidências de erro de coleta, decidiu-se pela manutenção dos outliers na amostra. Essa opção é justificada pela afirmação de Cohen et al. (2003) e Mohrman e Lawler (2012) de que esses casos podem conter conhecimento potencialmente valioso ou inesperado. 


\section{RESULTADOS}

\subsection{Estatísticas descritivas}

O total da amostra analisada é composto por 40 empresas que responderam aos questionários ISE nos anos de 2010 a 2013 e que dispunham de dados financeiros para o ano de 2014. As empresas foram agrupadas em 4 setores de atuação, conforme apresentado na Tabela 3.

Tabela 3 - Relação de empresas por setor de atuação

\begin{tabular}{lrr}
\hline Setor & Frequência & Percentual \\
\hline Bancos & 5 & 12,5 \\
Indústria & 7 & 17,5 \\
Serviço & 3 & 7,5 \\
Utilidades & 25 & 62,5 \\
\hline Total & 40 & 100 \\
\hline
\end{tabular}

A maior concentração de empresas está no setor de utilidades com 25 empresas, representando $62,5 \%$ do total. Este setor inclui três tipos de empresas: empresas de geração e transmissão de energia elétrica, empresas de água, esgoto e saneamento e empresas concessionárias de rodovias. A segunda maior frequência é a Indústria, com 17,5\%, seguida de bancos com 12,5\% e Serviço com 7,5\%. Bancos foram classificados em um setor diferente do de serviços uma vez que estes podem apresentar características muito distintas.

A Tabela 4 apresenta as estatísticas descritivas e correlações para as variáveis que foram utilizadas para testar as hipóteses do estudo. 
Tabela 4 - Estatísticas descritivas e correlações

\begin{tabular}{|c|c|c|c|c|c|c|c|c|c|c|c|c|c|c|}
\hline & ROA & Tam & VTan1 & VTan2 & VTan3 & VTan4 & VIn1 & VIn2 & VIn3 & VIn4 & Endiv1 & Endiv2 & Endiv3 & Endiv4 \\
\hline ROA & 1 & & & & & & & & & & & & & \\
\hline Tam & $-0,4574^{*}$ & 1 & & & & & & & & & & & & \\
\hline VTan1 & $0,4331^{*}$ & $-0,0711$ & 1 & & & & & & & & & & & \\
\hline VTan2 & $0,4029 *$ & $-0,1433^{*}$ & $0,7559^{*}$ & 1 & & & & & & & & & & \\
\hline VTan3 & $0,3676^{*}$ & $-0,1548^{*}$ & $0,7196^{*}$ & $0,8363^{*}$ & 1 & & & & & & & & & \\
\hline VTan4 & $0,3477 *$ & $-0,1699 *$ & $0,6809 *$ & $0,8268 *$ & $0,8359 *$ & 1 & & & & & & & & \\
\hline VIn1 & $-0,1389^{*}$ & $0,3061^{*}$ & $-0,1931 *$ & $-0,1675^{*}$ & $-0,2788^{*}$ & $-0,2197^{*}$ & 1 & & & & & & & \\
\hline VIn2 & $-0,2702^{*}$ & $0,3987^{*}$ & $-0,1870^{*}$ & $-0,1974 *$ & $-0,2585^{*}$ & $-0,2065^{*}$ & $0,8279 *$ & 1 & & & & & & \\
\hline VIn3 & $-0,1100^{*}$ & $0,3638^{*}$ & $-0,1047$ & $-0,1435^{*}$ & $-0,2041 *$ & $-0,1984^{*}$ & $0,8150^{*}$ & $0,8824^{*}$ & 1 & & & & & \\
\hline VIn4 & $0,2206^{*}$ & $0,1838 *$ & $0,2758 *$ & $0,1109^{*}$ & 0,0753 & 0,0723 & $0,6141^{*}$ & $0,6517 *$ & $0,7427 *$ & 1 & & & & \\
\hline Endiv1 & $0,3666^{*}$ & $-0,0072$ & 0,0875 & $0,1846^{*}$ & $0,1264^{*}$ & 0,0663 & $-0,0402$ & $-0,2365^{*}$ & $-0,1463^{*}$ & $-0,0603$ & 1 & & & \\
\hline Endiv2 & $0,3878^{*}$ & 0,0176 & 0,0805 & $0,1764^{*}$ & $0,1414^{*}$ & 0,0782 & $-0,0128$ & $-0,2166^{*}$ & $-0,1182 *$ & $-0,0362$ & $0,9896^{*}$ & 1 & & \\
\hline Endiv3 & $0,3880^{*}$ & 0,0191 & 0,0782 & $0,1740^{*}$ & $0,1450^{*}$ & 0,0819 & $-0,0364$ & $-0,2302 *$ & $-0,1281 *$ & $-0,0476$ & $0,9646^{*}$ & $0,9844^{*}$ & 1 & \\
\hline Endiv4 & $0,3880 *$ & 0,0183 & 0,0736 & $0,1637 *$ & $0,1431^{*}$ & 0,0799 & $-0,0202$ & $-0,2136^{*}$ & $-0,1096$ & $-0,0324$ & $0,9635^{*}$ & $0,9837 *$ & $0,9966^{*}$ & 1 \\
\hline Variável & $\mathrm{ROA}$ & Tam & VTan1 & VTan2 & VTan3 & VTan4 & VIn1 & VIn2 & VIn3 & VIn4 & Endiv1 & Endiv2 & Endiv3 & Endiv4 \\
\hline Média & 5,61 & 16,31 & 3,30 & 3,35 & 3,40 & 3,28 & 8,00 & 7,53 & 7,48 & 7,55 & $-976,35$ & $-994,81$ & $-1052,73$ & $-1111,88$ \\
\hline Dev.Pad & 7,63 & 1,65 & 1,02 & 1,03 & 1,06 & 1,06 & 2,09 & 2,20 & 1,85 & 2,32 & 2100,05 & 2025,66 & 2137,88 & 2247,79 \\
\hline Min & $-4,56$ & 13,40 & 1,00 & 1,00 & 1,00 & 2,00 & 4,00 & 4,00 & 4,00 & 3,00 & $-6488,08$ & $-6488,74$ & $-7596,41$ & $-8221,53$ \\
\hline Max & 33,72 & 21,05 & 5,00 & 5,00 & 5,00 & 5,00 & 12,00 & 12,00 & 11,00 & 12,00 & 620,47 & 93,73 & 93,47 & 93,15 \\
\hline Obs & 40 & 40 & 40 & 40 & 40 & 40 & 40 & 40 & 40 & 40 & 40 & 40 & 40 & 40 \\
\hline
\end{tabular}


De uma forma geral, as correlações entre as variáveis são de magnitude baixa à moderada. No entanto, a fim de evitar problemas decorrentes de multicolinearidade, foi também empregado o teste VIF (variance inflation factor), cujos resultados serão apresentados na próxima seção.

O ROA médio foi de 5,61 com um desvio padrão de 7,63. O tamanho médio das empresas, calculado pelo logaritmo do total de ativos, foi de 16,31 com desvio padrão de 1,65 e coeficiente de variação de $10,13 \%$. Esse resultado indica que há pouca variabilidade no tamanho das empresas da amostra.

Ao contrário do esperado, a variável tamanho apresentou correlação negativa e significante com ROA. Isso pode estar associado à característica da amostra de que em geral as empresas participantes são de médio e grande porte. Da mesma forma, o endividamento apresentou uma correlação positiva com ROA, embora a literatura normalmente reporte uma relação negativa (por exemplo, Barnett \& Salomon et al., 2012).

As variáveis independentes VTan apresentaram uma correlação positiva e significante a 5\% com ROA para os 4 anos. Além disso, as correlações apresentam uma tendência decrescente. A maior correlação ocorreu no ano 1 com valor igual a 0,4331 .

Ao contrário de VTan, as variáveis de VIn apresentaram uma relação negativa e significante a $5 \%$ nos 3 primeiros anos. No ano 4 esta relação passa a ser positiva e significante a $5 \%$. A partir do ano 2, VIn apresentou correlações crescentes, sendo no ano 4 a maior delas, com valor igual a 0,2206 .

As estatísticas descritivas demonstram, ainda, que a pontuação máxima da VTan foi igual a 5 pontos e VIn foi igual a 12. Esses resultados indicam que nenhuma das empresas atingiu o escore máximo de 18 pontos para a variável VIn. Em geral, a variação de um ano para o outro da média dessas variáveis é baixa, indicando que as empresas apresentam poucas mudanças nas suas políticas de distribuição de valor para os funcionários ao longo dos anos.

Apesar das correlações apresentarem significância estatística elas devem ser vistas com cuidado uma vez que estão sendo analisadas isoladamente, sem considerar a influência de outras variáveis. Para uma análise mais robusta da natureza da relação entre distribuição de valor e 
desempenho financeiro, na seção seguinte são apresentados os resultados da análise multivariada por meio da técnica de regressão.

\subsection{Análise do Valor Tangível no ROA}

A Tabela 5 apresenta 4 modelos para análise dos efeitos da variável VTan no ROA. Todos os como variáveis de controle o tamanho da empresa, setor de atuação e o endividamento no mesmo ano da distribuição de VTan.

O VIF indica que não há evidências de problemas com multicolinearidade uma vez que o valor máximo foi 6,82 no Modelo 3. A normalidade dos resíduos foi analisada por meio do teste Sapiro Wilk, o qual indicou que todos os modelos apresentam resíduos com distribuição normal. Por fim, o teste Breusch-Pagan rejeitou a hipótese de homocedasticidade dos resíduos. Em função disso, os modelos foram estimados com erros robustos para heterocedasticidade (Anexo I).

Tabela 5 - Modelos de Regressão com VTan e ROA

\begin{tabular}{|c|c|c|c|c|}
\hline . & $\begin{array}{c}\text { Modelo } 1 \\
1 \text { ano de defasagem }\end{array}$ & $\begin{array}{c}\text { Modelo } 2 \\
2 \text { anos de defasagem }\end{array}$ & $\begin{array}{c}\text { Modelo } 3 \\
3 \text { anos de defasagem }\end{array}$ & $\begin{array}{c}\text { Modelo } 4 \\
4 \text { anos de defasagem }\end{array}$ \\
\hline Tangível & $\begin{array}{r}0,379 * * \\
(1,361)\end{array}$ & $\begin{array}{l}0,279 * \\
(1,317)\end{array}$ & $\begin{array}{r}0,319 \\
(1,684)\end{array}$ & $\begin{array}{r}0,234 \\
(1,489)\end{array}$ \\
\hline Tamanho & $\begin{array}{r}-0,553 * * \\
(1,211)\end{array}$ & $\begin{array}{r}-0,472 \\
(1,468)\end{array}$ & $\begin{array}{r}-0,434 \\
(1,534)\end{array}$ & $\begin{array}{r}-0,494 \\
(1,510)\end{array}$ \\
\hline Indústria & $\begin{array}{r}-0,214 \\
(6,218)\end{array}$ & $\begin{array}{r}-0,102 \\
(7,892)\end{array}$ & $\begin{array}{r}-0,133 \\
(7,539)\end{array}$ & $\begin{array}{r}-0,138 \\
(7,849)\end{array}$ \\
\hline Serviço & $\begin{array}{r}-0,046 \\
(6,827)\end{array}$ & $\begin{array}{r}0,018 \\
(8,567)\end{array}$ & $\begin{array}{r}0,102 \\
(9,810)\end{array}$ & $\begin{array}{r}-0,026 \\
(8,811)\end{array}$ \\
\hline Utilidades & $\begin{array}{r}-0,262 \\
(6,253)\end{array}$ & $\begin{array}{l}-0,105 \\
(8,285)\end{array}$ & $\begin{array}{r}-0,050 \\
(8,605)\end{array}$ & $\begin{array}{r}-0,145 \\
(8,497)\end{array}$ \\
\hline Endivid & $\begin{array}{r}0,295 * * * \\
(0,000)\end{array}$ & $\begin{array}{r}0,334 * * * \\
(0,000)\end{array}$ & $\begin{array}{r}0,354 * * * \\
(0,000)\end{array}$ & $\begin{array}{r}0,360 * * * \\
(0,000)\end{array}$ \\
\hline
\end{tabular}




\begin{tabular}{lrrrr} 
Constante & $50,91^{* *}$ & 43,02 & 39,44 & 45,66 \\
& $(25,08)$ & $(31,02)$ & $(32,43)$ & $(31,90)$ \\
\hline $\mathrm{F}$ & $5,66^{* * *}$ & $5,93^{* * *}$ & $4,61^{* * *}$ & $4,4^{* * *}$ \\
$\mathrm{R}^{2}$ & 0,5006 & 0,4493 & 0,4512 & 0,4327 \\
VIF máx & 5,62 & 6,37 & 6,82 & 6,32 \\
VIF médio & 2,66 & 2,99 & 3,23 & 2,95 \\
Normalidade & $\mathrm{Sim}$ & $\mathrm{Sim}$ & $\mathrm{Sim}$ & $\mathrm{Sim}$ \\
Homocedastic. & Não & Não & Não & Não \\
Obs & 40 & 40 & 40 & 40 \\
\hline
\end{tabular}

Todos os coeficientes estão padronizados, com exceção da constante. Os valores apresentados na primeira linha de cada variável são os coeficientes padronizados. Na segunda linha, entre parênteses, está o erro padrão. ***Significante a $\mathrm{p}<0,01 ; * *$ Significante a $\mathrm{p}<0,05$; *Significante a $\mathrm{p}<0,10$.

O Modelo 1 apresenta a variável VTan com 1 ano de defasagem. Observa-se que o VTan apresenta uma relação positiva e significante ao nível de 5\%. No Modelo 2, VTan tem 2 anos de defasagem em relação a ROA, o qual apresentou também uma relação positiva e significante a 10\%. No Modelo 3, o VTan foi analisado com 3 anos de defasagem e também apresenta uma relação positiva, porém não significante. No Modelo 4, a variável VTan foi analisada com 4 anos de defasagem, não apresentando significância estatística. De uma forma geral, os coeficientes dos modelos apresentam uma tendência decrescente, sendo que o maior efeito de VTan no ROA ocorre no primeiro ano com coeficiente padronizado igual à 0,379 . Estes resultados evidenciam que o VTan apresenta maior associação com o desempenho no curto prazo. O R ${ }^{2}$ indica que o modelo que melhor explica a variação de ROA é o Modelo 1 com $50,05 \%$.

\subsection{Análise do Valor Intangível no ROA}

A Tabela 6 apresenta 4 modelos para análise dos efeitos da variável VIn no ROA. Todos os modelos incluem como variáveis de controle o tamanho da empresa, setor de atuação e o endividamento no mesmo ano da distribuição de VIn. 
O VIF indica que não há problemas de multicolinearidade uma vez que o valor máximo foi 5,59 no Modelo 1. O teste de normalidade indicou que os resíduos dos modelos apresentam distribuição normal ao nível de 5\%. Por fim, o teste Breusch-Pagan rejeitou a hipótese de homocedasticidade dos resíduos. Para correção da heterocedasticidade os modelos foram estimados com erros robustos (Anexo II).

Tabela 6 - Modelos de Regressão com VIn e ROA

\begin{tabular}{|c|c|c|c|c|}
\hline . & $\begin{array}{c}\text { Modelo } 1 \\
1 \text { ano de defasagem }\end{array}$ & $\begin{array}{c}\text { Modelo } 2 \\
2 \text { anos de defasagem }\end{array}$ & $\begin{array}{c}\text { Modelo } 3 \\
3 \text { anos de defasagem }\end{array}$ & $\begin{array}{c}\text { Modelo } 4 \\
4 \text { anos de defasagem }\end{array}$ \\
\hline Intangível & $\begin{array}{r}0,021 \\
(1,174)\end{array}$ & $\begin{array}{r}-0,019 \\
(1.126)\end{array}$ & $\begin{array}{r}0,124 \\
(1,295)\end{array}$ & $\begin{array}{r}0,317 * * \\
(1,186)\end{array}$ \\
\hline Tamanho & $\begin{array}{r}-0,637 * * \\
(1,569)\end{array}$ & $\begin{array}{r}-0,621 * \\
(1,576)\end{array}$ & $\begin{array}{r}-0,674^{*} \\
(1,592)\end{array}$ & $\begin{array}{r}-0,654 * * \\
(1,355)\end{array}$ \\
\hline Indústria & $\begin{array}{r}-0,264 \\
(8,241)\end{array}$ & $\begin{array}{r}-0,261 \\
(8,210)\end{array}$ & $\begin{array}{r}-0,234 \\
(8,142)\end{array}$ & $\begin{array}{r}-0,177 \\
(6,907)\end{array}$ \\
\hline Serviço & $\begin{array}{l}-0,165 \\
(8,899)\end{array}$ & $\begin{array}{r}-0,147 \\
(8,812)\end{array}$ & $\begin{array}{l}-0,155 \\
(9,026)\end{array}$ & $\begin{array}{r}-0,116 \\
(8,466)\end{array}$ \\
\hline Utilidades & $\begin{array}{r}-0,357 \\
(8,700)\end{array}$ & $\begin{array}{r}-0,337 \\
(8,642)\end{array}$ & $\begin{array}{r}-0,335 \\
(8,678)\end{array}$ & $\begin{array}{r}-0,270 \\
(7,342)\end{array}$ \\
\hline Endivid & $\begin{array}{r}0,313 * * * \\
(0,0003)\end{array}$ & $\begin{array}{r}0,347 * * * \\
(0,0003)\end{array}$ & $\begin{array}{r}0,366 * * * \\
(0,0004)\end{array}$ & $\begin{array}{r}0,365 * * * \\
(0,0003)\end{array}$ \\
\hline Constante & $\begin{array}{l}59,33 * \\
(33,03)\end{array}$ & $\begin{array}{l}58,26 * \\
(33,11)\end{array}$ & $\begin{array}{l}61,75^{*} \\
(33,21)\end{array}$ & $\begin{array}{r}58,86 * * \\
(27,89)\end{array}$ \\
\hline $\mathrm{F}$ & $4,91 * * *$ & $5,85 * * *$ & $4,5 * * *$ & $5,11 * * *$ \\
\hline $\mathrm{R}^{2}$ & 0,3656 & 0,3885 & 0,4017 & 0,4836 \\
\hline VIF máx & 5,59 & 5,50 & 5,49 & 5,54 \\
\hline VIF médio & 2,69 & 2,73 & 2,66 & 2,62 \\
\hline Normalidade & Sim a $5 \%$ & Sim a $5 \%$ & Sim a $5 \%$ & Sim \\
\hline Homocedastic. & Não & Não & Não & Não \\
\hline Obs & 40 & 40 & 40 & 40 \\
\hline
\end{tabular}

Todos os coeficientes estão padronizados, com exceção da constante. Os valores apresentados na primeira linha de cada variável são os coeficientes padronizados. Na segunda linha, entre parênteses, está o erro padrão. $* * *$ Significante a $\mathrm{p}<0,01 ; * *$ Significante a $\mathrm{p}<0,05 ; *$ Significante a $\mathrm{p}<0,10$. 
Para os Modelos 1, 2 e 3 a variável VIn não apresentou significância estatística. Esse resultado indica que o VIn não afeta de forma significativa o ROA no curto prazo. Por outro lado, no Modelo 4, a variável VIn apresenta uma relação positiva e significante ao nível de 5\%. Observase que os coeficientes apresentam uma tendência de crescimento a partir do ano 2. O modelo que apresentou melhor explicação, segundo o $\mathrm{R}^{2}$, foi o Modelo 4, que explicou 48,36\% da variação de ROA.

\subsection{Análise do Valor Tangível e Intangível no ROA}

Nesta seção são apresentados os resultados da regressão considerando a relação entre as duas variáveis de interesse e ROA. Conforme apresentado na Tabela 7, o VIF máximo foi 6,84 no Modelo 3, indicando que não há problemas de multicolinearidade. O teste de normalidade indicou que os resíduos de todos os modelos apresentam distribuição normal. Todos os modelos foram estimados com erros robustos para a heterocedasticidade, uma vez que o teste BreuschPagan rejeitou a hipótese de homocedasticidade dos resíduos (Anexo III).

Tabela 7 - Modelos de Regressão com VTan, VIn e ROA

\begin{tabular}{|c|c|c|c|c|}
\hline . & $\begin{array}{c}\text { Modelo } 1 \\
1 \text { ano de defasagem }\end{array}$ & $\begin{array}{c}\text { Modelo } 2 \\
2 \text { anos de defasagem }\end{array}$ & $\begin{array}{c}\text { Modelo } 3 \\
3 \text { anos de defasagem }\end{array}$ & $\begin{array}{c}\text { Modelo } 4 \\
4 \text { anos de defasagem }\end{array}$ \\
\hline Tangível & $\begin{array}{r}0,389 * * \\
(1,377)\end{array}$ & $\begin{array}{r}0,280 * \\
(1,335)\end{array}$ & $\begin{array}{r}0,339 * \\
(1,613)\end{array}$ & $\begin{array}{r}0,206 \\
(1,231)\end{array}$ \\
\hline Intangível & $\begin{array}{r}0,077 \\
(1,231)\end{array}$ & $\begin{array}{r}0,011 \\
(1,011)\end{array}$ & $\begin{array}{r}0,157 \\
(1,273)\end{array}$ & $\begin{array}{r}0,301 * * \\
(1,185)\end{array}$ \\
\hline Tamanho & $\begin{array}{r}-0,582 * * \\
(1,230)\end{array}$ & $\begin{array}{r}-0,475 \\
(1,520)\end{array}$ & $\begin{array}{r}-0,477 * \\
(1,551)\end{array}$ & $\begin{array}{r}-0,534 \\
(1,264)\end{array}$ \\
\hline Indústria & $\begin{array}{r}-0,211 \\
(6,091)\end{array}$ & $\begin{array}{r}-0,098 \\
(7,961)\end{array}$ & $\begin{array}{r}-0,097 \\
(7,440)\end{array}$ & $\begin{array}{r}-0,078 \\
(6,559)\end{array}$ \\
\hline Serviço & $\begin{array}{r}-0,064 \\
(6,881)\end{array}$ & $\begin{array}{r}0,017 \\
(8,726)\end{array}$ & $\begin{array}{r}0,115 \\
(10,29)\end{array}$ & $\begin{array}{r}-0,002 \\
(8,404)\end{array}$ \\
\hline
\end{tabular}




\begin{tabular}{|c|c|c|c|c|}
\hline Utilidades & $\begin{array}{r}-0,273 \\
(6,199)\end{array}$ & $\begin{array}{r}-0,104 \\
(8,384)\end{array}$ & $\begin{array}{r}-0,029 \\
(8,555)\end{array}$ & $\begin{array}{r}-0,106 \\
(7,087)\end{array}$ \\
\hline Endivid & $\begin{array}{r}0,294 * * * \\
(0,000)\end{array}$ & $\begin{array}{r}0,336 * * * \\
(0,000)\end{array}$ & $\begin{array}{r}0,372 * * * \\
(0,000)\end{array}$ & $\begin{array}{r}0,374 * * * \\
(0,000)\end{array}$ \\
\hline Constante & $\begin{array}{r}52,77 * * \\
(25,08)\end{array}$ & $\begin{array}{r}43,23 \\
(31,84)\end{array}$ & $\begin{array}{r}41,85 \\
(32,39)\end{array}$ & $\begin{array}{r}47,27 * * \\
(26,49)\end{array}$ \\
\hline $\mathrm{F}$ & $4,70 * * *$ & $4,96^{* * *}$ & $3,96 * * *$ & $4,25 * * *$ \\
\hline $\mathrm{R}^{2}$ & 0,5055 & 0,4494 & 0,4711 & 0,5176 \\
\hline VIF máx & 5,64 & 6,39 & 6,84 & 6,34 \\
\hline VIF médio & 2,49 & 2,83 & 2,98 & 2,7 \\
\hline Normalidade & Sim & Sim & Sim & Sim \\
\hline Homocedastic. & Não & Não & Não & Não \\
\hline Obs & 40 & 40 & 40 & 40 \\
\hline
\end{tabular}

Todos os coeficientes estão padronizados, com exceção da constante. Os valores apresentados na primeira linha de cada variável são os coeficientes padronizados. Na segunda linha, entre parênteses, está o erro padrão. $* * *$ Significante a $\mathrm{p}<0,01 ; * *$ Significante a $\mathrm{p}<0,05 ; *$ Significante a $\mathrm{p}<0,10$.

Os resultados dos modelos com VTan e VIn estão alinhados aos resultados apresentados nas seções anteriores, quando as variáveis foram analisadas sem a presença uma da outra. O modelo que apresentou diferença foi o Modelo 3 em que o VTan passa a ser significante a $10 \%$. Observa-se que o maior impacto do VTan no ROA ainda ocorre no ano 1 enquanto o maior efeito de VIn foi no ano 4. O ano 4 foi, também, o único modelo que apresentou significância estatística para VIn. Esses resultados corroboram com as hipóteses de que o VTan está mais associado ao desempenho de curto prazo e VIn ao desempenho de longo prazo. Os resultados apontam, ainda, que os efeitos de VTan, em geral, são maiores em magnitude do que os efeitos de VIn.

Segundo o $\mathrm{R}^{2}$, o modelo que melhor explica a variação de ROA é o Modelo 4, com valor igual a $51,76 \%$, seguido do Modelo 1 com $\mathrm{R}^{2}$ igual a 50,55\%. 


\subsection{Resumo dos resultados}

A Ilustração 7 apresenta um resumo dos resultados deste estudo em comparação com os objetivos e hipóteses.

\begin{tabular}{ccc}
\hline Objetivos & Hipóteses & Resultados \\
\hline $\begin{array}{c}\text { Analisar a relação entre distribuição } \\
\text { de valor tangível para os funcionários } \\
\text { e o desempenho de curto e longo } \\
\text { prazo da empresa. }\end{array}$ & $\begin{array}{c}\text { A distribuição de valor tangível está } \\
\text { positivamente associada com o } \\
\text { desempenho organizacional de curto } \\
\text { prazo. }\end{array}$ & Confirmada \\
$\begin{array}{c}\text { Analisar a relação entre distribuição } \\
\text { de valor intangível para os } \\
\text { funcionários e o desempenho de curto } \\
\text { e longo prazo da empresa. }\end{array}$ & $\begin{array}{c}\text { A distribuição de valor intangível } \\
\text { está positivamente associada com o } \\
\text { desempenho organizacional de } \\
\text { longo prazo. }\end{array}$ & Confirmada \\
\hline
\end{tabular}

Ilustração 7 - Resumo dos resultados

Conforme apresentado na Ilustração 7, as hipóteses do estudo foram confirmadas pelas análises estatísticas. Ressalta-se que esses resultados restringem-se à amostra estudada, não sendo possível fazer generalizações. 


\section{DISCUSSÃO DOS RESULTADOS}

A teoria dos stakeholders tem evoluído nos últimos anos no sentido de entender sobre a criação e distribuição de valor nas interações entre a empresa e os seus stakeholders. Algumas proposições teóricas têm contribuído para essa discussão, como é o caso dos trabalhos de Bosse et al. (2009), Harrison et al. (2010), Harrison e Wicks (2013), Tantalo e Priem (2016) e GarciaCastro e Aguilera (2015).

Esta pesquisa contribui para esta discussão ao esclarecer como a distribuição de valor para o stakeholder funcionário afeta o desempenho organizacional. Neste sentido, propôs-se que a distribuição de ambos os tipos de valor, tangível e intangível, são capazes de afetar positivamente o desempenho.

Argumentou-se que as empresas que atendessem a função utilidade de seus funcionários com práticas de valor tangível, como pagamentos e benefícios, motivariam de forma eficaz os funcionários do tipo auto-interessados a desempenhar melhor suas atividades no curto prazo. Como resultado, a empresa poderia apresentar um alto desempenho no curto prazo. Por outro lado, a distribuição de valor intangível, mensurada por meio da justiça organizacional, afetaria a motivação dos funcionários do tipo recíprocos em contribuir com os objetivos da empresa, o que resultaria em um alto desempenho no longo prazo.

Consistente com essas proposições, os resultados desse estudo apresentaram uma associação positiva e significante entre distribuição de valor tangível e desempenho de curto prazo e distribuição de valor intangível e desempenho de longo prazo, indicando que quanto maior a distribuição de valor para o funcionário, maior é o desempenho financeiro da empresa. Em outras palavras, a distribuição de valor tangível gera resultados mais imediatos, dada a relação positiva e significante do valor tangível com o ROA até o terceiro ano. A distribuição de resultados intangíveis, por sua vez, tem seus efeitos no longo prazo, dado que a associação entre intangível e ROA foi positiva e estatisticamente significante apenas no quarto ano. Assim, as evidências empíricas apoiam o argumento de que as empresas que despendem um tratamento 
bom e justo aos seus stakeholders podem obter maior desempenho organizacional (Freeman, 1984, Bosse et al., 2009, Harrison et al., 2010, Tantalo \& Priem, 2016).

Embora o objetivo desta pesquisa não foi analisar especificamente questões de justiça organizacional, a variável valor intangível utilizou medidas de justiça para sua análise. Neste ínterim, Bosse et al. (2009) propõem que empresas percebidas como justas por seus stakeholders criarão mais renda. De fato, a distribuição de valor intangível teve um impacto positivo e significante no desempenho financeiro. No entanto, destaca-se que os efeitos decorrentes da distribuição deste tipo de valor não são imediatos, ou seja, afetaram o desempenho financeiro apenas no longo prazo.

As empresas podem oferecer valor aos seus funcionários por diferentes meios. Para esta pesquisa propôs-se que as práticas de RH são fontes de utilidade em termos de valor tangível e intangível para os funcionários. Segundo Harrison e Wicks (2013) as empresas que fornecem mais utilidade para seus stakeholders são mais capazes de manter sua participação e apoio nos processos de criação de valor. Os resultados revelam que quanto maior o valor distribuído maior o desempenho financeiro. No entanto, a importância das fontes de utilidade muda ao longo do tempo uma vez que, em geral, no curto prazo valores tangíveis foram mais importantes para explicar o resultado organizacional, ao passo que no longo prazo foram valores intangíveis. 


\section{CONSIDERAÇÕES FINAIS}

O objetivo desta pesquisa foi investigar a distribuição de valores tangíveis e intangíveis para o stakeholder funcionário e sua relação com o desempenho organizacional. Para esta análise, o valor tangível foi mensurado em termos de benefícios e pagamentos e o valor intangível foi mensurado por meio de duas dimensões de justiça organizacional: a justiça distributiva, que considerou a equidade na remuneração de minorias e a justiça interacional, que incluiu questões relacionadas à diversidade.

Com relação ao primeiro objetivo específico, de analisar a relação entre distribuição de valor tangível para os funcionários e o desempenho de curto e longo prazo da empresa, os resultados indicam que o valor tangível está mais associado ao desempenho de curto prazo. Além disso, o efeito da distribuição desse tipo de valor tende a reduzir ao longo do tempo.

Com relação ao segundo objetivo específico, de analisar a relação entre distribuição de valor intangível para os funcionários e o desempenho de curto e longo prazo da empresa, os resultados apontam para efeitos de longo prazo. A distribuição de valor intangível apresentou significância estatística apenas no quarto ano.

O tipo de relacionamento entre o stakeholder e a empresa e, portanto, o comportamento do stakeholder, depende da proposta de valor que a empresa apresenta em relação a outras oportunidades disponíveis (Harrison \& Bosse, 2013). Os resultados encontrados indicam que uma proposta de valor capaz de gerar benefícios ao longo do tempo deve incluir ambos os tipos de valor, tangível e intangível. 


\subsection{Contribuições}

Na seção de introdução deste trabalho foi apontado como lacunas da teoria dos stakeholders o pouco conhecimento de como a distribuição de valor para os stakeholders está associada ao desempenho organizacional, e se ambos os valores, tangíveis e intangíveis, são igualmente importantes ou podem variar.

Esta pesquisa contribui com estes dois pontos. Quanto ao primeiro, explica como a distribuição de valor para o stakeholder funcionário por meio de práticas de $\mathrm{RH}$ afeta o desempenho organizacional. Em suma, argumentou-se que o valor distribuído pela empresa motiva os funcionários a desempenharem melhor suas atividades, o que reflete em um alto desempenho organizacional. Em relação ao segundo ponto, destaca-se que as hipóteses formuladas incluem a dinâmica temporal, ou seja, propõem-se que os valores tangíveis e intangíveis têm impacto diferente no desempenho ao longo do tempo. Essa proposição é uma importante contribuição para o avanço da teoria dos stakeholders uma vez que a teoria, embora reconheça a importância de ambos os tipos de valores, não deixava claro como eles estariam relacionados ao desempenho organizacional.

Quanto ao limite de que a teoria está preocupada principalmente com a distribuição de resultados financeiros (Phillips et al., 2003; Freeman et al., 2010), apresenta-se evidências empíricas da distribuição de valores não financeiros ao stakeholder funcionário e sua relação com o desempenho.

Esta pesquisa também contribui com a literatura de GERH ao testar a relação entre práticas de RH voltadas à justiça com o desempenho organizacional. Embora alguns estudos, como o de Huselid et al. (1997), tenham analisado práticas relacionadas ao tratamento de minorias, questões de justiça organizacional ainda são pouco discutidas nesta literatura.

Por fim, em termos gerenciais, o conhecimento dos efeitos da distribuição de valor no desempenho organizacional permite que os gestores aloquem mais eficientemente os recursos da empresa. 


\subsection{Limitações}

Esta pesquisa apresenta algumas limitações. A primeira delas refere-se à amostra pequena de empresas. Embora se tenha atingido o mínimo de cinco observações por variável independente, uma amostra pequena pode comprometer a robustez do método, uma vez que o número desejado para a análise de regressão seria entre 15 e 20 observações por variável (Hair et al., 2005, p. 148). Além disso, amostras pequenas tendem a inflacionar o erro padrão e não permitem a generalização dos resultados encontrados.

Ainda quanto ao método, embora tenha-se utilizado variáveis de controle indicadas na literatura como determinantes do desempenho organizacional, os modelos testados podem apresentar problemas de endogeneidade decorrentes de variáveis omitidas e simultaneidade. Assim, não se pode excluir a hipótese de viés nos coeficientes das regressões.

Outra limitação é devido a análise isolada do stakeholder funcionário. Esta limitação refere-se ao fato de que as empresas relacionam-se com diversos stakeholders. Quando analisados em conjunto, os resultados encontrados neste estudo podem ser diferentes.

A análise da distribuição de valor ficou limitada a apenas quatro anos. Isso limitou a análise do comportamento do valor intangível uma vez que seus efeitos foram significantes apenas com quatro anos de defasagem. Pesquisas futuras poderiam ampliar esse período para investigar o comportamento desta variável com um horizonte temporal maior.

Por fim, utilizou-se como proxy para avaliar a distribuição de valor tangível pagamentos e benefícios e para a distribuição de valor intangível questões relacionadas a justiça organizacional. No entanto, existem outras formas de distribuir esses tipos de valores, tais como responsabilidade social para tangível e distribuição de informações e participação no processo decisório para intangível. O uso de diferentes tipos de práticas para a composição das variáveis Tangível e Intangível pode produzir diferentes resultados. 


\subsection{Sugestões para pesquisas futuras}

Decorrente dos resultados e limitações desta pesquisa emergem algumas sugestões para pesquisas futuras. A primeira sugestão é investigar o comportamento das variáveis analisadas, valor tangível e valor intangível, para outros stakeholders da empresa, tais como compradores, fornecedores, acionistas. Para o stakeholder funcionário a relação entre distribuição de valor e desempenho apresentou diferentes resultados ao longo do tempo, esses resultados seriam semelhantes para os demais stakeholders?

Uma segunda sugestão é a aplicação deste estudo numa amostra maior de empresas com horizonte temporal maior. Isso é especialmente importante para o estudo do valor intangível, o qual apresentou efeitos apenas no quarto ano. Adicionalmente, podem ser utilizadas outras formas de mensuração para valor tangível, intangível e desempenho organizacional. Fatores intangíveis como o impacto da distribuição de informações e participação dos stakeholders no processo decisório ainda são poucos estudados nesta literatura. 


\section{REFERÊNCIAS}

Aguinis, H., Gottfredson, R. K., \& Joo, H. (2013). Best-practice recommendations for defining, identifying, and handling outliers. Organizational Research Methods, 16(2), 270-301.

Arthur, J. B. (1994). Effects of human resource systems on manufacturing performance and turnover. Academy of Management journal, 37(3), 670-687.

Barney, J. B. (2011). Gaining and sustaining competitive advantage. Upper Saddle River, NJ: Pearson Education, Inc.

Barnett, A. (1997). Towards a stakeholder democracy. Stakeholder capitalism, 82-98.

Barnett, M. L., \& Salomon, R. M. (2012). Does it pay to be really good? Addressing the shape of the relationship between social and financial performance. Strategic Management Journal, 33(11), 1304-1320.

Becker, G. S. (1964). Human Capital. New York: Columbia University Press.

Becker, B. E., \& Huselid, M. A. (2006). Strategic human resources management: where do we go from here? Journal of management, 32(6), 898-925.

Bidwell, M., Won, S., Barbulescu, R., \& Mollick, E. (2015). I used to work at Goldman Sachs! How firms benefit from organizational status in the market for human capital. Strategic Management Journal, 36(8), 1164-1173.

Boaventura, J. M. G., Silva, R. S. D., \& Bandeira-de-Mello, R. (2012). Corporate Financial Performance and Corporate Social Performance: methodological development and the theoretical contribution of empirical studies. Revista Contabilidade \& Finanças, 23(60), 232245.

Bosse, D. A., Phillips, R. A., \& Harrison, J. S. (2009). Stakeholders, reciprocity, and firm performance. Strategic Management Journal, 30(4), 447-456.

Bowen, D. E., \& Ostroff, C. (2004). Understanding HRM-firm performance linkages: The role 
of the "strength" of the HRM system. Academy of Management Review, 29(2), 203-221.

Bridoux, F., Coeurderoy, R., \& Durand, R. (2011). Heterogeneous motives and the collective creation of value. Academy of Management Review, 36(4), 711-730.

Bridoux, F., \& Stoelhorst, J. W. (2014). Microfoundations for stakeholder theory: Managing stakeholders with heterogeneous motives. Strategic Management Journal, 35(1), 107-125.

Camerer, C. F., \& Fehr, E. (2006). When does" economic man" dominate social behavior?. Science, 311(5757), 47-52.

Chadwick, C., \& Dabu, A. (2009). Human resources, human resource management, and the competitive advantage of firms: Toward a more comprehensive model of causal linkages. Organization Science, 20(1), 253-272.

Clarkson, M. E. (1995). A stakeholder framework for analyzing and evaluating corporate social performance. Academy of Management Review, 20(1), 92-117.

Coff, R. 1997. Human assets and management dilemmas: Coping with hazards on the road to resource-based theory. Academy of Management Review, 22(2), 374-402

Coff, R. W. (1999). When competitive advantage doesn't lead to performance: The resourcebased view and stakeholder bargaining power. Organization Science, 10(2), 119-133.

Cohen, J., Cohen, P., West, S. G., \& Aiken, L. S. (2003). Applied multiple regression/correlation analysis for the behavioral sciences. Mahwah, NJ: Lawrence Erlbaum.

Collins, C. J., \& Clark, K. D. (2003). Strategic human resource practices, top management team social networks, and firm performance: The role of human resource practices in creating organizational competitive advantage. Academy of Management Journal, 46(6), 740-751.

Cragg, W., \& Greenbaum, A. (2002). Reasoning about responsibilities: Mining company managers on what stakeholders are owed. Journal of Business Ethics, 39(3), 319-335.

Delery, J. E., \& Doty, D. H. (1996). Modes of theorizing in strategic human resource management: Tests of universalistic, contingency, and configurational performance predictions. Academy of Management Journal, 39(4), 802-835. 
DeVaro, J. (2006). Strategic promotion tournaments and worker performance. Strategic Management Journal, 27, 721-740.

DeGeest, D. S., Follmer, E. H., Walter, S. L., \& O’Boyle, E. H. (2015). The Benefits of Benefits A Dynamic Approach to Motivation-Enhancing Human Resource Practices and Entrepreneurial Survival. Journal of Management.

Donaldson, T., \& Preston, L. E. (1995). The stakeholder theory of the corporation: Concepts, evidence, and implications. Academy of Management Review, 20(1), 65-91.

Evans, W. R., \& Davis, W. D. (2005). High-performance work systems and organizational performance: The mediating role of internal social structure. Journal of Management, 31(5), 758-775.

Fehr, E., \& Falk, A. (2002). Psychological foundations of incentives. European Economic Review, 46(4), 687-724.

Fehr, E., \& Fischbacher, U. (2002). Why social preferences matter-the impact of non-selfish motives on competition, cooperation and incentives. The Economic Journal, 112(478), C1-C33.

Fehr, E., \& Rockenbach, B. (2003). Detrimental effects of sanctions on human altruism. Nature, 422(6928), 137-140.

Folger, R., \& Salvador, R. (2008). Is management theory too "self-ish"?. Journal of Management, 34(6), 1127-1151.

Freeman, R. E. (1984). Strategic management: a stakeholder approach. Boston: Pitman.

Freeman, R. E. (1999). Divergent stakeholder theory. Academy of Management Review, 24(2), 233-236.

Freeman, R. E., \& Reed, D. L. (1983). Stockholders and stakeholders: A new perspective on corporate governance. California Management Review, 25(3), 88-106.

Freeman, R. E., Wicks, A. C., \& Parmar, B. (2004). Stakeholder theory and "the corporate objective revisited". Organization Science, 15(3), 364-369. 
Freeman, R. E., Harrison, J. S., Wicks, A. C., Parmar, B. L., \& De Colle, S. (2010). Stakeholder Theory: The state of the art. Cambridge University Press.

Friedman, A. L., \& Miles, S. (2006). Stakeholders: Theory and Practice. Oxford University Press.

Frooman, J. (1999). Stakeholder influence strategies. Academy of Management Review, 24(2), 191-205.

Gambardella, A., Panico, C., \& Valentini, G. (2015). Strategic incentives to human capital. Strategic Management Journal, 36(1), 37-52.

Garcia-Castro, R., \& Aguilera, R. V. (2015). Incremental value creation and appropriation in a world with multiple stakeholders. Strategic Management Journal, 36(1), 137-147.

Gioia, D. A. (1999). Practicability, paradigms, and problems in stakeholder theorizing. Academy of Management Review, 24(2), 228-232.

Gittell, J. H., Seidner, R., \& Wimbush, J. (2010). A relational model of how high-performance work systems work. Organization Science, 21(2), 490-506.

Hair, J. F, Anderson, R. E., Tatham, R. L. \& Black, W. C. (2005). Análise multivariada de dados. Bookman Editora.

Harrison, J. S., \& Wicks, A. C. (2013). Stakeholder theory, value, and firm performance. Business Ethics Quarterly, 23(1), 97-124.

Harrison, J. S., \& Bosse, D. A. (2013). How much is too much? The limits to generous treatment of stakeholders. Business Horizons, 56(3), 313-322.

Harrison, J. S., Bosse, D. A., \& Phillips, R. A. (2010). Managing for stakeholders, stakeholder utility functions, and competitive advantage. Strategic Management Journal, 31(1), 58-74.

Halali, E., Bereby-Meyer, Y., \& Meiran, N. (2014). Between self-interest and reciprocity: the social bright side of self-control failure. Journal of Experimental Psychology: General, 143(2), 745-754. 
Heath, J., \& Norman, W. (2004). Stakeholder theory, corporate governance and public management: what can the history of state-run enterprises teach us in the post-Enron era?. Journal of Business Ethics, 53(3), 247-265.

Hendry, J. (2001). Missing the target: Normative stakeholder theory and the corporate governance debate. Business Ethics Quarterly, 11(01), 159-176.

Huselid, M. A. (1995). The impact of human resource management practices on turnover, productivity, and corporate financial performance. Academy of Management Journal, 38(3), 635-672.

Huselid, M. A., Jackson, S. E., \& Schuler, R. S. (1997). Technical and strategic human resources management effectiveness as determinants of firm performance. Academy of Management Journal, 40(1), 171-188.

Huselid, M. A., \& Becker, B. E. (2011). Bridging micro and macro domains: Workforce differentiation and strategic human resource management. Journal of Management, 37(2), 421428.

Hutton, W. (1997). The State We're In. London: Jonathan Cape.

Índice de Sustentabilidade Empresarial - ISE. (2015). Recuperado em 15 de dezembro de 2015. http://www.bmfbovespa.com.br/indices/ResumoIndice.aspx? Indice=ISE\&idioma=pt-br

Jensen, M. C. (2002). Value maximization, stakeholder theory, and the corporate objective function. Business ethics quarterly, 12(02), 235-256.

Jiang, K., Lepak, D., Hu, J., \& Baer, J. (2012). How does human resource management influence organizational outcomes? A meta-analytic investigation of mediating mechanisms. Academy of management Journal, 55(6), 1264-1294.

Jones, T. M. (1995). Instrumental stakeholder theory: A synthesis of ethics and economics. Academy of Management Review, 20(2), 404-437.

Jones, T. M., \& Wicks, A. C. (1999). Convergent stakeholder theory. Academy of Management Review, 24(2), 206-221. 
Lepak, D. P., \& Snell, S. A. (2002). Examining the human resource architecture: The relationships among human capital, employment, and human resource configurations. Journal of Management, 28(4), 517-543.

Marcoux, A. M. (2000). Balancing act. Contemporary issues in business ethics, 92-98.

Mischel, W., \& Peake, P. K. (1982). Beyond déjà vu in the search for cross-situational consistency. Psychological Review, 89(6), 730.

Mitchell, R. K., Agle, B. R., \& Wood, D. J. (1997). Toward a theory of stakeholder identification and salience: Defining the principle of who and what really counts. Academy of Management Review, 22(4), 853-886.

Mohrman, S. A., \& Lawler, E. E. (2012). Generating knowledge that drives change. The Academy of Management Perspectives, 26(1), 41-51.

Moura-Leite, R. C., Padgett, R. C., \& Galan, J. I. (2014). Stakeholder management and nonparticipation in controversial business. Business \& Society, 53(1), 45-70.

Orts, E. W., \& Strudler, A. (2002). The ethical and environmental limits of stakeholder theory. Business Ethics Quarterly, 12(02), 215-233.

Pil, F. K., \& Leana, C. (2009). Applying organizational research to public school reform: The effects of teacher human and social capital on student performance. Academy of Management Journal, 52(6), 1101-1124.

Pitelis, C. N. (2009). The co-evolution of organizational value capture, value creation and sustainable advantage. Organization Studies, 30(10), 1115-1139.

Pfeffer, J. (1995). Competitive advantage through people: Unleashing the power of the work force. Harvard Business Press.

Phillips, R. (2003). Stakeholder theory and organizational ethics. Berrett-Koehler Publishers.

Phillips, R., Freeman, R. E., \& Wicks, A. C. (2003). What stakeholder theory is not. Business Ethics Quarterly, 13(4), 479-502. 
Phillips, R. A., \& Reichart, J. (2000). The environment as a stakeholder? A fairness-based approach. Journal of Business Ethics, 23(2), 185-197.

Ployhart, R. E., \& Moliterno, T. P. (2011). Emergence of the human capital resource: A multilevel model. Academy of Management Review, 36(1), 127-150.

Ployhart, R. E., Nyberg, A. J., Reilly, G., \& Maltarich, M. A. (2014). Human capital is dead; long live human capital resources!. Journal of Management, 40(2), 371-398.

Priem, R. L. (2007). A consumer perspective on value creation. Academy of Management Review, 32(1), 219-235.

Rowley, T. J. (1997). Moving beyond dyadic ties: A network theory of stakeholder influences. Academy of Management Review, 22(4), 887-910.

Rumelt, R. P., Schendel, D., \& Teece, D. J. (1991). Strategic management and economics. Strategic Management Journal, 12, 5-29.

Rustin, M. (1997). Stakeholding and the public sector. Stakeholder Capitalism (Mac Millan, London), 72-81.

Sternberg, E. (1998). Corporate Governance: Accountability in the Marketplace. London: The Institute of Economic Affairs.

Sauer, C., \& Valet, P. (2013). Less is sometimes more: Consequences of overpayment on job satisfaction and absenteeism. Social Justice Research, 26(2), 132-150.

Tantalo, C., \& Priem, R. L. (2016). Value creation through stakeholder synergy. Strategic Management Journal, 37(2), 314-329.

Waddock, S. A., \& Graves, S. B. (1997). The corporate social performance-financial performance link. Strategic Management Journal, 18(4), 303-319.

Wooldridge, J. M. (2006). Introdução à econometria: uma abordagem moderna. Pioneira Thomson Learning.

Wright, P. M., Coff, R., \& Moliterno, T. P. (2014). Strategic Human Capital Crossing the Great 
Divide. Journal of Management, 40(2), 353-370.

Wright, P. M., Dunford, B. B., \& Snell, S. A. (2001). Human resources and the resource based view of the firm. Journal of Management, 27(6), 701-721.

Ye, G., Priem, R. L., \& Alshwer, A. A. (2012). Achieving demand-side synergy from strategic diversification: How combining mundane assets can leverage consumer utilities. Organization Science, 23(1), 207-224.

Youndt, M. A., Snell, S. A., Dean, J. W., \& Lepak, D. P. (1996). Human resource management, manufacturing strategy, and firm performance. Academy of Management Journal, 39(4), 836866. 


\section{ANEXO I - Modelos de Regressão com VTan e ROA}

\section{Modelo 1 - VTan com 1 ano de defasagem}

\begin{tabular}{|c|c|c|c|c|c|c|}
\hline \multicolumn{5}{|c|}{ Linear regression } & $\begin{array}{l}\text { Number of obs } \\
\text { F( 6, 33) } \\
\text { Prob > F } \\
\text { R-squared } \\
\text { Root MSE }\end{array}$ & $\begin{array}{rr}= & 40 \\
= & 5.66 \\
= & 0.0004 \\
= & 0.5006 \\
= & 5.8585\end{array}$ \\
\hline \begin{tabular}{l|l} 
& 1 \\
roa & $\mid$
\end{tabular} & Coef. & $\begin{array}{l}\text { Robust } \\
\text { Std. Err. }\end{array}$ & $t$ & $P>|t|$ & & Beta \\
\hline \begin{tabular}{r|}
$\tan 1$ \\
$\operatorname{tam}$ \\
setor2 \\
setor3 \\
setor4 \\
endiv1 \\
cons
\end{tabular} & $\begin{array}{r}3.383295 \\
-2.554399 \\
-4.240473 \\
-1.321402 \\
-4.081111 \\
.0010698 \\
50.90592\end{array}$ & $\begin{array}{l}1.361082 \\
1.211411 \\
6.218191 \\
6.826523 \\
6.252521 \\
.0003221 \\
25.07468\end{array}$ & $\begin{array}{r}2.49 \\
-2.11 \\
-0.68 \\
-0.19 \\
-0.65 \\
3.32 \\
2.03\end{array}$ & $\begin{array}{l}0.018 \\
0.043 \\
0.500 \\
0.848 \\
0.518 \\
0.002 \\
0.050\end{array}$ & & $\begin{array}{r}.3790472 \\
-.5533172 \\
-.2139706 \\
-.04622 \\
-.2623782 \\
.2945947\end{array}$ \\
\hline
\end{tabular}

Shapiro-Wilk W test for normal data

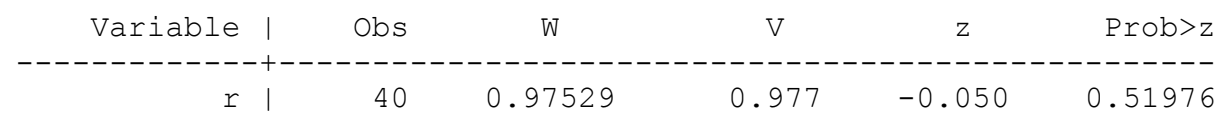

Durbin-Watson d-statistic $(7,40)=1.809357$

Breusch-Pagan / Cook-Weisberg test for heteroskedasticity Ho: Constant variance

Variables: fitted values of roa

$\operatorname{chi2}(1)=11.36$

Prob $>$ chi2 $=0.0008$

\begin{tabular}{r|rr} 
vif & & \\
Variable | & VIF & $1 /$ VIF \\
--1 & 5.62 & 0.177997 \\
setor4 | & 3.35 & 0.298482 \\
tam & 2.39 & 0.418360 \\
setor3 | & 2.38 & 0.420145 \\
endiv1 | & 1.16 & 0.861965 \\
tan1 | & 1.06 & 0.942200 \\
---------+--------------
\end{tabular}




\section{Modelo 2 - VTan com 2 anos de defasagem}

- reg roa tan2 tam setor2-setor4 endiv2, beta vce(robust)

Linear regression

$\begin{array}{lrr}\text { Number of obs } & = & 40 \\ \text { F 6, 33) } & 5.93 \\ \text { Prob }>\text { F } & =0.0003 \\ \text { R-squared } & =0.4493 \\ \text { Root MSE } & =6.1524\end{array}$

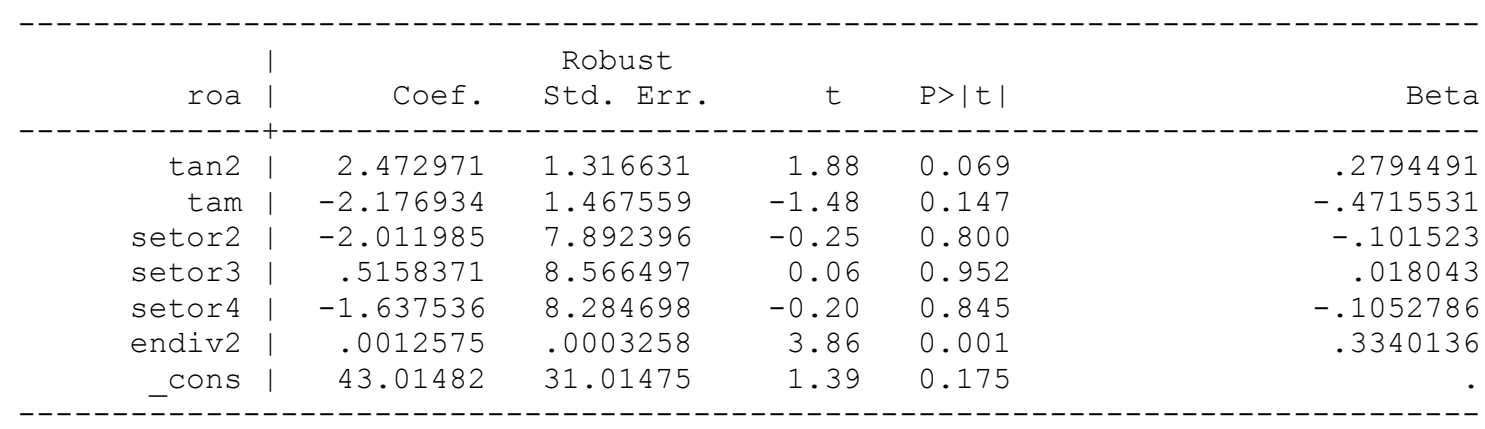

Shapiro-Wilk W test for normal data

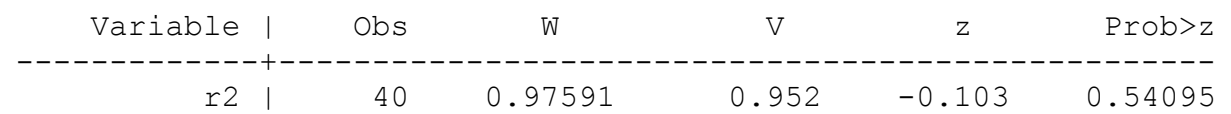

Durbin-Watson d-statistic ( 7, 40) $=1.555817$

Breusch-Pagan / Cook-Weisberg test for heteroskedasticity Ho: Constant variance

Variables: fitted values of roa

$\operatorname{chi2}(1)=14.30$

Prob $>$ chi2 $=0.0002$

\begin{tabular}{r|rr} 
Vif & \\
Variable & VIF & $1 /$ VIF \\
setor4 & 6.37 & 0.156945 \\
setor2 & 3.71 & 0.269604 \\
setor3 & 2.74 & 0.364971 \\
tam & 2.72 & 0.367785 \\
tan2 & 1.28 & 0.781543 \\
endiv2 & 1.15 & 0.871978 \\
---1 &
\end{tabular}




\section{Modelo 3 - VTan com 3 anos de defasagem}

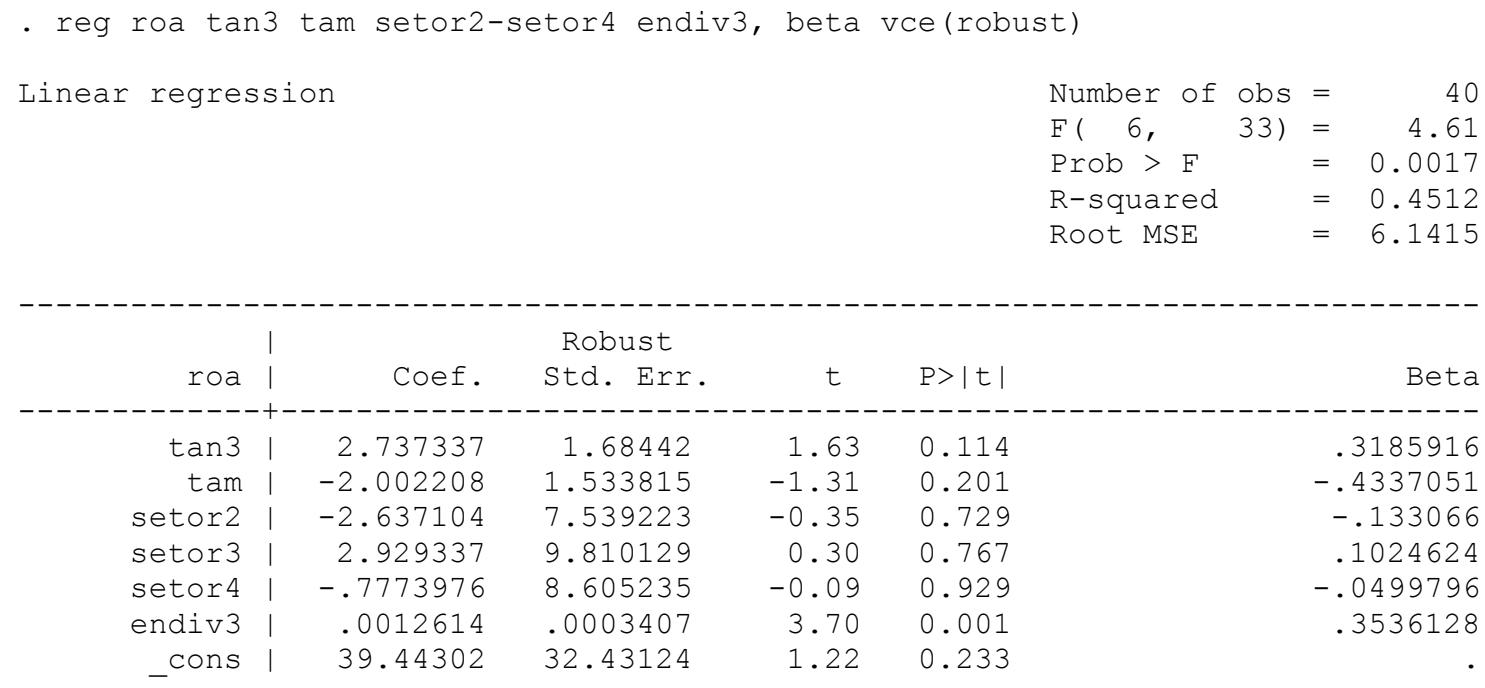

Shapiro-Wilk $w$ test for normal data

\begin{tabular}{|c|c|c|c|c|c|}
\hline Variable | & Obs & W & V & $\mathrm{z}$ & Prob $>z$ \\
\hline r3 1 & 40 & .96509 & 1.380 & 0.678 & 0.24895 \\
\hline
\end{tabular}

Durbin-Watson d-statistic $(7,40)=1.724125$

Breusch-Pagan / Cook-Weisberg test for heteroskedasticity Ho: Constant variance

Variables: fitted values of roa

$\operatorname{chi2}(1) \quad=\quad 11.17$

Prob $>$ chi2 $=0.0008$

$\begin{array}{rrr}\text { Vif } & \\ \text { Variable | } & \text { VIF } & 1 / \text { VIF } \\ -1 & 6.82 & 0.146707 \\ \text { setor4 | } & 3.56 & 0.280836 \\ \text { setor2 | } & 3.31 & 0.301753 \\ \text { tam | } & 2.93 & 0.341360 \\ \text { tan3 | } & 1.63 & 0.613121 \\ \text { endiv3 | } & 1.14 & 0.877312 \\ --------+-----1 & \end{array}$




\section{Modelo 4 - VTan com 4 anos de defasagem}

- reg roa tan4 tam setor2-setor4 endiv4, beta vce(robust)

Linear regression

$\begin{array}{lrr}\text { Number of obs } & = & 40 \\ \text { F 6, 33) } & 4.40 \\ \text { Prob }>\text { F } & = & 0.0023 \\ \text { R-squared } & = & 0.4327 \\ \text { Root MSE } & = & 6.2444\end{array}$

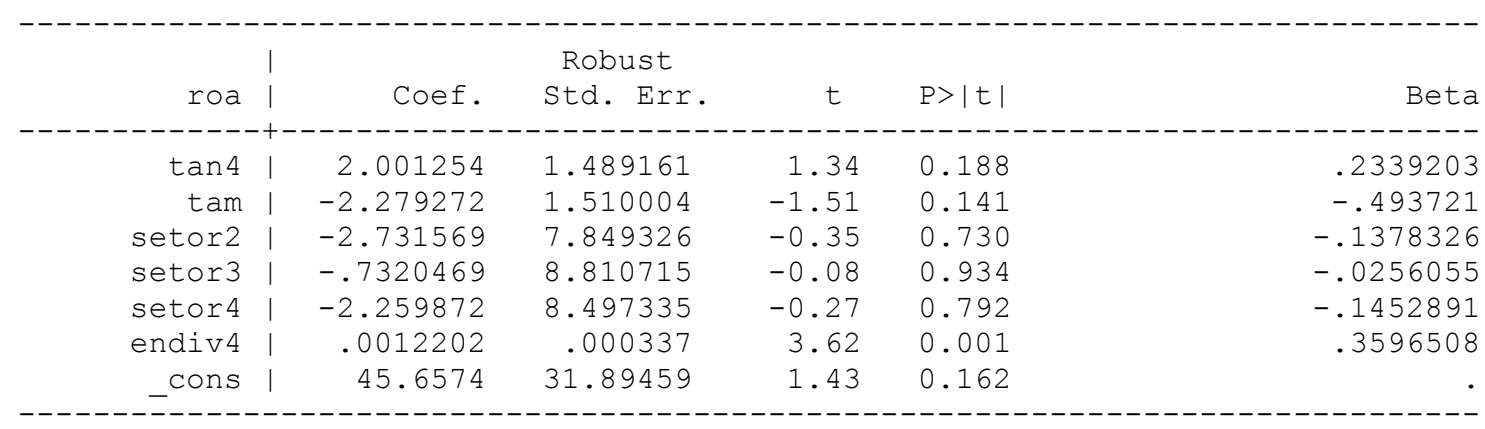

Shapiro-Wilk W test for normal data

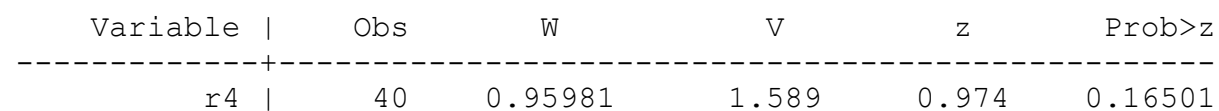

Durbin-Watson d-statistic ( 7, 40) $=1.665356$

Breusch-Pagan / Cook-Weisberg test for heteroskedasticity Ho: Constant variance

Variables: fitted values of roa

$\operatorname{chi2}(1)=11.45$

Prob $>$ chi2 $=0.0007$

\begin{tabular}{r|rr} 
vif & \\
Variable & VIF & $1 /$ VIF \\
setor4 & 6.32 & 0.158192 \\
setor2 & 3.63 & 0.275611 \\
tam & 2.73 & 0.366499 \\
setor3 & 2.65 & 0.376715 \\
tan4 & 1.24 & 0.809616 \\
endiv4 & 1.14 & 0.874883 \\
--1 &
\end{tabular}




\section{ANEXO II - Modelos de Regressão com VIn e ROA}

Modelo 1 - VIn com 1 ano de defasagem

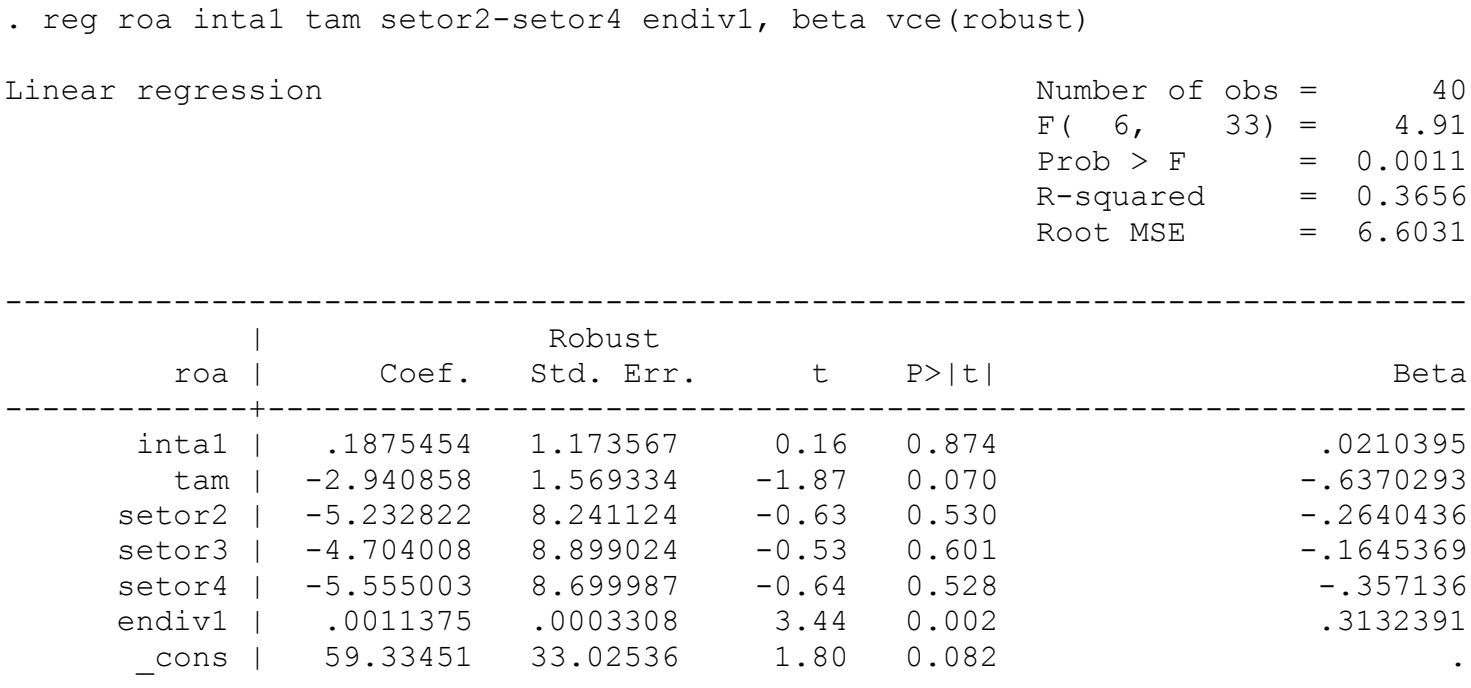

Shapiro-Wilk W test for normal data

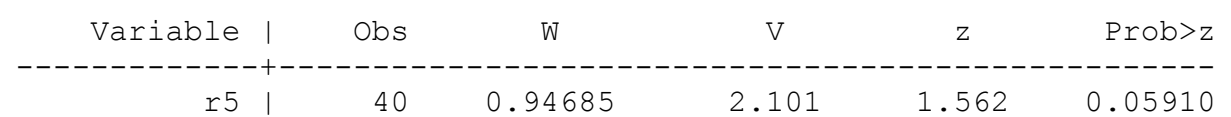

Durbin-Watson d-statistic $(7,40)=1.610131$

Breusch-Pagan / Cook-Weisberg test for heteroskedasticity

Ho: Constant variance

Variables: fitted values of roa

$\operatorname{chi2}(1)=18.67$

Prob $>$ chi2 $=0.0000$

\begin{tabular}{r|rr} 
vif & & \\
Variable | & VIF & $1 /$ VIF \\
setor4 | & 5.59 & 0.178948 \\
setor2 | & 3.33 & 0.300119 \\
tam & 2.53 & 0.394760 \\
setor3 | & 2.37 & 0.422199 \\
inta1 & 1.19 & 0.843541 \\
endiv1 | & 1.16 & 0.863882 \\
--16 &
\end{tabular}




\section{Modelo 2 - VIn com 2 anos de defasagem}

- reg roa inta2 tam setor2-setor4 endiv2, beta vce(robust)

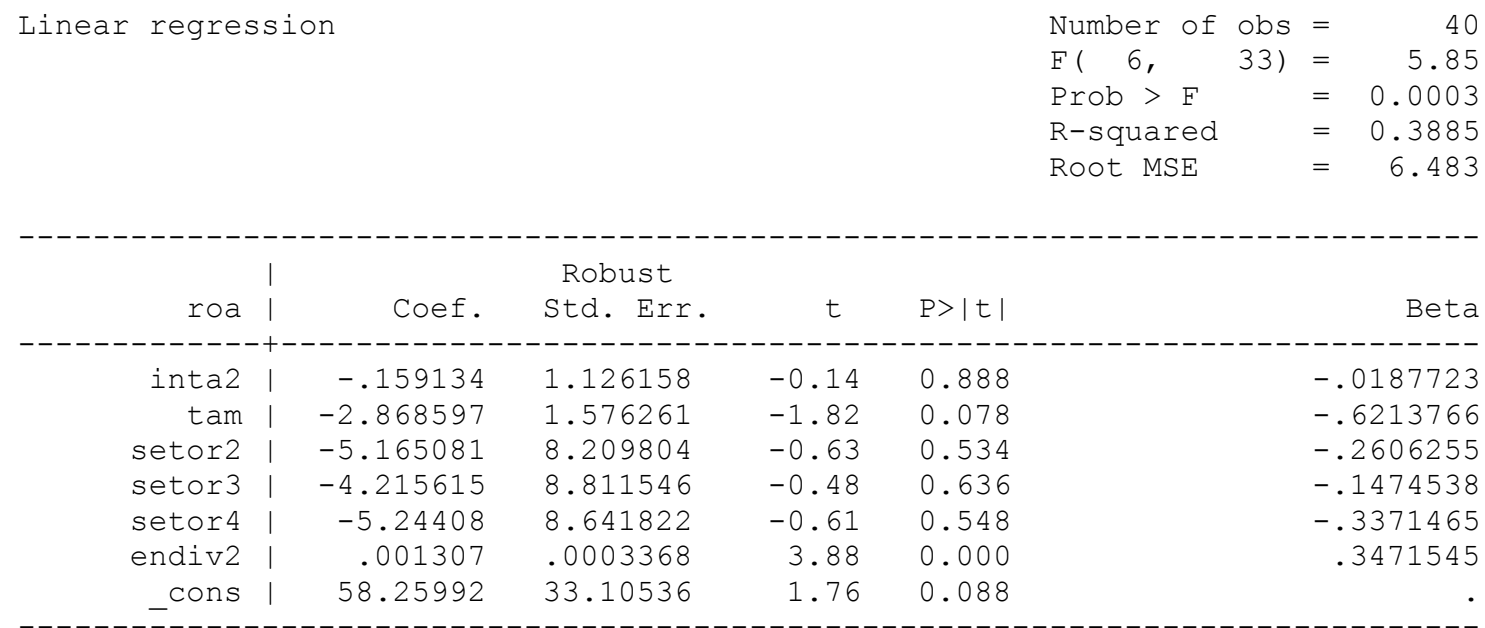

Shapiro-Wilk w test for normal data

$\begin{array}{rrrrrr}\text { Variable | } & \text { Obs } & \text { W } & \text { V } & \text { z } & \text { Prob>z } \\ -16 & 40 & 0.94869 & 2.028 & 1.488 & 0.06834\end{array}$

Durbin-Watson d-statistic ( 7, 40) = 1.557647

Breusch-Pagan / Cook-Weisberg test for heteroskedasticity Ho: Constant variance

Variables: fitted values of roa

$\operatorname{chi2}(1)=17.05$

Prob $>$ chi2 $=0.0000$

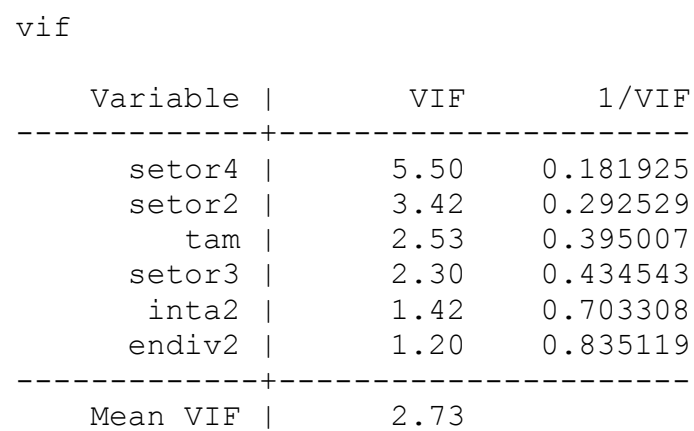




\section{Modelo 3 - VIn com 3 anos de defasagem}

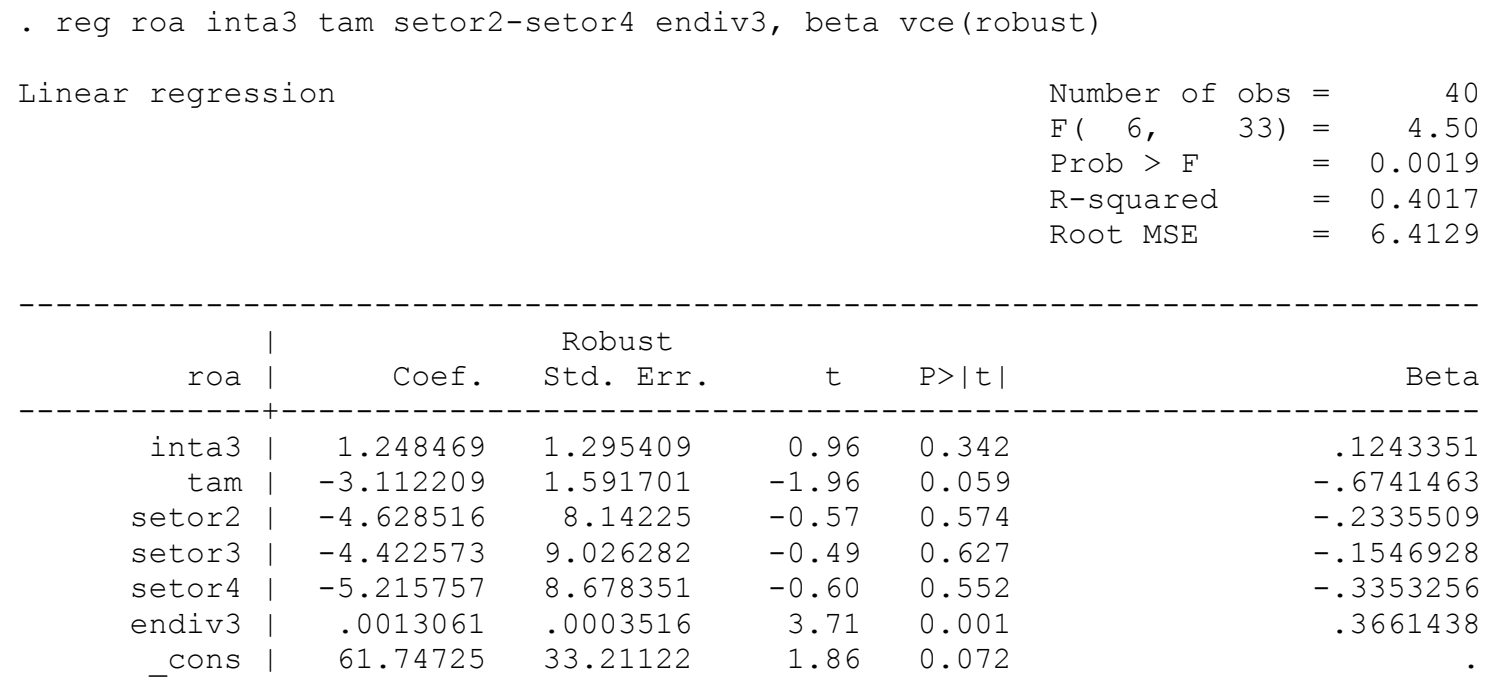

Shapiro-Wilk $w$ test for normal data

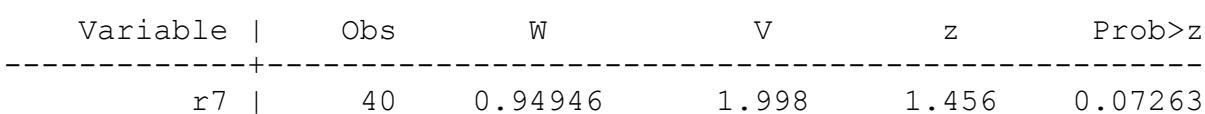

Durbin-Watson d-statistic ( 7, 40) = 1.589685

Breusch-Pagan / Cook-Weisberg test for heteroskedasticity Ho: Constant variance

Variables: fitted values of roa

$\operatorname{chi2}(1)=15.55$

Prob $>$ chi2 $=0.0001$

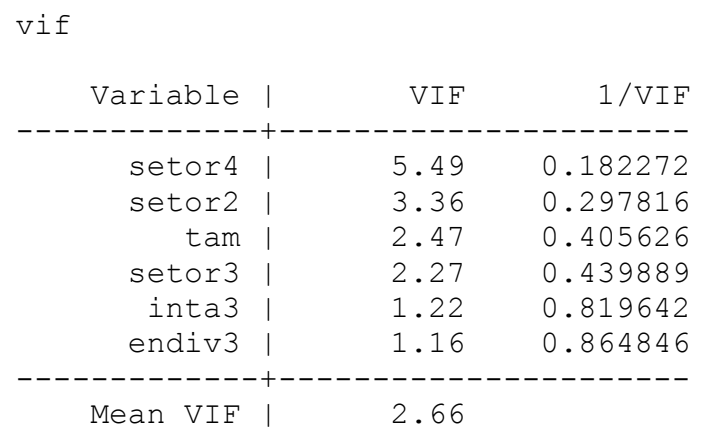




\section{Modelo 4 - VIn com 4 anos de defasagem}

- reg roa inta4 tam setor2-setor4 endiv4, beta vce(robust)

Linear regression

$\begin{array}{llr}\text { Number of obs } & = & 40 \\ \text { F 6, 33) } & = & 5.11 \\ \text { Prob }>\text { F } & = & 0.0008 \\ \text { R-squared } & = & 0.4836 \\ \text { Root MSE } & = & 5.9578\end{array}$

\begin{tabular}{|c|c|c|c|c|c|c|}
\hline \multicolumn{7}{|c|}{ । } \\
\hline roa & | & Coef. & Std. Err. & $t$ & $P>|t|$ & Beta \\
\hline \multicolumn{7}{|c|}{-------------+----------------------------------------------------------------} \\
\hline inta 4 & | & 2.545345 & 1.186322 & 2.15 & 0.039 & .3172904 \\
\hline tam & | & -3.022 & 1.335034 & -2.26 & 0.030 & -.6546059 \\
\hline setor 2 & | & -3.50034 & 6.907091 & -0.51 & 0.616 & -.1766241 \\
\hline setor 3 & | & -3.321671 & 8.456958 & -0.39 & 0.697 & -.1161855 \\
\hline setor 4 & | & -4.212586 & 7.341661 & -0.57 & 0.570 & -.2708308 \\
\hline endiv4 & | & .0012401 & .0003355 & 3.70 & 0.001 & .3655071 \\
\hline _cons & | & 58.86881 & 27.88942 & 2.11 & 0.042 & \\
\hline
\end{tabular}

Shapiro-Wilk W test for normal data

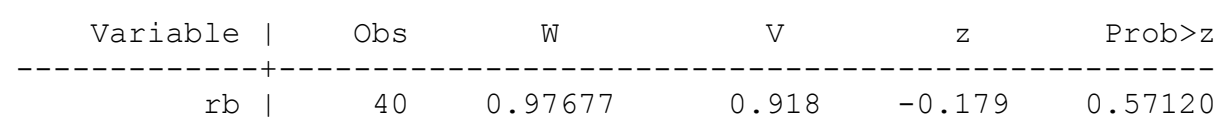

Durbin-Watson d-statistic $(7, \quad 40)=1.744466$

Breusch-Pagan / Cook-Weisberg test for heteroskedasticity Ho: Constant variance

Variables: fitted values of roa

$\operatorname{chi2}(1)=12.02$

Prob $>$ chi2 $=0.0005$

vif

\begin{tabular}{r|cr} 
Variable & VIF & $1 /$ VIF \\
- setor4 & 5.54 & 0.180537 \\
setor2 & 3.39 & 0.295320 \\
tam & 2.32 & 0.431202 \\
setor3 & 2.28 & 0.438427 \\
endiv4 & 1.14 & 0.874488 \\
inta4 & 1.06 & 0.945527 \\
---------+--------------
\end{tabular}




\section{ANEXO III - Modelos de Regressão com VTan, VIn e ROA}

Modelo 1 - VTan e VIn com 1 ano de defasagem

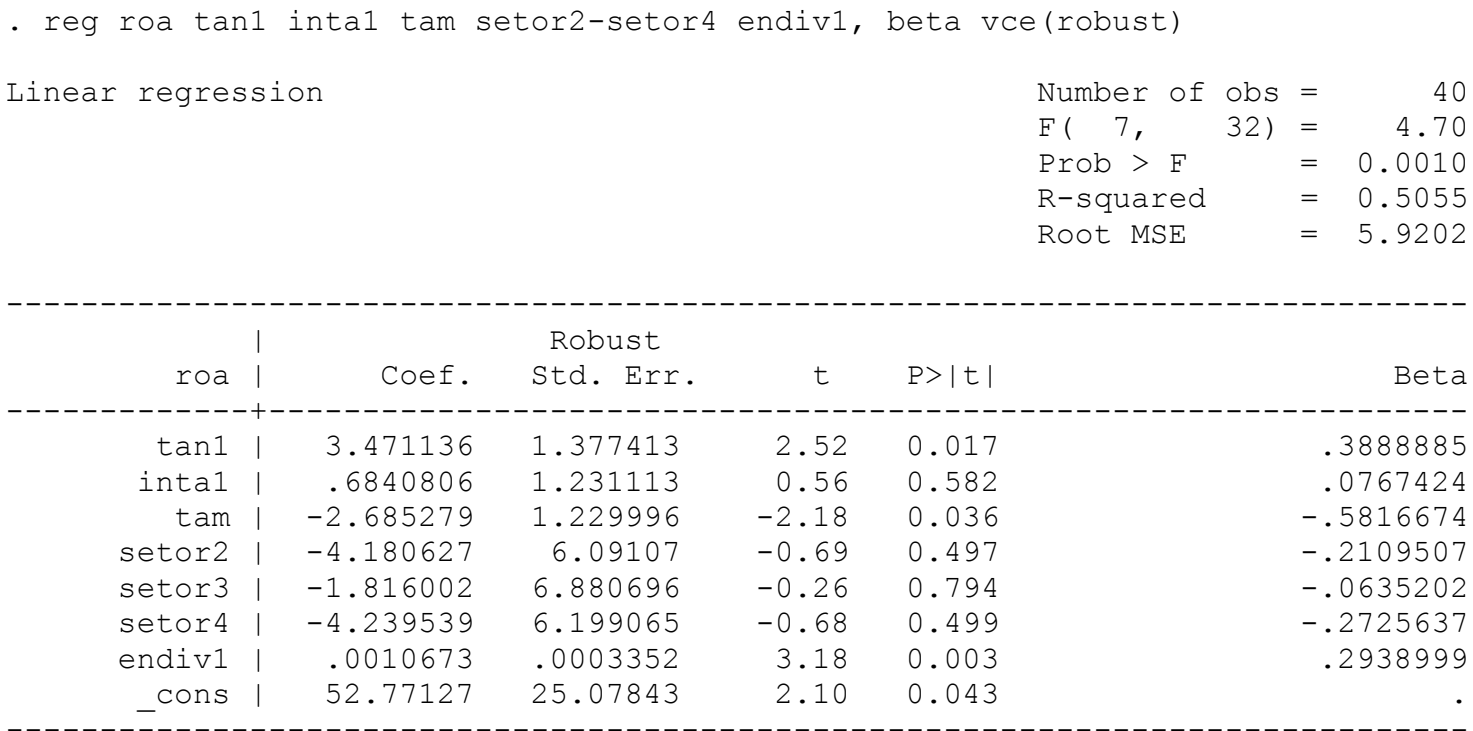

Shapiro-Wilk w test for normal data

$\begin{array}{rrrrrr}\text { Variable | } & \text { Obs } & \text { W } & \text { V } & \text { z } & \text { Prob }>z \\ -19 & 40 & 0.97245 & 1.089 & 0.179 & 0.42893\end{array}$

Durbin-Watson d-statistic $(8,40)=1.783201$

Breusch-Pagan / Cook-Weisberg test for heteroskedasticity Ho: Constant variance

Variables: fitted values of roa

$\operatorname{chi2}(1)=9.67$

Prob $>$ chi2 $=0.0019$

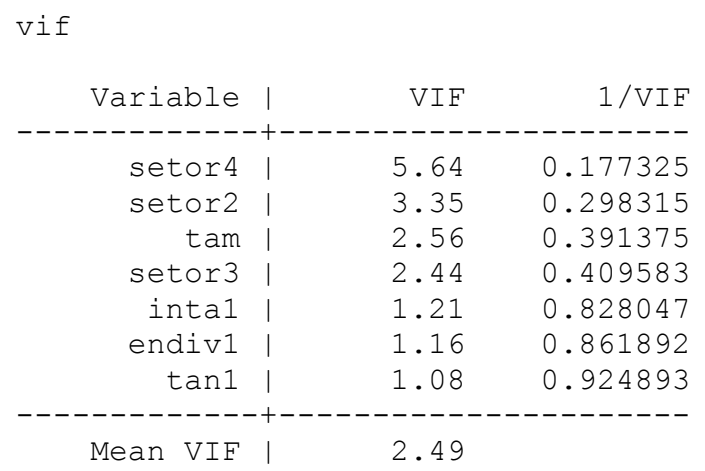




\section{Modelo 2 - VTan e VIn com 2 anos de defasagem}

\begin{tabular}{|c|c|c|c|c|c|c|}
\hline \multicolumn{5}{|c|}{ Linear regression } & $\begin{array}{l}\text { Number of obs } \\
\text { F( 7, 32) } \\
\text { Prob > F } \\
\text { R-squared } \\
\text { Root MSE }\end{array}$ & $\begin{array}{lr}= & 40 \\
= & 4.96 \\
= & 0.0007 \\
= & 0.4494 \\
= & 6.2473\end{array}$ \\
\hline \begin{tabular}{l|l} 
& $\mid$ \\
roa & $\mid$
\end{tabular} & Coef. & $\begin{array}{c}\text { Robust } \\
\text { Std. Err. }\end{array}$ & t & $P>|t|$ & & Beta \\
\hline $\tan 2$ & 2.481922 & 1.334938 & 1.86 & 0.072 & & .2804606 \\
\hline inta2 | & .0906791 & 1.011195 & 0.09 & 0.929 & & .010697 \\
\hline tam | & -2.193614 & 1.520122 & -1.44 & 0.159 & & -.4751663 \\
\hline setor2 | & -1.945076 & 7.960866 & -0.24 & 0.809 & & -.0981468 \\
\hline setor3 | & .4941596 & 8.725736 & 0.06 & 0.955 & & .0172847 \\
\hline setor 4 & -1.619214 & 8.384214 & -0.19 & 0.848 & & -.1041007 \\
\hline endiv2 | & .0012652 & .0003382 & 3.74 & 0.001 & & .3360616 \\
\hline cons | & 43.23891 & 31.84074 & 1.36 & 0.184 & & \\
\hline
\end{tabular}

Shapiro-Wilk W test for normal data

\begin{tabular}{|c|c|c|c|c|c|}
\hline Variable | & Obs & W & V & z & Prob $>z$ \\
\hline r10 & 40 & 0.97606 & 0.946 & -0.116 & 0.54609 \\
\hline
\end{tabular}

Durbin-Watson d-statistic $(8,40)=1.554413$

Breusch-Pagan / Cook-Weisberg test for heteroskedasticity

Ho: Constant variance

Variables: fitted values of roa

$\operatorname{chi2}(1)=14.24$

Prob $>$ chi2 $=0.0002$

\begin{tabular}{|c|c|c|}
\hline Variable | & VIF & $1 / \mathrm{VIF}$ \\
\hline setor 4 | & 6.39 & 0.156517 \\
\hline setor2 | & 3.85 & 0.259592 \\
\hline tam | & 2.88 & 0.346881 \\
\hline setor 3 | & 2.75 & 0.364012 \\
\hline inta2 | & 1.44 & 0.696320 \\
\hline $\tan 2$ & 1.29 & 0.773778 \\
\hline endiv2 | & 1.20 & 0.833711 \\
\hline
\end{tabular}

Modelo 3 - VTan e VIn com 3 anos de defasagem 
- reg roa tan3 inta3 tam setor2-setor4 endiv3, beta vce(robust) Linear regression

$\begin{array}{lrr}\text { Number of obs } & = \\ \text { F ( 7, 32) } & 40 \\ \text { Prob }>\text { F } & =0.9032 \\ \text { R-squared } & =0.4711 \\ \text { Root MSE } & =6.1226\end{array}$

\begin{tabular}{|c|c|c|c|c|c|}
\hline & & Robust & & & \\
\hline roa & Coef. & Std. Err. & t & $P>|t|$ & Beta \\
\hline $\tan 3$ & 2.90997 & 1.612778 & 1.80 & 0.081 & .3386839 \\
\hline inta3 & 1.574445 & 1.273427 & 1.24 & 0.225 & .1567991 \\
\hline tam & -2.202635 & 1.550771 & -1.42 & 0.165 & -.4771204 \\
\hline setor 2 & -1.925764 & 7.440256 & -0.26 & 0.797 & -.0971724 \\
\hline setor 3 & 3.294397 & 10.23832 & 0.32 & 0.750 & .1152315 \\
\hline setor 4 & -.4480434 & 8.554797 & -0.05 & 0.959 & -.0288051 \\
\hline endiv3 & .0013268 & .0003501 & 3.79 & 0.001 & .3719627 \\
\hline cons & 41.85099 & 32.38972 & 1.29 & 0.206 & \\
\hline
\end{tabular}

Shapiro-Wilk w test for normal data

$\begin{array}{rrrrrr}\text { Variable | } & \text { Obs } & \text { W } & \text { V } & \text { Z } & \text { Prob }>\text { z } \\ -r 11 & 40 & 0.96816 & 1.259 & 0.484 & 0.31410\end{array}$

Durbin-Watson d-statistic $(8,40)=1.712941$

Breusch-Pagan / Cook-Weisberg test for heteroskedasticity

Ho: Constant variance

Variables: fitted values of roa

$\begin{array}{llr}\operatorname{chi2}(1) & 11.33 \\ \text { Prob }>\text { chi2 } & =0.0008\end{array}$

vif

\begin{tabular}{r|rr} 
Variable & VIF & $1 / \mathrm{VIF}$ \\
setor4 | & 6.84 & 0.146223 \\
setor2 | & 3.63 & 0.275822 \\
setor3 | & 3.32 & 0.301009 \\
tam | & 3.02 & 0.330671 \\
tan3 | & 1.65 & 0.605590 \\
enta3 & 1.24 & 0.809575 \\
---1 & 1.16 & 0.864482 \\
Mean VIF & 2.98 &
\end{tabular}




\section{Modelo 4 - VTan e VIn com 4 anos de defasagem}

- reg roa tan4 inta4 tam setor2-setor4 endiv4, beta vce(robust)

Linear regression

$$
\begin{array}{lrr}
\text { Number of obs } & = & 40 \\
\text { F } 7, \quad 32) & = & 4.25 \\
\text { Prob }>\text { F } & =0.0020 \\
\text { R-squared } & =0.5176 \\
\text { Root MSE } & =5.8473
\end{array}
$$

\begin{tabular}{|c|c|c|c|c|c|}
\hline roa & Coef. & $\begin{array}{l}\text { Robust } \\
\text { Std. Err. }\end{array}$ & t & $P>|t|$ & Beta \\
\hline $\tan 4$ & 1.761003 & 1.231842 & 1.43 & 0.163 & .2058382 \\
\hline inta 4 & 2.413362 & 1.184885 & 2.04 & 0.050 & .300838 \\
\hline tam & -2.464476 & 1.264366 & -1.95 & 0.060 & -.5338385 \\
\hline setor2 & -1.552102 & 6.559043 & -0.24 & 0.814 & -.0783177 \\
\hline setor 3 & -.0699541 & 8.403594 & -0.01 & 0.993 & -.0024469 \\
\hline setor 4 & -1.644206 & 7.087225 & -0.23 & 0.818 & -.1057075 \\
\hline endiv4 & .0012635 & .0003336 & 3.79 & 0.001 & .3724195 \\
\hline _cons & 47.27222 & 26.48531 & 1.78 & 0.084 & \\
\hline
\end{tabular}

\begin{tabular}{|c|c|c|c|c|c|}
\hline Variable | & $\mathrm{Obs}$ & W & $\mathrm{V}$ & z & Prob $>z$ \\
\hline$r \quad 1$ & 40 & 0.98190 & 0.716 & -0.704 & 0.75944 \\
\hline
\end{tabular}

\section{Shapiro-Wilk w test for normal data}

Durbin-Watson d-statistic $(8,40)=1.789629$

Breusch-Pagan / Cook-Weisberg test for heteroskedasticity Ho: Constant variance

Variables: fitted values of roa

$\begin{array}{llr}\operatorname{chi}(1) & =8.82 \\ \text { Prob }>\text { chi2 } & =0.0030\end{array}$

vif

\begin{tabular}{r|cr} 
Variable & VIF & $1 / \mathrm{VIF}$ \\
setor4 | & 6.34 & 0.157732 \\
setor2 | & 3.67 & 0.272479 \\
tam & 2.75 & 0.363971 \\
setor3 | & 2.66 & 0.375821 \\
tan4 & 1.24 & 0.803575 \\
endiv4 & 1.14 & 0.873416 \\
inta4 & 1.07 & 0.938472 \\
- Mean VIF & 2.70 &
\end{tabular}

